$1-11-2019$

\title{
Simultaneous high-temperature gas chromatography with flame ionization and mass spectrometric analysis of monocarboxylic acids and acylglycerols in biofuels and biofuel intermediate products
}

Gana Flanagan

Anastasia A. Andrianova

Jana Casey

Eric Hellrung

Bonnie A. Diep

See next page for additional authors

How does access to this work benefit you? Let us know!

Follow this and additional works at: https://commons.und.edu/chem-fac

\section{Recommended Citation}

Gana Flanagan, Anastasia A. Andrianova, Jana Casey, et al.. "Simultaneous high-temperature gas chromatography with flame ionization and mass spectrometric analysis of monocarboxylic acids and acylglycerols in biofuels and biofuel intermediate products" (2019). Chemistry Faculty Publications. 17. https://commons.und.edu/chem-fac/17 


\section{Authors}

Gana Flanagan, Anastasia A. Andrianova, Jana Casey, Eric Hellrung, Bonnie A. Diep, Wayne Seames, and Alena Kubatova 
Flanagan, G.; Andrianova, A. A.; Casey, J.; Hellrung, E.; Diep, B. A.; Seames, W. S.; Kubátová, A., Simultaneous high-temperature gas chromatography with flame ionization and mass spectrometric analysis of monocarboxylic acids and acylglycerols in biofuels and biofuel intermediate products. Journal of Chromatography A 2019, 1584, 165-178.

https://doi.org/10.1016/j.chroma.2018.11.044

\section{Simultaneous High-Temperature GC-FID/MS Analysis of Monocarboxylic Acids and Acylglycerols in Biofuels and Biofuel Intermediate Products}

Ganna Flanagan ${ }^{\mathrm{a}, 1}$, Anastasia A. Andrianova ${ }^{\mathrm{a}}$, Jana Casey ${ }^{\mathrm{a}, 2}$, Eric Hellrung ${ }^{\mathrm{a}}$, Bonnie A. Diep ${ }^{\mathrm{a}, 3}$, Wayne S. Seames ${ }^{\mathrm{b}}$, Alena Kubátováa,*

aDepartment of Chemistry, University of North Dakota, 151 Cornell St., Grand Forks, ND, 582029024, USA.

${ }^{\mathrm{b}}$ Chemical Engineering Department, University of North Dakota, 241 Centennial Dr., Grand Forks, ND, 58202-7101, USA

${ }^{1}$ Present address: Kemin Nutrisurance, 1900 Scott Ave, Des Moines, IA 50317, USA

${ }^{2}$ Present address: Bristol-Myers Squibb, 1 Squibb Dr., New Brunswick, NJ, 08901, USA.

${ }^{3}$ Present address: US EPA, Research Triangle Park, NC 27711, USA.

*Corresponding author: Department of Chemistry, University of North Dakota, 151 Cornell St., Grand Forks, ND, 58202-9024, USA. Tel.: +1 701777 0348; fax: +1 701777 2331; E-mail address: alena.kubatova@UND.edu

\section{Keywords}

Acylglycerols, monocarboxylic acids, biofuels, gas chromatography, mass spectrometry, DOE 


\section{Introduction}

Biofuels produced from natural sources of triacylglycerols (TAGs), such as vegetable oils, algae, or bacteria have gained popularity as a feedstock for the production of renewable transportation fuels [1]. Common ways to convert TAGs feedstock into biofuels are: transesterification with an alcohol, hydroprocessing, and thermal cracking (i.e., pyrolysis with or without a catalyst) $[1,2]$. The organic liquid product (OLP) generated in the primary reaction step of many of these processes may still contain un-reacted starting material (i.e., TAGs) or acidic intermediates such as mono- and diacylglycerols (MAGs and DAGs), free glycerol [1, 2], high molecular weight (MW) monocarboxylic acids (MCA) (particularly $\mathrm{C}_{16}-\mathrm{C}_{18}$, originally present in the feedstocks as triesters of glycerol), and free $\left(\mathrm{C}_{4}-\mathrm{C}_{18}\right)$ MCAs [3].

The occurrence of these undesired species in the primary biofuel product can create problems during biofuel storage, cause damage to engines and fuel tanks from corrosion, and affect fuel system performance by filter clogging and injector fouling [4]. Moreover, it can negatively affect the yield and degree of subsequent processing required to generate acceptable fuels conforming to standard specifications such as those listed in ASTM D 6751 or EN-14214. Therefore, speciation characterization is essential to optimize biofuel conversion pathways and to ensure that adequate fuel quality is achieved

To comply with applicable fuel standards, multiple analytical methods have been previously developed to selectively determine specific classes of carbonyl compounds of various size ranges, as discussed below. However, none of these methods provide a detailed analysis of both organic acids and acylglycerols in one run, partially due to the wide molecular weight range (from $100 \mathrm{amu}$ for MCAs to 1000 amu for TAGs) of target compounds.

ASTM D664 is a standard method for the determination of a total acid number using potentiometric titration. ASTM D664 was originally developed to measure the content of acidic compounds in petroleum fuel products, most notably reduced sulfur compounds [12]. When applied to TAG-derived fuels, which lack these sulfur compounds, it provides a measure of the total concentration of free fatty acids. However, this method lacks selectivity, as it measures both organic and inorganic acidic components, which may or may not originate from the triacylglycerols during oil-to-biofuel conversion. Moreover, it provides no information on the distribution of the individual MCAs.

By contrast, a GC-FID analysis of derivatized MCAs can provide a detailed speciation of MCAs $\mathrm{C}_{6}-\mathrm{C}_{24}$ [13] and MCA $\mathrm{C}_{14}-\mathrm{C}_{18}$. For example, Lau and coworkers demonstrated comparable results and repeatability to titration using GC-FID to characterize MCAs in palm oil [14] .

For the analysis of free and total glycerols, i.e., totals of glycerol, MAGs, DAGs and TAGs, derivatization followed by high-temperature GC-FID (HTGC-FID) is often employed using a nonpolar stationary phase and cold on-column injection [15-19] following standard methods ASTM D6584 [4] or EN 14105 [20], which utilize $N$-methyl- $N$-(trimethylsilyl) trifluoroacetamide (MSTFA) derivatization. Anion-exchange chromatography with pulsed amperometric detection has been proposed to eliminate the need for the derivatization step [21]. However, neither of these methods provides characterization of individual species, which is essential for mechanistic insights during the biofuel development.

When performing a GC analysis of TAGs, the injection technique is one of the critical parameters to ensure a complete transfer of such high molecular weight components onto the column. On-column injection is most often employed [15-19, 22, 23] but may result in column contamination with undesirable non-volatile species from TAG feedstock conversion[24]. A programmed temperature vaporizer (PTV) can be used to achieve transfer efficiencies comparable to on-column injection for high molecular weight species while minimizing the introduction of non-volatile species. Several research groups have reported the application of PTV for the analysis of highly concentrated 
samples of synthetic and food fat TAG mixtures [24-31]. It should be noted that a slight discrimination of larger TAGs was observed during the use of splitless PTV injection [24-30]. This was assumed to be due to insufficient elution out of the syringe needle or irreversible adsorption to the chromatographic column [24, 32]. Šánek et al. [33] showed the importance of careful optimization of the injection conditions when analyzing fatty acid methyl esters and acylglycerols and developed a method for their simultaneous determination.

A number of chromatographic methods employing a MS detector have been developed over the last couple of decades [23, 34-42] to enable detailed analysis of individual acylglycerol species. Both GC-MS [34-37] and LC-MS [38-42] have been employed for the analyses of compositionally different TAG samples. Yet HTGC has been suggested as a favored technique in a review summarizing the developments in the field of TAG GC and LC analysis over the past decade[23]. The majority of these LC and GC methods have focused on the separation and identification of species in lipid mixtures (i.e., food products) that have high concentrations of TAGs, which allowed to first fractionate samples using thin layer prior to GC or LC analysis [34-36, 38, 41, 42]. A few studies also used a GC equipped with two detectors, i.e., MS and FID, to ensure reliable identification and quantification of TGAs and MCAs [43-47]. To our knowledge, the sensitivity of these methods was not reported, possibly due to the high concentrations of the target analytes.

A few studies reported methods for simultaneous detailed analysis of MCAs and acylglycerols in vegetable oils, animal fats, or biodiesel matrices using GC [13, 14, 48], LC [49-51] or SFC [52, 53] (Suppl. Table 1), all with various limitations. The HTGC-FID methods did not allow for an accurate identification of heterogeneous DAGs and TAGs $[13,14]$, whereas the reported GC-MS applications $[31,48]$ did not use high temperature programs (i.e., HTGC) and thus were unable to address DAGs and TAGs. In the reported LC [49-51] and SFC $[52,53]$ methods, low MW acids, i.e., below $\mathrm{C}_{16}$ or $\mathrm{C}_{18}$, were not considered. In addition, quantification was not reported in either LC [49-51] or SFC [52, 53] studies.

The aim of the presented work was to develop a method for simultaneous analysis of a wide range of free MCAs, MAGs, DAGs, and TAGs using HTGC coupled with simultaneous FID and MS detection (HTGC-FID/MS), enabling identification of intermediate products in various matrices. A central composite design (CCD) was employed to optimize the PTV injection conditions to minimize the discrimination of low and high molecular weight species. Also, the GC oven temperature program and MS parameters were evaluated. The applicability and efficiency of the developed method was validated using intermediate biofuel samples generated by the partial noncatalytic thermal cracking of soybean oil. Additional parameters evaluated include method inter- and intra-day repeatability and instrumental limits of detection (LOD). Accuracy and precision of quantification was ensured by the use of an appropriate set of internal and recovery standards.

\section{Materials and methods}

\subsection{Materials}

All relevant information on the individual compounds used in this study, including manufacturer, molecular formula, weight, and quantification and confirmation ions $(\mathrm{m} / \mathrm{z})$, are listed in Table 1. Two TAG standard mixtures were used: 1) GLC-768 (TAGs $\mathrm{C}_{7}-\mathrm{C}_{22}$, Nu-Chek Prep., Inc., Elysian, MN, USA) for the analytical method development, including the determination of LODs, and 2) GLC-437 (TAGs $\mathrm{C}_{16}, \mathrm{C}_{18}, \mathrm{C}_{18: 1}, \mathrm{C}_{18: 2}, \mathrm{C}_{18: 3}, \mathrm{C}_{20}$, Nu-Chek Prep., Inc.) for method evaluation and quantification of OLP samples. To account for errors during sample preparation, injection accuracy/precision and volume changes, various recovery (R.S.) and internal (I.S.) standards were employed (Table 1). Samples and standards were prepared in methylene chloride (GC grade, Fisher Scientific, Pittsburg, PA, USA). The $N$-methyl- $N$-(trimethylsilyl) trifluoroacetamide (MSTFA) derivatization agent was obtained from Supelco Analytical (St. Louis, MO, USA). 


\subsection{Preparation of standard solutions and calibration standards}

Standards for method optimization and determination of LODs (compounds marked as $O$, Table 1) were prepared in methylene chloride via serial dilution in the range of $0.15-20 \mu \mathrm{g} / \mathrm{mL}$ for 18 MCAs, 4 MAGs, and 4 DAGs, and in the range of $0.35-50 \mu \mathrm{g} / \mathrm{mL}$ for 18 TAGs. The derivatization protocol of ASTM D 6584 using MSTFA [4] was adapted as follows: $100 \mu \mathrm{L}$ of MSTFA was added to each of six standard solutions, followed by heating at $60{ }^{\circ} \mathrm{C}$ for 1 hour. Butanetriol (1.2 ng) was used as the I.S. for the quantification of acylglycerols. Hexadecanoic acid- $d_{31}(0.59 \mathrm{ng})$ was used as the I.S. for the quantification of MCAs.

Calibration standards (compounds marked as $C$, Table 1) were prepared in methylene chloride at five concentration levels via serial dilution in the range of $2-300 \mu \mathrm{g} / \mathrm{mL}$ for $18 \mathrm{MCAs}, 2-160 \mu \mathrm{g} / \mathrm{mL}$ for 4 MAGs, $1.2-100 \mu \mathrm{g} / \mathrm{mL}$ for 4 DAGs, $1.2-40 \mu \mathrm{g} / \mathrm{mL}$ for 6 TAGs, and $0.4-30 \mu \mathrm{g} / \mathrm{mL}$ for glycerol. The concentration ranges of the R.S. (Table 1) in the calibration standards were $3-250 \mu \mathrm{g} / \mathrm{mL}$ for R.S.1a, R.S.1b and R.S.1c, $0.3-25 \mu \mathrm{g} / \mathrm{mL}$ for R.S.2, and $1.5-125 \mu \mathrm{g} / \mathrm{mL}$ for R.S.3 and R.S.4. The standards were derivatized with $100 \mu \mathrm{L}$ of MSTFA at $60{ }^{\circ} \mathrm{C}$ for 1 hour. The final amounts of I.S.1 and I.S.2 were $94 \mathrm{ng}$ and $80 \mathrm{ng}$, respectively.

A 100-fold molar excess of MSTFA compared to the derivatized species was used to ensure that the derivatization was complete.

\subsection{Generation and preparation of OLP samples}

Six OLP samples were generated via partial cracking of soybean oil in a miniaturized tubular batch stainless steel reactor (Fig. 1). The reactor body $(5 \mathrm{~mL})$ was placed in a heating base with a temperature control system consisting of a solid-state relay (Omega 25A SSR, SSRL240DC25, Omega, Stamford, CT, USA) and a ramp/soak controller (Omega, CN7823). Heating was accomplished using a McMaster-Carr (Robbinsville, NJ, USA) $400 \mathrm{~W}$ cartridge heater (3618K454, diameter of 0.371 " and voltage of $120 \mathrm{~V}$ ). An Omega miniature type K ceramic thermocouple probe was used to measure the temperature inside of the reactor during the experiments (SICSS-062U-5SHX, 0.062" O.D., 5" long). The pressure was monitored by a Swagelok stainless steel miniature industrial pressure gauge (PGI-40M-PG3000-LANX with a working pressure range up to 20.6 MPa, Swagelok, Bismarck, ND, USA). To prevent buildup of pressure, a Swagelok one-piece instrumentation stainless steel ball valve (SS-41S2) rated for 17.2 MPa was used. A high temperature HIP valve (60-11HF2-HT, Erie, PA, USA) rated for $413.7 \mathrm{MPa}$ at $538{ }^{\circ} \mathrm{C}$ was used as an outlet valve to enable transfer of the OLP into two sequential collection vials. Swagelok stainless steel fittings and tubing (0.0225" I.D.) were used for all connections.

For OLP generation, the soybean oil $(1 \mathrm{~mL})$ was introduced to the reactor, which was subsequently purged with nitrogen. The system was sealed and then heated until the required temperature $\left(470-620^{\circ} \mathrm{C}\right)$ was reached while the pressure was monitored $(2.9-10 \mathrm{MPa})$. The system was held at the desired temperature for $5 \mathrm{~min}$. Upon completion of the experiment (total ca. 10-15 $\mathrm{min}$ ), the reactor was cooled to near room temperature using a cooling system integrated into the same base containing the heating elements. The OLP samples were transferred into cooled collection vials.

An aliquot $(10 \mu \mathrm{L})$ of an OLP sample was first mixed with $200 \mathrm{ng}$ of each R.S.1a, R.S.1b, and R.S.1c, $20 \mathrm{ng}$ of R.S.2, and $100 \mathrm{ng}$ of each R.S.3 and R.S.4 (Table 1). The resulting mixture was then derivatized the same way as the calibration standards (described in Section 2.2).

\subsection{HTGC-FID/MS analysis}

The analyses were performed using an Agilent 7890 GC-FID/5975C MS (Agilent Technologies, Santa Clara, CA, USA) equipped with an autosampler (7386B series) and PTV with 
septum (Gerstel, Linthicum Heights, MD, USA) employing a baffled glass liner (Restek, Bellefonte, PA, USA).

To ensure efficient transfer of analytes from the PTV injection port to the column, three injection parameters were optimized in five levels using a CCD (Suppl. Table 2). The first parameter was the hold time $(0.70-2.44 \mathrm{~min})$ of the PTV injector at $40{ }^{\circ} \mathrm{C}$. The second was the column hold time $(1.09-4.11 \mathrm{~min})$ at $35^{\circ} \mathrm{C}$. The last was the splitless time (1.09-2.60 $\left.\mathrm{min}\right)$. The starting inlet temperature $\left(40{ }^{\circ} \mathrm{C}\right)$ was the minimum temperature that could be reached in a reasonable period of time (i.e., $15 \mathrm{~min})$ without applying cryogenic cooling. The final PTV temperature $\left(380{ }^{\circ} \mathrm{C}\right)$ was set to match the final column temperature. The heating rate $\left(720^{\circ} \mathrm{C} / \mathrm{min}\right)$ was set to the maximum possible value to insure complete vaporization of all high molecular mass analytes. A lower PTV heating rate $\left(50^{\circ} \mathrm{C} / \mathrm{min}\right)$ was not considered as it was shown to be ineffective in our previous work addressing the analyses of a wide range of alkanes [54]. The optimized injection program applied to the OLP samples was as follows: $40^{\circ} \mathrm{C}$ for $0.7 \mathrm{~min}, 720^{\circ} \mathrm{C} / \mathrm{min}$ to $380{ }^{\circ} \mathrm{C}$, and hold for $10 \mathrm{~min}$, with a splitless time of $2.6 \mathrm{~min}$.

The chromatographic separation was carried out on a DB-1HT column (15 m x $0.25 \mathrm{~mm}$ I.D. x $0.1 \mu \mathrm{m}$ film thickness) obtained from Agilent Technologies. The injection volume was $0.2 \mu \mathrm{L}$. Helium was used as a carrier gas at a constant flow rate of $1 \mathrm{~mL} / \mathrm{min}$. The final column temperature program started at $35^{\circ} \mathrm{C}$ for $2.6 \mathrm{~min}$ followed by ramp $\# 1\left(15^{\circ} \mathrm{C} / \mathrm{min}\right)$ to $230^{\circ} \mathrm{C}$, ramp \#2 $\left(20^{\circ} \mathrm{C} / \mathrm{min}\right)$ to $380{ }^{\circ} \mathrm{C}$, and a final hold for $10 \mathrm{~min}$. Total run time was $33 \mathrm{~min}$. This program was shorter than that specified in ASTM D 6584 [4] and accounted for instrument capabilities and separation of more volatile MCAs.

Compounds eluting from the GC column were partitioned via a 2-way splitter with makeup gas (He at a constant pressure of $28 \mathrm{kPa}$ ) between the FID and MS detectors in a 2:1 ratio (FID:MS) to provide simultaneous mass spectra identification and FID quantification. The lengths of the connecting capillaries (0.15 mm I.D.) to the MS and FID detectors were $1.71 \mathrm{~m}$ and $0.31 \mathrm{~m}$, respectively. FID and MS transfer line temperatures were set to $400{ }^{\circ} \mathrm{C}$ and $300{ }^{\circ} \mathrm{C}$, respectively.

The effect of several electron ionization (EI) source / quadrupole analyzer temperatures, namely $350 / 200{ }^{\circ} \mathrm{C}, 300 / 200{ }^{\circ} \mathrm{C}$ and $250 / 150{ }^{\circ} \mathrm{C}$, on the MS fragmentation pattern of TAGs was evaluated. The optimum conditions, were found at $350 / 200{ }^{\circ} \mathrm{C}$ (see Section 3.2). Total ion current (TIC), selected ion monitoring (SIM), and SITI (simultaneous SIM and TIC) quadrupole scan modes were compared. TIC was essential for analyte identification, while SIM was more sensitive. The final sample acquisition was performed in SITI mode since too many ions were required to be monitored at the same time due to the complexity of OLP samples. The quantification and confirmation ions for the target analytes are listed in Table 1 . TIC data were acquired in three mass ranges: $\mathrm{m} / \mathrm{z} 50-450$ for MCAs, $m / z$ 250-700 for MAGs and DAGs, and $m / z$ 350-750 for TAGs. For the majority of compounds two ions (Table 1) with dwell times of $50 \mathrm{msec}$ were monitored in SIM analysis. Analytes which eluted closer than $0.2 \mathrm{~min}$ from each other were combined in one group of four ions and monitored with a $30 \mathrm{msec}$ dwell time. All TAGs were monitored as one group of 14 ions with a 20 msec dwell time. The setup of SITI combined from SIM and TIC scans resulted in nine cycles/peak for most analytes.

A retention time shift of $0.01-0.02$ min to earlier elution times was observed for all target analytes every 20-35 sample injections. This may be due to stationary phase modification due to the covering of active sites in the beginning of the column by the sample matrix.

Based on a routine check of the calibration standard responses, we noticed a signal reduction leading to irreproducibility of the MS signal over time, necessitating source cleanup after approximately 50 OLP sample runs (the standards did not seem to have an impact on MS signal reproducibility). 


\subsection{Identification and quantification}

The target species in the OLP samples were identified by matching retention times and mass spectra of analytes to those of standards and in the MS library. To identify heterogeneous acylglycerols, for which neither standards nor NIST spectra were available, we used specific fragmentation ions reported elsewhere $[35,55,56]$ and further confirmed in our study. To determine the nature of the fatty acyl chains, the following fragment ions were used: (1) MAGs, $\left[\mathrm{M}-\mathrm{CH}_{2} \mathrm{O}-\right.$ $\mathrm{TMS}]^{+}$fragment ions, (2) DAGs, [M-RCOO- $\left.\mathrm{CH}_{2}\right]^{+}$ions, (3) TAGs, [RCO+128] $]^{+}$ions (corresponding to one acyl chain attached to a glycerol backbone plus a $\mathrm{C}_{2} \mathrm{H}_{3} \mathrm{COO}$ fragment). The identity of acylglycerols was further confirmed by using the fragments with the highest $\mathrm{m} / \mathrm{z}$, namely [M-RCOO$]^{+}$ (i.e., molecular ion minus one fatty acid) in the spectra of TAGs and the $\left[\mathrm{M}-\mathrm{CH}_{3}\right]^{+}$in the spectra of MAGs and DAGs. Positional isomers of DAGs were distinguished by the presence/absence of the $\left[\mathrm{M}-\mathrm{RCOO}-\mathrm{CH}_{2}\right]^{+}$ion, which indicated the primary positions $(\mathrm{sn}-1 / \mathrm{sn}-3)$ of the acyl groups, whereas an abundant $[\mathrm{M}-\mathrm{RCOO}]^{+}$ion identified the $s n-2$ position on the glycerol backbone [56]. To simplify the identification of acylglycerols, we generated Suppl. Table 2 which summarizes fragment ions of all theoretically possible MAGs, DAGs, and TAGs constructed from $\mathrm{C}_{16}, \mathrm{C}_{18}, \mathrm{C}_{18: 1}, \mathrm{C}_{18: 2}$ and $\mathrm{C}_{18: 3}$ acid moieties.

For standards, the FID calibration parameters for co-eluting diolein/dilinolein and triolein/trilinolein were calculated from a calibration slope determined by separate analysis of individual compounds. Heterogeneous DAG and TAG standards (i.e., consisting of non-identical acyl chains) were not commercially available, so the quantification of OLP samples was performed based on the prevailing acyl chain identified by MS. FID quantification of DAGs with an acyl carbon number (i.e., total carbon atoms; $\mathrm{ACN}$ ) of $34\left(\mathrm{C}_{16}\right.$ and $\left.\mathrm{C}_{18}\right)$ or 36 (two $\mathrm{C}_{18}$ ) were performed using dipalmitin and dilinolein, respectively. FID quantification of TAGs with an ACN of 50 (two $\mathrm{C}_{16}$ and one $\mathrm{C}_{18}$ ) was based on tripalmitin calibration. TAGs with an $\mathrm{ACN}$ of 52 (two $\mathrm{C}_{18}$ and one $\mathrm{C}_{16}$ ) and with an $\mathrm{ACN}$ of 54 (three $\mathrm{C}_{18}$ ) were quantified using trilinolein calibration. These $\mathrm{ACN}$ are the most common for TAGs occurring in biofuel intermediate products as a result of soybean oil noncatalytic cracking.

For MS/TIC quantification of target compounds, the ions listed in Table 1, were employed. For TAGs, quantification methods using two fragmentation ions, namely $[\mathrm{RCO}+128]^{+}$and $[\mathrm{M}-$ $\mathrm{RCOO}^{+}$, were compared. The $[\mathrm{M}-\mathrm{RCOO}]^{+}$fragments could not be employed for quantifications because of the interference from too many other different ions eluting within one retention time window. The quantification of heterogeneous $[\mathrm{M}-\mathrm{RCOO}]^{+}$ions, i.e., the ions consisting of one $\mathrm{C}_{16}$ and one $\mathrm{C}_{18}$ acyl chain (observed in TAGs with an ACN of 50 and 52), was performed using the calibration of tripalmitin. Heterogeneous $[\mathrm{M}-\mathrm{RCOO}]^{+}$ions consisting of two different $\mathrm{C}_{18}$ chains (observed in TAGs with an ACN of 52 and 54) were quantified using the nearest homogeneous standard ion of higher $\mathrm{m} / \mathrm{z}$. Thus, for the quantification using $\mathrm{m} / \mathrm{z} 605$ ion (i.e., consisting of stearin and olein acyl chains, Suppl. Table 3), the standard ion of $m / z 607$ (i.e., consisting of two stearin acyl chains, Suppl. Table 3) was used. The SIM quantification of TAGs was performed using $[\mathrm{RCO}+128]^{+}$ ions only.

To evaluate the matrix's impact on analysis performance, a mid-level calibration solution was analyzed after every three samples and the calibration standards were analyzed after every six sample runs. .

\subsection{Data processing and method validation}

The GC data were processed via MSD ChemStation E.01.00.237 from Agilent Technologies.

CCD experiments were modeled using Minitab ${ }^{\circledR}$ 15.1.30.0 (Minitab Inc., State College, PA, USA). The CCD experiments were performed in duplicate (the central points in quadruplicate) and were split into two blocks, eliminating any potential batch-to-batch source of variability. This resulted in a total of 40 (i.e., $20 \times 2$ ) experiments (Suppl. Table 2). The analysis of variance (ANOVA) and $P$ - 
values were calculated to indicate the impact of studied factors and interactions on analyte peak areas. A factor or interaction was considered to be influential if the $P$-value $\leq 0.05$.

The LODs were calculated from the four lowest concentrations (covering one order of magnitude) of calibration curves using the formula $\mathrm{LOD}=3.3 \cdot s_{y} /$ slope, where $s_{y}$ is the standard error for the $y$ estimate [57]. Given a split of gas flow between FID and MS in a ratio of 2:1 (FID:MS), the calculated FID and MS LODs were adjusted by factors of $2 / 3$ and $1 / 3$, respectively. The limits of quantification (LOQ) were calculated as $10 \cdot \mathrm{s}_{y} /$ slope [57].

Method repeatability was evaluated using six OLP samples. The precision of sample preparation was based on derivatization of triplicate samples. The precision of the chromatographic method was determined by three injections of an OLP sample in random order within the same day (the intra-day repeatability). For inter-day repeatability, nine replicates of OLP samples were analyzed over an eight-day period. Standard deviation (SD) was used to express the precision of the analyses.

The stability of MSTFA-derivatized samples, kept at an ambient temperature $\left(20-25^{\circ} \mathrm{C}\right)$, was determined by injecting the same OLP sample consecutively for up to eight days.

\section{Results and discussion}

\subsection{Optimization of PTV injection conditions}

To evaluate the significance of the injection techniques on analyte discrimination, we assessed and optimized three major injection parameters, namely the PTV hold time at an initial $40^{\circ} \mathrm{C}$, the splitless time and the initial oven hold time at $35^{\circ} \mathrm{C}$, using CCD (Suppl. Table 2).

A regression analysis (i.e., $P$-values in Table 2 ) of the injection program revealed that the PTV hold time, the splitless time, and the interaction between these two parameters had a statistically significant effect on the response of the target analytes, particularly of the high MW species. On the other hand, the following parameters did not significantly affect the response of a majority of the analytes: the time for which the column was kept at an initial temperature, interaction between the column and the PTV hold times at the initial temperature, column hold time and splitless time. This trend was observed even for experiments where the column time at an initial temperature was shorter than that of the PTV hold time.

PTV hold times below $1.5 \mathrm{~min}$ at an initial temperature of $40{ }^{\circ} \mathrm{C}$ and splitless times longer than 2.5 min resulted in a higher response for most of the analytes (Fig. 2) except for volatile low MW MCAs, namely $\mathrm{C}_{4}, \mathrm{C}_{6}$ and $\mathrm{C}_{7}$ (Table 2). Moreover, $\mathrm{C}_{4}-\mathrm{C}_{6}$ MCAs were effectively transferred from the PTV to the column in a splitless time of only one min. Splitless times longer than 2.5 min decreased the separation of butyric acid and the derivatization agent.

Interaction between the PTV hold time at an initial temperature and the splitless time was significant only for high MW species (Table 2). The representative interaction patterns are displayed in Fig. 3 as response surface plots (RSP) for $\mathrm{C}_{8}$ MCA and $\mathrm{C}_{16}$ TAG. In the analyses where the splitless time was lower than the PTV time, the response of a majority of the analytes was at a minimum; no signal was observed for $\mathrm{C}_{18}-\mathrm{C}_{22}$ TAGs (Fig. 4). As demonstrated in Fig. 4, the optimal conditions were obtained whenever the difference between splitless and PTV times was one minute or higher thus allowing for complete transfer of compounds heavier than $\mathrm{C}_{7}$.

The optimum PTV injection conditions and chosen values for the analysis of OLP samples are listed in the Table 2. Since the time during which the column stays at the initial $35^{\circ} \mathrm{C}$ was influential, it was set to be equal to the splitless time, for consistency reasons.

\subsection{Effect of EI source temperature}

The fragmentation patterns in mass spectra are typically affected by the temperature of the ionization source. While lower temperatures may be beneficial in preserving the high mass ions, higher temperatures may eliminate a number of background ions (i.e., providing cleaner mass spectra) 
[58]. Various EI source temperatures for the analysis of TAGs have been reported in the literature, ranging from 175 [36] to $370^{\circ} \mathrm{C}$ [34]. However to our knowledge, no experimental evaluation of the most efficient ionization conditions has been previously reported.

Our results showed that the temperature of the EI source mainly affected the apparent concentration of TAGs. Among the three ion source temperatures tested, $250{ }^{\circ} \mathrm{C}, 300{ }^{\circ} \mathrm{C}$ and $350{ }^{\circ} \mathrm{C}$, $350{ }^{\circ} \mathrm{C}$ provided the highest response of $[\mathrm{M}-\mathrm{RCOO}]^{+}$fragment in $\mathrm{C}_{14} \mathrm{TAG}, \mathrm{C}_{16} \mathrm{TAG}$, and $\mathrm{C}_{18} \mathrm{TAG}$ mass spectra (Fig. 5a). The signal-to-noise ratio $(\mathrm{S} / \mathrm{N})$ for these types of fragments could not be evaluated as no noise was observed. For the $[\mathrm{RCO}+128]^{+}$fragment, the $\mathrm{S} / \mathrm{N}$ values were adjusted for the root mean square (RMS) value of the measured noise and expressed as RMS S/N. The highest RMS S/N was observed for EI source temperatures of $300^{\circ} \mathrm{C}\left(\mathrm{C}_{14}\right.$ and $\mathrm{C}_{16}$ TAGs, Fig. $\left.5 b\right)$ and 350 ${ }^{\circ} \mathrm{C}\left(\mathrm{C}_{18}\right.$ TAG,Fig. $\left.5 \mathrm{~b}\right)$, respectively. Since [M-RCOO $]^{+}$high mass fragments are more suitable for the identification of TAGs, the highest ion source temperature, $350{ }^{\circ} \mathrm{C}$, was chosen for all further experiments. The temperature of the quadrupole analyzer was adjusted only to reduce the temperature gradient between the source and the analyzer.

\subsection{Separation of MCAs, MAGs, DAGs, TAGs and glycerol}

Several oven temperature programs were evaluated in order to achieve sufficient separation of target analytes. The temperature program proposed by ASTM D 6584 [4] (i.e., initial temperature 50 ${ }^{\circ} \mathrm{C}$, hold $1 \mathrm{~min}$, gradient $\# 1=15^{\circ} \mathrm{C} / \mathrm{min}$ to $180^{\circ} \mathrm{C}$, gradient $\# 2=7^{\circ} \mathrm{C} / \mathrm{min}$ to $230^{\circ} \mathrm{C}$, gradient $\# 3=$ $30{ }^{\circ} \mathrm{C} / \mathrm{min}$ to $380{ }^{\circ} \mathrm{C}$, hold for $10 \mathrm{~min}$ ) was found to be unsuitable for the latest model of Agilent $7890 \mathrm{~A} \mathrm{GC}$ used in this study. Since the maximum applicable temperature gradient with a reproducible heating rate for the Agilent $7890 \mathrm{~A} \mathrm{GC}$ is $20^{\circ} \mathrm{C} / \mathrm{min}$ for temperatures above $300{ }^{\circ} \mathrm{C}$, gradient $\# 3$ from ASTM D 6584 [4] was decreased accordingly. Also, it was found that the slow gradient $\# 2\left(7^{\circ} \mathrm{C} / \mathrm{min}\right)$ in the ASTM method did not improve the resolution between unsaturated MAGs, and thus it was combined with gradient $\# 1$ of $15^{\circ} \mathrm{C} / \mathrm{min}$. Further increase in the ramp rate for gradient \#1 (up to gradient $\# 3$ of $20{ }^{\circ} \mathrm{C} / \mathrm{min}$, which would allow the use of a single temperature gradient) resulted in lower resolution between unsaturated $\mathrm{C}_{18}$ MCAs. The final temperature program was: initial temperature of $35^{\circ} \mathrm{C}$ for $2.6 \mathrm{~min}$ followed by gradient $\# 1$ with a ramp rate of $15{ }^{\circ} \mathrm{C} / \mathrm{min}$ to $230^{\circ} \mathrm{C}$, gradient \#2 with a ramp rate of $20^{\circ} \mathrm{C} / \mathrm{min}$ to $380^{\circ} \mathrm{C}$, and a final hold for $10 \mathrm{~min}$. a four min faster The total analysis time was decreased by 4 minutes compared to ASTM D 6584 [4], and provided a more stable linear temperature increase.

The temperature program we developed resulted in a separation of major classes of compounds (Fig. 6), as required in ASTM D 6584 [4]. In addition, otherwise co-eluting monoolein and monolinolein were sufficiently resolved $\left(\mathrm{Rs}_{\mathrm{S}}=0.6\right)$ to enable their quantification. We were also able to separate positional isomers of MAGs and DAGs (i.e., sn-2 or $s n-1,3$ acyl chain positions on glycerol backbone). Unsaturated DAGs were baseline separated from distearin, with diolein overlapping with dilinolein. Separation of TAGs was similar to the ASTM method, i.e., tristearin co-eluted with trilinolenin, and triolein overlapped with trilinolein.

\subsection{Calibration parameters and limits of detections}

Calibration parameters for all target analytes and for all monitored signals (i.e., FID, TIC, TIC/EIC, SIM) are summarized in Suppl. Tables 4 and 5.

The FID signal provided similar slopes for saturated $\mathrm{C}_{5}-\mathrm{C}_{10}$ MCAs $(0.0168 \pm 0.0007)$ and for $\mathrm{C}_{11}-\mathrm{C}_{18} \mathrm{MCAs}(0.0214 \pm 0.0006)$, with slightly lower sensitivity observed for unsaturated $\mathrm{C}_{18} \mathrm{MCAs}$ (Suppl. Table 4). Butyric acid partially co-eluted with R.S.1a (Fig.6) which led to its lower sensitivity. Similar FID signal slopes were observed for all saturated and unsaturated MAGs and DAGs $(0.0210$ \pm 0.0008 and $0.0193 \pm 0.0008$, respectively, Suppl. Table 5 ). By contrast, the sensitivity for TAGs decreased with an increasing acyl chain length and with the number of double bonds. 
ASTM D 6584, which is designed for biodiesel, recommends using the FID slope of C18:1 acylglycerols (i.e., monoolein, diolein and triolein) for quantification of all other acylglycerols in series [4]. As shown above, this assumption was only appropriate for MAGs and DAGs. Based on our results, the application of ASTM D 6584 may lead to an underestimate of the TAGs because the slopes for trilinolein and trilinolenin were 1.5 and 2 times, respectively, lower than that of triolein (Suppl. Table 5). Therefore, the use of the triolein slope to determine the concentrations of polyunsaturated TAGs with prevailing $\mathrm{C}_{18: 2}$ and $\mathrm{C}_{18: 3}$ acyl chains may lead to underestimation of the results depending on sample type.

The MS signal (TIC, TIC/EIC, or SIM) produced a high slope dependency on acyl chain length and degree of unsaturation in both MCAs and acylglycerols (Suppl. Tables 4 and 5, respectively). These results, obtained for homogenous (i.e., containing identical acids chains) TAGs, were in agreement with results reported by other research groups $[36,37,41]$ for a series of homogeneous and heterogeneous TAGs. Although lower sensitivity was observed for the MS signal, quantification of acylglycerols using the fragmentation ions listed in Table 1 can provide quantitative information on the distribution of acyl chains in heterogeneous species, as discussed in section 3.5.2.

The instrumental LOD values for targeted MSTFA-derivatized compounds obtained using FID and MS (using $[\mathrm{RCO}+128]^{+}$fragments for TAGs) signals are listed in Table 3. As mentioned in Section 2.5, TAG quantification using $[\mathrm{M}-\mathrm{RCOO}]^{+}$ions provided higher variability. The LODs (not shown) in MS/TIC mode were in a range of 0.2-1.3 ng. It was not feasible to evaluate TAG LODs using $[\mathrm{M}-\mathrm{RCOO}]^{+}$ions in MS/SIM mode as too many ions would have to be monitored.

As expected, the lowest LODs were obtained in a SIM mode resulting in $0.01-0.05 \mathrm{ng}$ for MCAs and 0.03-0.14 ng for acylglycerols. FID, which is considered to be a nearly universal detector, provided LODs of 0.07-0.27 ng for both MCAs and acylglycerols. Higher LODs were observed for trilinolein and trilinolenin, due to the high degree of unsaturation, and for butanoic acid, which eluted near to the MSTFA peak. For TIC/EIC signal LOD values increased with an increase of the acyl chain length and degree of unsaturation, ranging from 0.03 to $0.18 \mathrm{ng}$ for MCAs, and 0.03 to $15.5 \mathrm{ng}$ for acylglycerols (Table 3). For acids the determined LODs were higher than those reported previously [59] for analysis of MCA possibly due to a narrower $m / z$ range used previously.

In general, for all of the signals (i.e., FID, TIC/EIC, and SIM), we were able to obtain LOD values below the working range (6-57 ng) suggested for the analysis of acylglycerols in ASTM D 6584 [4]. The only exception was for the LOD value of trilinolenin (i.e., $15.5 \mathrm{ng}$ ) obtained using TIC/EIC mode. However this compound was not used in the ASTM method at all.

\subsection{Characterization of OLPs}

The HTGC-FID/MS method we developed was applied to six OLP samples generated by the partial cracking of soybean oil. The samples were prepared under different temperatures representing various degrees of noncatalytic thermal cracking. These pyrolysis experiments were performed at relatively short residence times, 5-10 min, to yield a high concentration of DAGs and TAGs. While these conditions are not commercially attractive, they were beneficial for analytical method evaluation. A detailed evaluation of reproducibility was completed for two representative samples (Section 3.6) using FID and MS (Tables 4 and 5, respectively). The described trends were confirmed with the FID and MS data for the other four soybean oil OLP samples (Suppl. Tables 6 and 7).

The chromatographic resolution of OLP compounds was based on their total number of carbon atoms, positional isomerization, and, to some extent, the degree of unsaturation (Fig. 7). Satisfactory sensitivity of the developed HTGC-FID/MS method and the absence of significant interferences from the oil matrix were demonstrated. The only complications observed were for co-eluted heterogeneous TAGs, resulting in equivocal peak identification. The quantification of target species was successfully performed by both FID and MS signals as discussed below. 


\subsubsection{MCAs analysis in the OLPs}

The total organic acid concentration in the soybean OLP samples ranged from 5.4 to 13.0 weight \% (Tables 4 and 5, Suppl. Table 6). The MCA composition varied slightly from sample to sample, with oleic, linoleic and palmitic acids being the most predominant (in equivalent amounts, Table 5). The detected high concentrations of heptanoic acid demonstrated the necessity to monitor MCAs shorter than $\mathrm{C}_{16}$ and $\mathrm{C}_{18}$. The relatively high concentrations of $\mathrm{C}_{5}-\mathrm{C}_{10}$ MCA observed in the study were in agreement with previously reported results for OLPs obtained by non-catalytic cracking [60].

$\mathrm{C}_{11}$ MCA was only detected by FID in the soybean OLP samples, even though the $\mathrm{C}_{11} \mathrm{MCA}$ LOD in the FID signal was higher than in MS/SIM for the standards (Table 3). The MS spectra of the $\mathrm{C}_{11}$ MCA peak revealed a contribution of unsaturated $\mathrm{C}_{11: 1} \mathrm{MCA}$, which resulted in an overestimation of the $\mathrm{C}_{11}$ MCA concentration by FID.

Although the baseline separation of the critical pair of oleic and linoleic acids was obtained in the standard mixture (Fig. 6), in soybean oil OLP samples $\mathrm{C}_{18: 2}$ MCA was present in the form of three isomeric peaks, resulting in partial co-elution with $\mathrm{C}_{18: 1} \mathrm{MCA}$ (detected as two resolved isomers of equal abundance). Should the detailed composition of unsaturated $\mathrm{C}_{18}$ MCAs be required, quantification by MS signal may be preferred (both TIC/EIC and SIM produced the same results). However, the total amounts of MCAs were similar and thus may be estimated by either FID or MS (Tables 4 and 5).

\subsubsection{Acylglycerol analysis in the OLPS}

The novelty of this work centers around an evaluation of the feasibility of TIC/EIC for acylglycerol speciation and quantification, and its comparison to common FID approaches applied to OLP samples. The MS SIM is not recommended for quantification due to the complexity of the OLP samples, and the consecutive requirement to simultaneously monitor too many ions. Quantification of acyglycerols using MS and FID provided similar results (Table 4 and 5, Suppl. Table 6), demonstrating the comparable accuracy of both methods. Most discrepancies were attributed to higher LODs for MS EIC detection, though some can be related to the lack of speciation using FID (as shown below).

The majority of the detected MAGs were below LOQ levels. Only monolinolein was observed when employing FID. While its presence was confirmed in SIM, in MS/TIC analysis it was below LOQ (Table 5).

DAGs with ACNs of 34 and 36 were baseline resolved, each into two peaks (Fig. 7), indicating the presence of two structural isomers, i.e., 1,3-DAGs 1,2-DAGs. The MS revealed the heterogeneous nature of DAGs with an ACN of 36, with a $\mathrm{C}_{18: 2}$ acyl chain concentration being much higher than that of $\mathrm{C}_{18: 1}$ and $\mathrm{C}_{18: 3}$ acyl chains. The total concentrations quantified by MS were lower than those obtained by FID as some of the DAGs could not be detected by FID due to the higher LODs.

TAGs in soybean oil OLPs were resolved into three major peaks according to their carbon number (Fig. 7). The dominant components were unsaturated (up to 6 double bonds) TAGs with ACN of 54, i.e., (containing three $\mathrm{C}_{18}$ acyl chains), TAGs with an $\mathrm{ACN}$ of 52 (containing two $\mathrm{C}_{18}$ acyl chains and one $\mathrm{C}_{16}$ acyl chain) and the most abundant TAGs with an ACN 50 (two $\mathrm{C}_{16}$ acyl chains and one $\mathrm{C}_{18}$ acyl chain). Similar results for FID and MS were obtained for TAGs with an ACN of 52 . Higher concentrations of TAGs with an ACN of 54 obtained by FID (compared to MS) may be attributed to the selection of a single FID calibration standard for all levels of saturation. This approach could have resulted in an overestimation of TAGs having a higher degree of saturation than trilinolein.

\subsection{Method repeatability}


The repeatability of the sample derivatization protocol and intra- and inter-day HTGC analysis for the target compounds in soybean oil OLPs using FID and MS are summarized in Tables 4 and 5, respectively. The lowest standard deviations (SDs) were observed for intra-day GC analysis for both FID and MS signals. For the inter-day analysis, the instrumental variability increased up to 3-fold for 8 -day old samples. Some differences in the results were caused by an increase in the LOQ values of 8 -day old standards, particularly for the TAG $[\mathrm{RCO}+128]^{+}$fragmentation ions. However, based on the ratios of peak area to area of internal standard, the MSTFA-derivatized samples seemed to be stable after eight days of storage at laboratory room temperature (ca. $17^{\circ} \mathrm{C}$ ). Sample preparation (i.e., derivatization) exhibited the highest degree of variability with up to $10 \% \mathrm{RSD}$.

\section{Conclusions}

In this work, we demonstrated the applicability of the HTGC-FID/MS method for the simultaneous identification and quantification of a variety of TAG decomposition products. To our knowledge, it is the first successful simultaneous analysis of MCAs, MAGs, DAGs, and TAGs from a single run.

Optimization of the PTV injection conditions, column temperature program, and MS parameters allowed for the separation of the majority of the target compounds based on their total number of carbon atoms, positional isomerization and, to some extent, degree of unsaturation. The optimum PTV conditions were particularly critical for detection of TAGs. The application of MS detection offered complementary information to the FID on the structure of co-eluting analytes and enabled more accurate quantification than FID alone. Results from the MS speciation of heterogeneous TAGs were used to select the most appropriate FID quantification standard.

In this paper, the suggested quantification method using TIC/EIC provided similar results to those obtained by FID, thus the developed method can solely employ an MS detector. However, MS requires more frequent cleanup and its sensitivity is affected by relatively high bleed from the column. Routine analysis of standards before and after oil or biofuel samples is an important step for ensuring high accuracy analysis. It is also important to note that similar to ASTM method D 6584, we have used fairly diluted samples [4]. The detection limits could be further improved if the analyzed samples were more concentrated. However, this would be detrimental to the detection of butanoic acid as it would elute in an extended solvent delay necessary due to higher volume of derivatization agent used (or its products).

This method, together with our previous work on the quantification of the hydrocarbon content of biofuels [61], has the potential to be incorporated into standard methods used by the emerging next generation biofuels industry since they both provide detailed and complete characterization of the major by-products of biofuel production, with a higher degree of accuracy for both identification and quantification than currently applied standard methods.

\section{Acknowledgements}

The authors acknowledge Danese C. Stahl for her help with instrumentation and data processing and editing of the manuscript. Many thanks to David Young for designing and building the reactor that was used for the non-catalytical thermal cracking experiments in this work. Evguenii Kozliak is gratefully acknowledged for valuable input into the pyrolysis experiments and help with manuscript preparation. Funding for this work was provided by the National Science Foundation (NSF), North Dakota EPSCoR Infrastructure Improvement Program (\#EPS-0447679), the SUNRISE Bioproducts North Dakota Center of Excellence, and the North Dakota Soybean Council. The completion of this study was supported through ND EPSCoR CSMS grant IIA-1355466 2014-19. Support of REU 
528 students was provided from NSF REU award 1156584 Any opinions, findings, and conclusions or 529 recommendations expressed in this material are those of the author(s) and do not necessarily reflect 530 the views of the NSF or ND EPSCoR. 
Fig. 1. Batch reactor used for the noncatalytic cracking of soybean oil.

Fig. 2. CCD main effect plots of (A, C) the PTV hold time at an initial temperature of $40{ }^{\circ} \mathrm{C}$ and $(\mathrm{B}$, D) the splitless time as functions of a peak area for MCAs (A, B) and selected TAGs (C, D). MCAs $\mathrm{C}_{11-\mathrm{C}_{18}}$ followed analogous to MCA $\mathrm{C}_{10}$ trends.

Fig. 3. Response surface plots for the PTV hold time at an initial temperature of $40{ }^{\circ} \mathrm{C}$ and splitless time obtained via central composite design for (A) $\mathrm{MCA} \mathrm{C}_{8}$ (MCAs $\mathrm{C}_{9}-\mathrm{C}_{18}$ followed analogous trend) and (B) TAG $\mathrm{C}_{16}$ (TAGs $\mathrm{C}_{8}-\mathrm{C}_{15}$ and $\mathrm{TAGs} \mathrm{C}_{17}-\mathrm{C}_{22}$ showed analogous trend). The oven hold time at an initial temperature of $35^{\circ} \mathrm{C}$ was kept at $2.6 \mathrm{~min}$.

Fig. 4. Difference between the splitless time and the PTV hold time at an initial temperature of $40{ }^{\circ} \mathrm{C}$ as a function of a peak area for (A) MCA $\mathrm{C}_{11}-\mathrm{C}_{18}$ and (B) representative TAGs.

Fig. 5. The dependence of (A) signal height (ion $[\mathrm{M}-\mathrm{RCOO}]^{+}$, no noise was observed), (B) signal to noise ratio $(\mathrm{RMS} \mathrm{S} / \mathrm{N})\left(\right.$ ion $\left.[\mathrm{RCO}+128]^{+}\right)$of representative TAGs on EI source / quadrupole analyzer temperatures, obtained in TIC/EIC mode.

Fig. 6. HTGC-FID chromatogram of standard mixture of MCAs, MAGs, DAGs, TAGs and glycerol after derivatization with MSTFA. Peak identification is reported in Table 1.

Fig. 7. (A) HTGC-FID chromatogram and (B) HTGC-MS/TIC chromatogram of OLP 2 (see Tables 4 and 5 for detailed composition) obtained simultaneously after derivatization with MSTFA. Recovery and internal standards are reported in Table 1. 
558 [1] X. Dupain, Costa, D.J., Schaverien, C.J., Makkee, M., Moulijn, J.A., Cracking of a rapeseed vegetable oil under realistic FCC conditions, Appl. Catal. B-Environ., 72 (2007) 44-61.

560 [2] K.D. Maher, Bressler, D.C., Pyrolysis of triglyceride materials for the production of renewable fuels and chemicals, Bioresource Technol., 98 (2007) 2351-2368.

[3] Y. Luo, Ahmed, I., Kubátová, A., Št’ávová, J., Aulich, T., Sadrameli, S.M., Seames, W.S., The thermal cracking of soybean/canola oils and their methyl esters, Fuel Process Technol., 91 (2010) 613-617.

[4] ASTM Standard D6584 - 10, Standard test method for determination of total monoglyceride, total diglyceride, total triglyceride, and free and total glycerin in B-100 biodiesel methyl esters by gas chromatography, ASTM International, West Conshohocken, PA, 2006.

568 [5] M.R. Monteiro, Ambrozin, A.R.P., Lião, L.M., Ferreira, A.G., Critical review on analytical methods for biodiesel characterization, Talanta, 77 (2008) 593-605

[6] M. Buchgraber, Ulberth, F., Emons, H., Anklam, E., Triacylglycerol profiling by using chromatographic techniques, Eur. J. Lipid Sci. Tech., 106 (2004) 621-648.

[7] M. Mittelbach, Diesel fuel derived from vegetable oils, V [1]: Gas chromatographic determination of free glycerol in transesterified vegetable oils, Chromatographia, 37 (1993) 623-626.

[8] M. Mittelbach, Roth, G., Bergmann A., Simultaneous gas chromatographic determination of methanol and free glycerol in biodiesel, Chromatographia, 42 (1996) 431-434.

[9] N.K. Andrikopoulos, Chromatographic and spectroscopic methods in the analysis of triacylglycerol species and regiospecific isomers of oils and fats, Crit. Rev. Food Sci., 42 (2002) 473505.

[10] J.J. Myher, Kuksis, A., General strategies in chromatographic analysis of lipids, J. Chromatogr. B, 671 (1995) 3-33.

[11] V. Ruiz-Gutierrez, Barron, L.J.R., Methods for the analysis of triacylglycerols, J. Chromatogr. B, 671 (1995) 133-168

[12] ASTM Standard D664 - 09a, Standard test method for acid number of petroleum products by potentiometric titration, ASTM International, West Conshohocken, PA, 2006.

[13] P.J. Wan, Dowd, M.K., Thomas, A.E., Butler B.H., Trimethylsilyl derivatization/gas chromatography as a method to determine the free fatty acid content of vegetable oils, J. Am. Oil Chem. Soc., 84 (2007) 701-708.

[14] H.L.N. Lau, Puah, C.W., Choo, Y.M., Ma, A.N., Chuah, C.H., Simultaneous quantification of free fatty acids, free sterols, squalene, and acylglycerol molecular species in palm oil by hightemperature gas chromatography-flame ionization detection, Lipids, 40 (2005) 523-528.

[15] T. Řezanka, ̌̌ezanková H., Characterization of fatty acids and triacylglycerols in vegetable oils by gas chromatography and statistical analysis, Anal. Chim. Acta, 398 (1999) 253-261.

[16] A. Peña, Nevárez, L., Labastida, C., Capella, S., Triglyceride characterization of different mexican cheeses by high temperature capillary gas chromatography (HT-CGC), J. High Res. Chromatogr., 20 (1997) 572-574.

[17] R. Wawrzyniak, Wasiak, W., Determination of acylglycerols in diesel oils by GC, Toxicol. Mech. Method., 18 (2008) 531-536.

[18] C. Mariani, Bondioli, P., Venturini, S., Fedeli, E., Vegetable oil derivatives as diesel fuel. Analytical aspects. Note 1: determination of methyl esters, mono-, di-, and triglycerides, Riv. Ital. Sostanze Grasse, 68 (1991) 549-551.

601 [19] C. Plank, Lorbeer, E., Simultaneous determination of glycerol, and mono-, di- and triglycerides 602 in vegetable oil methyl esters by capillary gas chromatography, J. Chromatogr. A, 697 (1995) 461603468. 
[20] EN 14105: Fat and oil derivatives - Fatty Acid Methyl Esters (FAME) - Determination of free and total glycerol and mono-, di-, tri-glyceride content, in.

[21] T.T. Christison, B.M. De Borba, J.S. Rohrer, Determination of free and total glycerol in biodiesel, in, LCGC Editors, 2011.

[22] F. Munari, D. Cavagnino, A. Cadoppiv, Application Note: 10215. Determination of Free and Total Glycerin in Pure Biodiesel (B100) by GC in Compliance with EN 14105, in, Thermo Fisher Scientific Inc, 2007.

[23] C. Ruiz-Samblás, A. González-Casado, L. Cuadros-Rodríguez, Triacylglycerols Determination by High-temperature Gas Chromatography in the Analysis of Vegetable Oils and Foods: A Review of the Past 10 Years, Critical Reviews in Food Science and Nutrition, 55 (2015) 1618-1631.

[24] J.V. Hinshaw Jr., Seferovic, W., Programmed-temperture split-splitless injection of triglycerides: Comparison to cold on-column injection, J. High Res. Chromatogr., 9 (1986) 69-72.

[25] M. Buchgraber, Ulberth, F., Anklam, E., Interlaboratory evaluation of injection techniques for triglyceride analysis of cocoa butter by capillary gas chromatography, J. Chromatogr. A, 1036 (2004) 197-203.

[26] J.V. Hinshaw Jr., Seferovic, W., Analysis of triglycerides by capillary gas chromatography with programmed-temperature injection, J. High Res. Chromatogr., 9 (1986) 731-736.

[27] S. Banfi, Bergna, M., Povolo, M., Contarini, G., Programmable Temperature Vaporizer (PTV) applied to the triglyceride analysis of milk fat, J. High Res. Chromatog., 22 (1999) 93-96.

[28] J.A. Garcia Regueiro, Diaz, I., David, F., Sandra, P., Possibilities of PTV injection for the analysis of triglycerides, J. High Res. Chromatogr., 17 (1994) 180-183.

[29] J. Chang, Biniakewitz, R., Harkey, G., Determination of free and total glycerin in B-100 biodiesel via method ASTM D6584, Thermo Sci. Appl. Note: 10192, (2007).

[30] L. Lozada, Fuente, M.A., Fontecha, J., Juárez, M., Considerations of the quantitative aspect of the determination of milkfat triglycerides with split PTV and on-column injection, J. High Res. Chromatogr., 18 (1995) 771-775.

[31] A.N. Dias, M.B.R. Cerqueira, R.R.d. Moura, M.H.S. Kurz, R.M. Clementin, M.G.M. D’Oca, E.G. Primel, Optimization of a method for the simultaneous determination of glycerides, free and total glycerol in biodiesel ethyl esters from castor oil using gas chromatography, Fuel, 94 (2012) 178-183. [32] K. Grob Jr., Evaluation of injection techniques for triglycerides in capillary gas chromatography, J. Chromatogr. A, 178 (1979) 387-392.

[33] L. Sanek, J. Pecha, K. Kolomaznik, Simultaneous determination of main reaction components in the reaction mixture during biodiesel production, J Sep Sci, 36 (2013) 1029-1036.

[34] J. Fontecha, Ríos, J.J., Lozada, L., Fraga, M.J., Juárez, M., Composition of goat's milk fat triglycerides analysed by silver ion adsorption-TLC and GC-MS, Int. Dairy J., 10 (2000) 119-128.

[35] T. Ohshima, Yoon, H.S., Koizumi, C., Application of selective ion monitoring to the analysis of molecular species of vegetable oil triacylglycerols separated by open-tubular column GLC on a methylphenylsilicone phase at high temperature, Lipids, 24 (1989) 535-544.

[36] A. Kemppinen, Kalo, P., Quantification of triacylglycerols in butterfat by gas chromatographyelectron impact mass spectrometry using molar correction factors for $[\mathrm{M}-\mathrm{RCOO}]^{+}$ions, $\mathrm{J}$. Chromatogr. A, 1134 (2006) 260-283.

[37] R.P. Evershed, High-resolution triacylglycerol mixture analysis using high-temperature gas chromatography/mass spectrometry with a polarizable stationary phase, negative ion chemical ionization, and mass-resolved chromatography, J. Am. Soc. Mass Spectr., 7 (1996) 350-361.

[38] T. Řezanka, Mareš, P., Determination of plant triacylglycerols using capillary gas chromatography, high-performance liquid chromatography and mass spectrometry, J. Chromatogr., 542 (1991) 145-159 
[39] M. Holčapek, Jandera, P., Zderadička, P., Hrubá, L., Characterization of triacylglycerol and diacylglycerol composition of plant oils using high-performance liquid chromatography-atmospheric pressure chemical ionization mass spectrometry, J. Chromatogr. A, 1010 (2003) 195-215. [40] T. Rezanka, Sigler, K., The use of atmospheric pressure chemical ionization mass spectrometry triacylglycerols, Curr. Anal. Chem., 3 (2007) 252-271.

[41] W.C. Byrdwell, Atmospheric pressure chemical ionization mass spectrometry for analysis of lipids, Lipids, 36 (2001) 327-346.

[42] L.A. Marzilli, Fay, L.B., Dionisi, F., Vouros P., Structural characterization of triacylglycerols using electrospray ionization-MS ${ }^{n}$ ion-trap MS, J. Am. Oil Chem. Soc., 80 (2003) 195-202.

[43] S.C. Moldoveanu, Y. Chang, Dual analysis of triglycerides from certain common lipids and seed extracts, J. Agric. Food Chem., 59 (2011) 2137-2147.

[44] S. Chen, Y. Bi, S. Sun, J. Chen, The Content and Composition of Total, Free, and Esterified Sterols of Lotus Plumule Oil by GC-MS/FID, J. Am. Oil Chem. Soc., 94 (2017) 363-373.

[45] S.T. Anuar, S.M. Mugo, J.M. Curtis, A flow-through enzymatic microreactor for the rapid conversion of triacylglycerols into fatty acid ethyl ester and fatty acid methyl ester derivatives for GC analysis, Analytical Methods, 7 (2015) 5898-5906.

[46] M. Lisa, K. Netusilova, L. Franek, H. Dvorakova, V. Vrkoslav, M. Holcapek, Characterization of fatty acid and triacylglycerol composition in animal fats using silver-ion and non-aqueous reversedphase high-performance liquid chromatography/mass spectrometry and gas chromatography/flame ionization detection, J Chromatogr A, 1218 (2011) 7499-7510.

[47] C.S. Mohanty, R.C. Pradhan, V. Singh, N. Singh, R. Pattanayak, O. Prakash, C.S. Chanotiya, P.K. Rout, Physicochemical analysis of Psophocarpus tetragonolobus (L.) DC seeds with fatty acids and total lipids compositions, J Food Sci Technol, 52 (2015) 3660-3670.

[48] Z. Yang, Hollebone, B.P., Wang, Z., Yang, C., Landriault, M., Determination of polar impurities in biodiesels using solid-phase extraction and gas chromatography-mass spectrometry, J. Sep. Sci., 34 (2011) 409-421.

[49] T.A. Foglia, Jones, K.C., Nunez, A., Phillips, J.G., Mittelbach, M., Comparison of chromatographic methods for the determination of bound glycerol in biodiesel, Chromatographia, 60 (2004) 305-311.

[50] G. Di Nicola, Pacetti, M., Polonara, F., Santori, G., Stryjek, R., Development and optimization of a method for analyzing biodiesel mixtures with non-aqueous reversed phase liquid chromatography, J. Chromatogr. A, 1190 (2008) 120-126.

[51] P.J. Lee, Di Gioia, A.J., One methdology for FFA, FAME, and TAG analysis in biodiesel using ultra performance LC and ELSD and photodiode array detection, Waters Appl. Note, (2007).

[52] K. Kittirattanapiboon, Krisnangkura, K., Separation of acylglycerols, FAME and FFA in biodiesel by size exclusion chromatography, Eur. J. Lipid Sci. Tech., 110 (2008) 422-427.

[53] J. Cole, Lefler, J., Chen, R., Fast separation of FFA, FAME and glycerol for biodiesel analysis by supercritical fluid chromatography, LC GC Eur., (2008) 44-46.

[54] J. Št'ávová, Stahl, D., Seames, W.S., Kubátová, A., Method development for the characterization of biofuel intermediate products using gas chromatography with simultaneous mass spectrometric and flame ionization detections, J. Chromatogr. A, (2011).

[55] Q.-T. Liu, Kinderlerer, J.L., Preparative thin-layer chromatographic separation and subsequent gas chromatographic-mass spectrometric analysis of monoacylglycerols derived from butter oil by fungal degradation, J. Chromatogr. A, 855 (1999) 617-624.

[56] A. Kuksis, Myher, J.J., Marai, L., Lipid methodology - Chromatography and beyond. Part I. GC/MS and LC/MS of glycerolipids, J. Am. Oil Chem. Soc., 61 (1984) 1582-1589.

[57] D.C. Harris, Quantitative chemical analysis, W. H. Freeman and Company, New York, 2003. 
699 [58] J.H. Gross, Practical Aspects of Electron Ionization, in: Mass Spectrometry: A Textbook, 700 Springer Berlin Heidelberg, Berlin, Heidelberg, 2011, pp. 223-248.

701 [59] J. Štávová, Beránek, J., Nelson, E.P., Diep, B.A., Kubátová, A., Limits of detection for the 702 determination of mono- and dicarboxylic acids using gas and liquid chromatographic methods coupled 703 with mass spectrometry, J. Chromatogr. B., 879 (2011) 1429-1438.

704 [60] A. Kubátová, Luo, Y., Št’ávová, J., Sadrameli, M., Aulich, T., Kozliak, E., Seames, W., New path 705 in thermal cracking of triacylglycerides (canola and soybean oil), Fuel, 90 (2011) 2958-2602.

706 [61] J. Št’ávová, C.S. Stahl, W.S. Seames, A. Kubátová, Method development for characterization of 707 biofuel intermediate products using gas chromatography with simultaneous mass spectrometric and 708 flame ionization detections, J. Chromatogr., A, 1224 (2012) 79-88. 
Figure 1

\section{Figure 1}

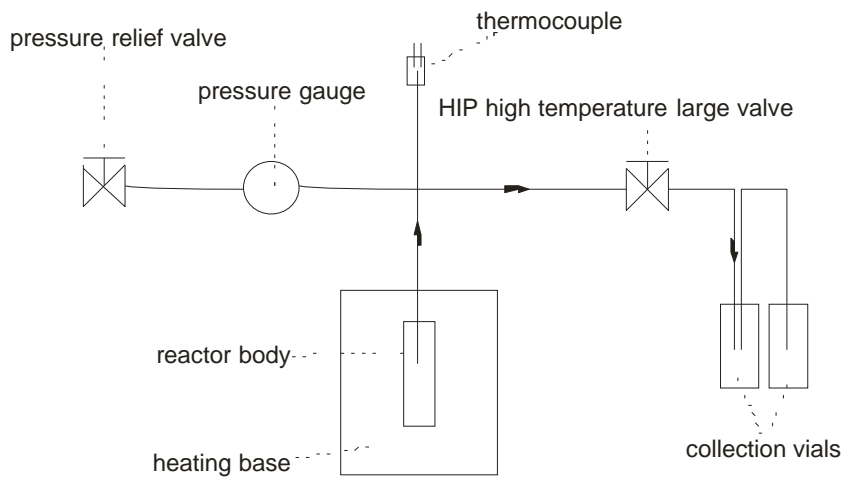




\section{Figure 2}

\section{Figure 2}
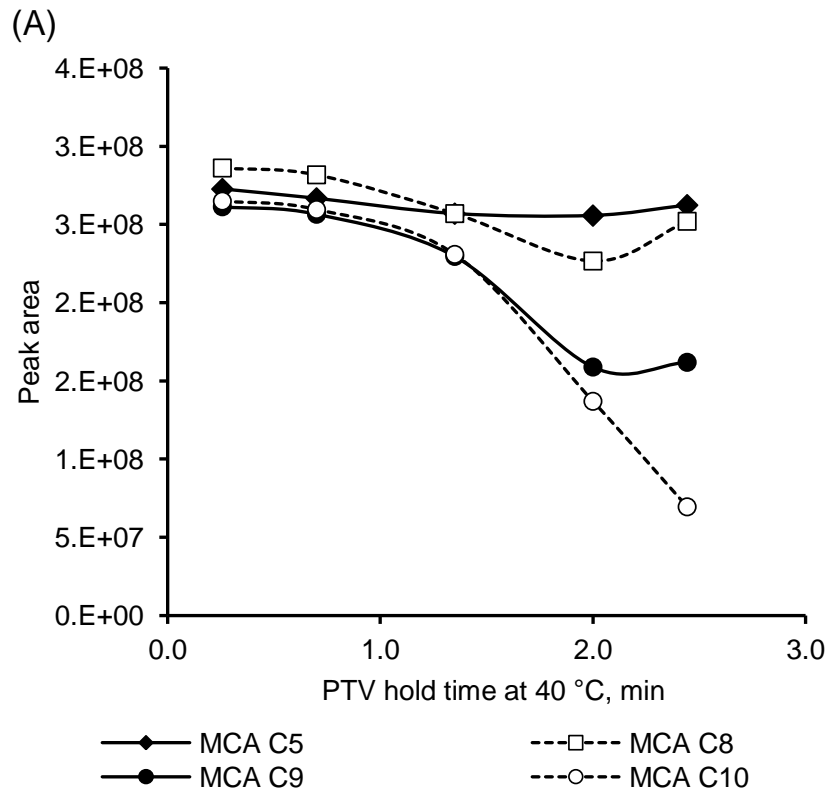

(C)
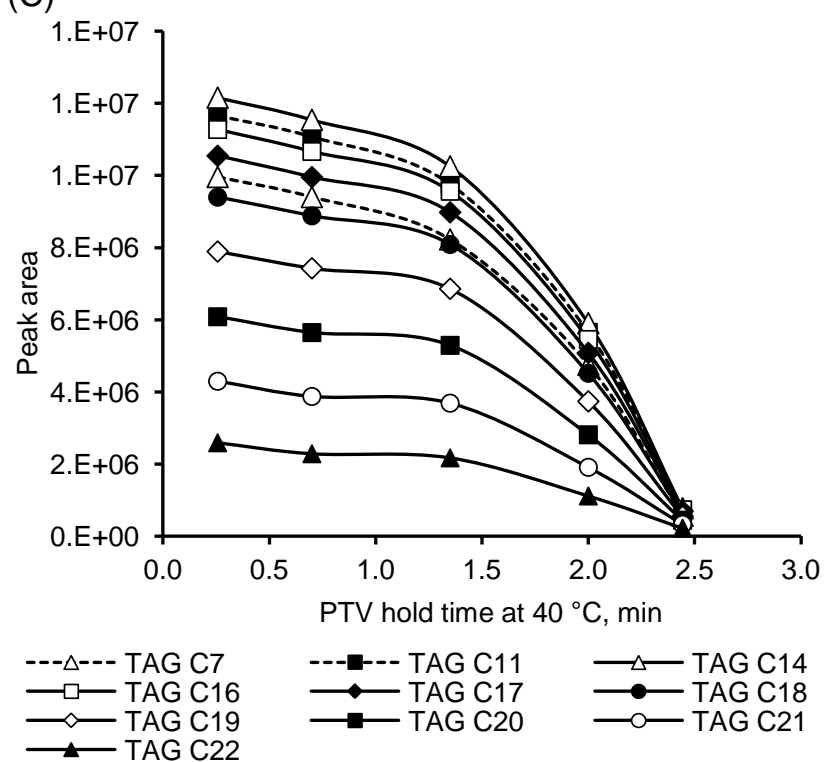
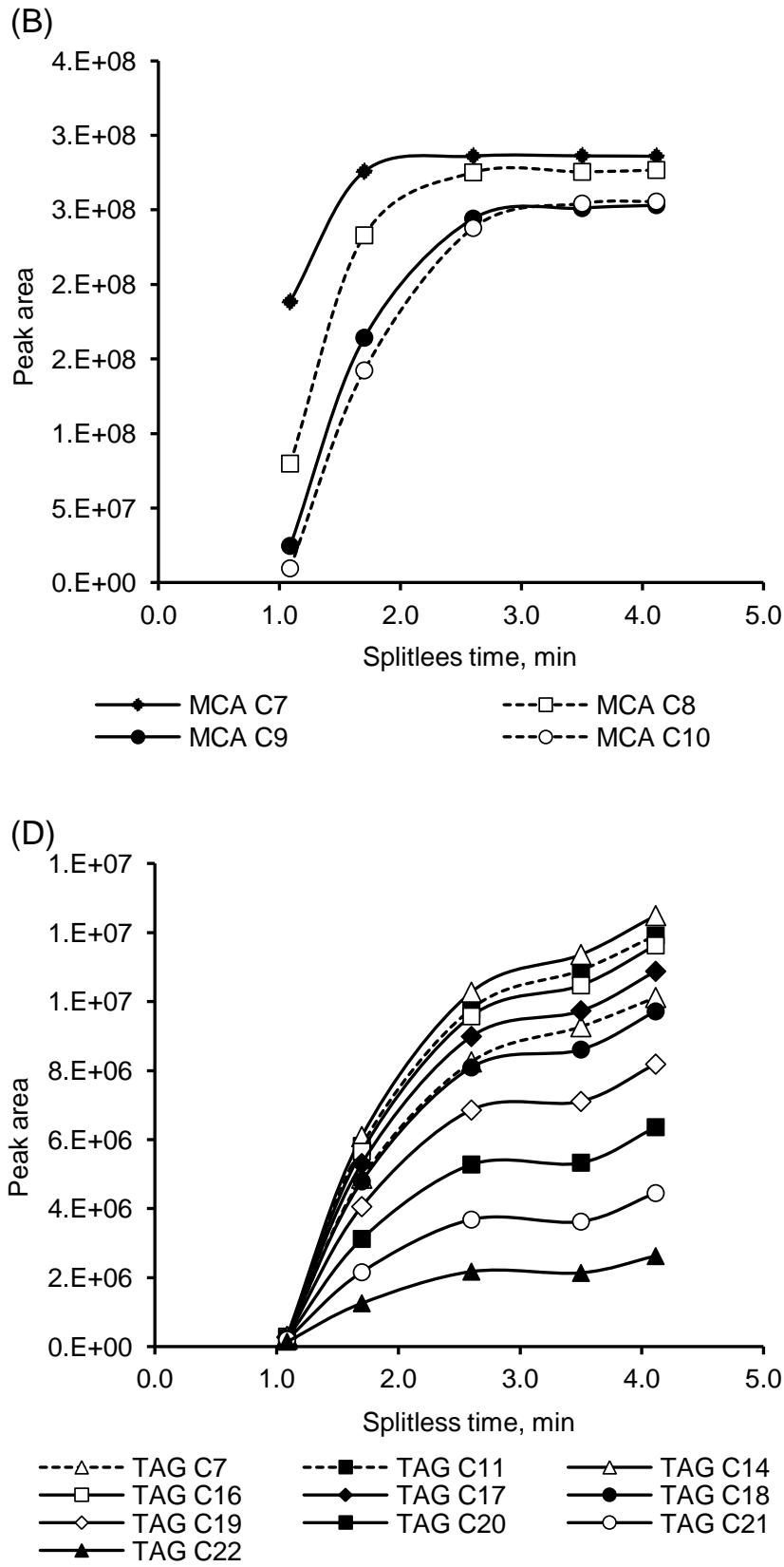


\section{Figure 3}

Figure 3
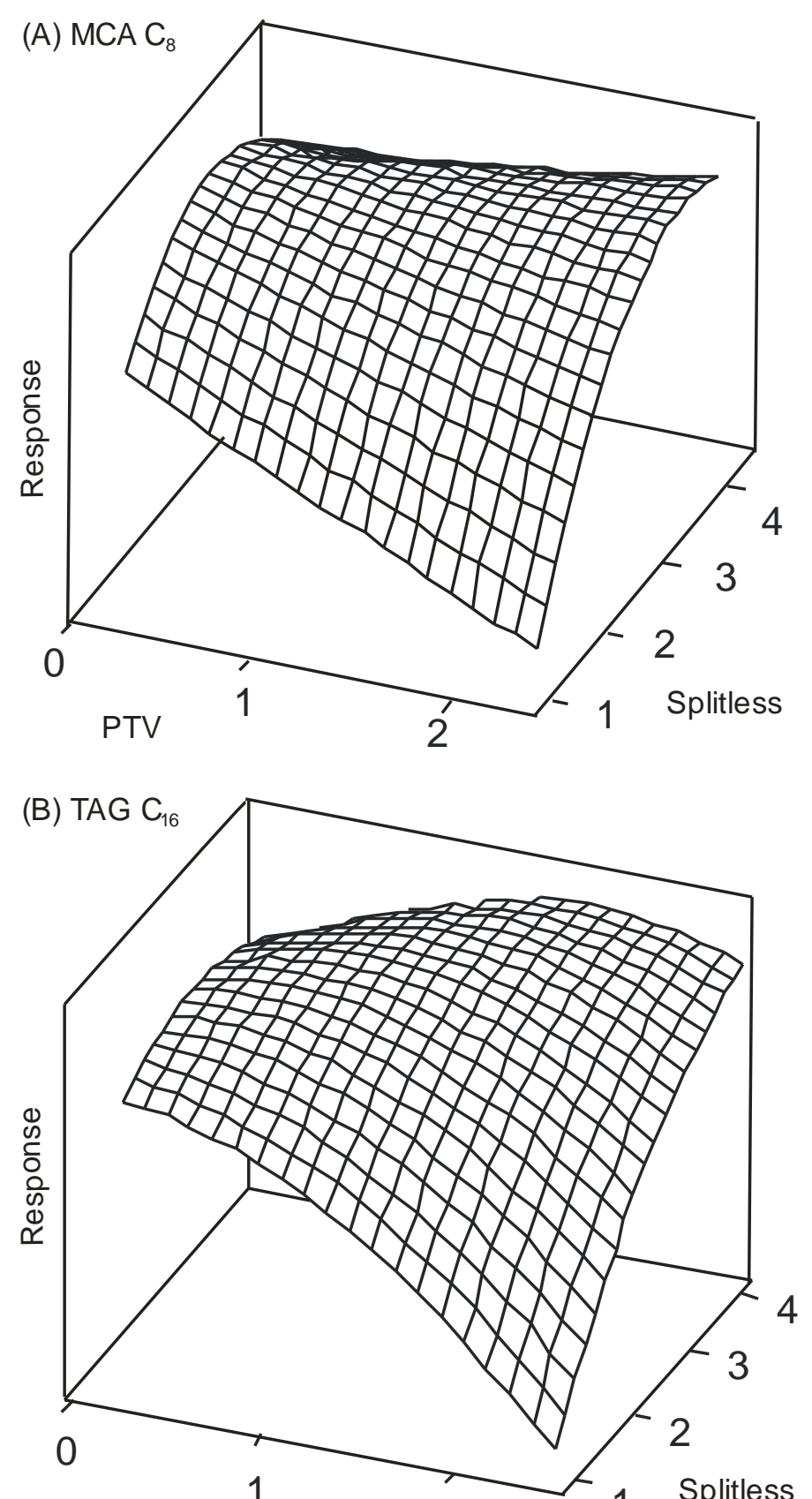
Figure 4

Figure 4

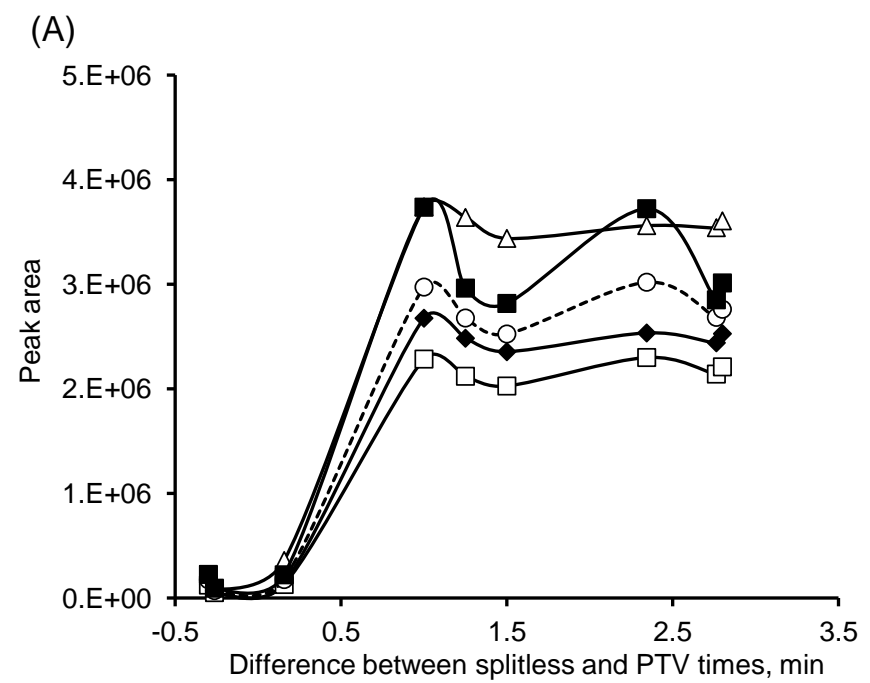

$\longrightarrow$ MCA C11
----- MCA C16 MCA C13 $\longrightarrow$ MCA C18

(B)

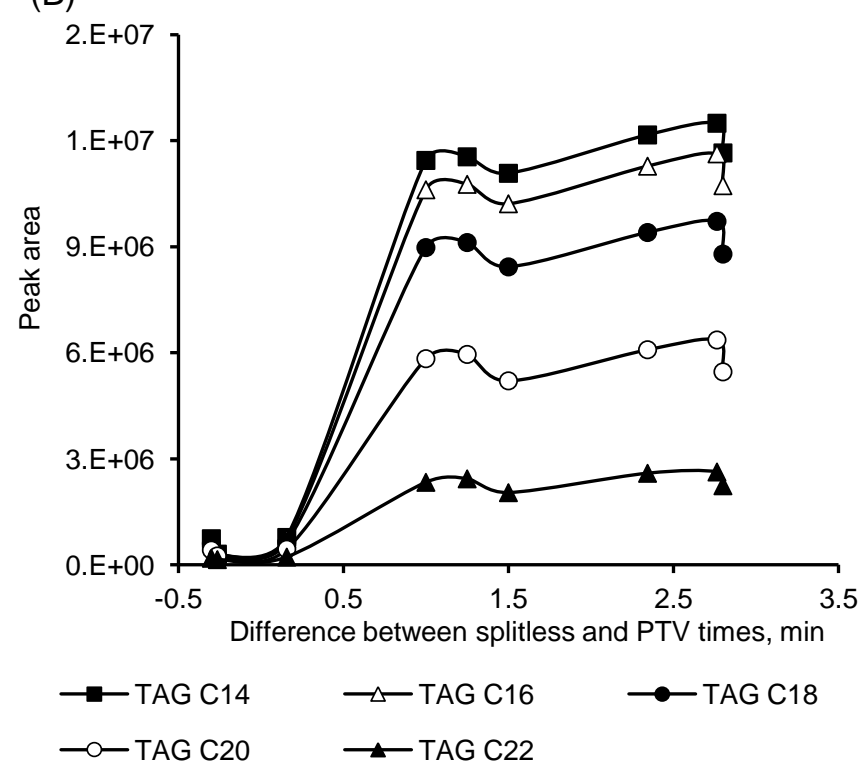


Figure 5

Figure 5

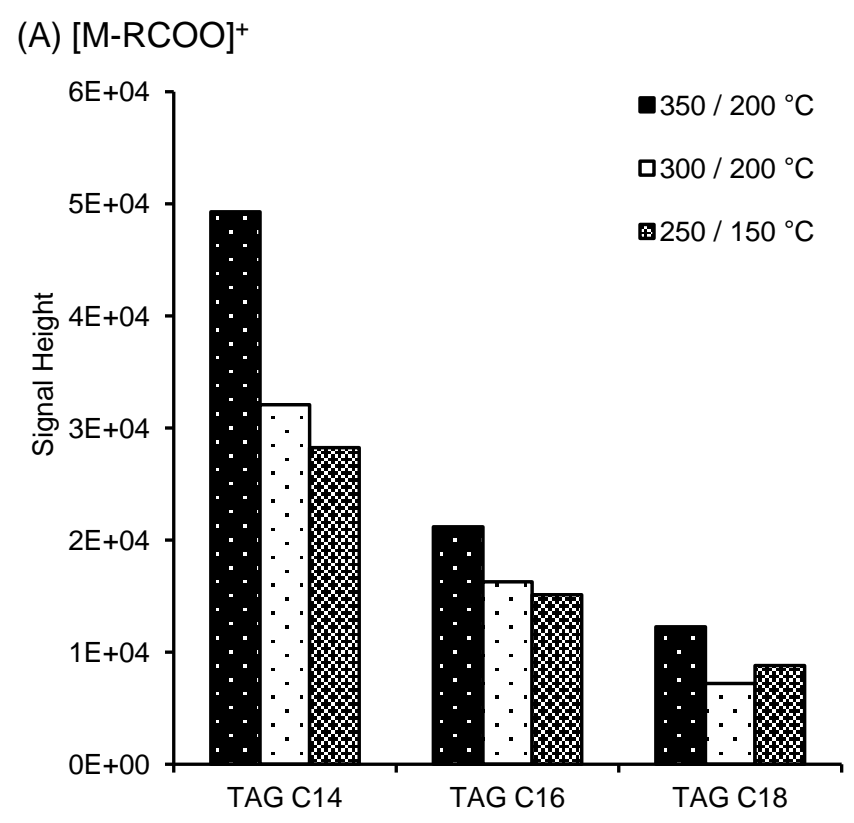

(B) $[\mathrm{RCO}+128]^{+}$

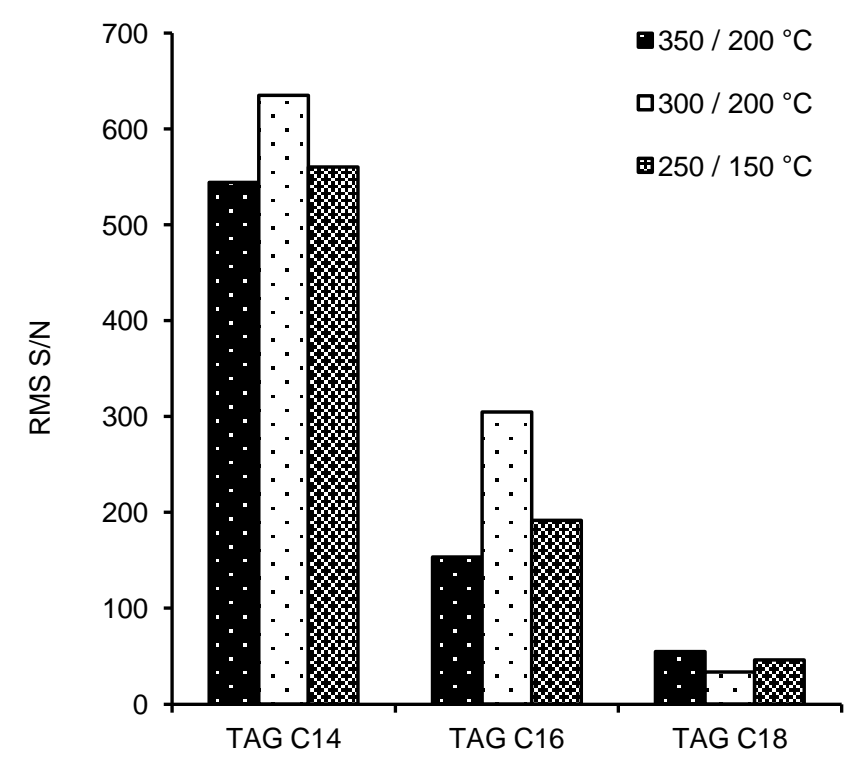


Figure 6

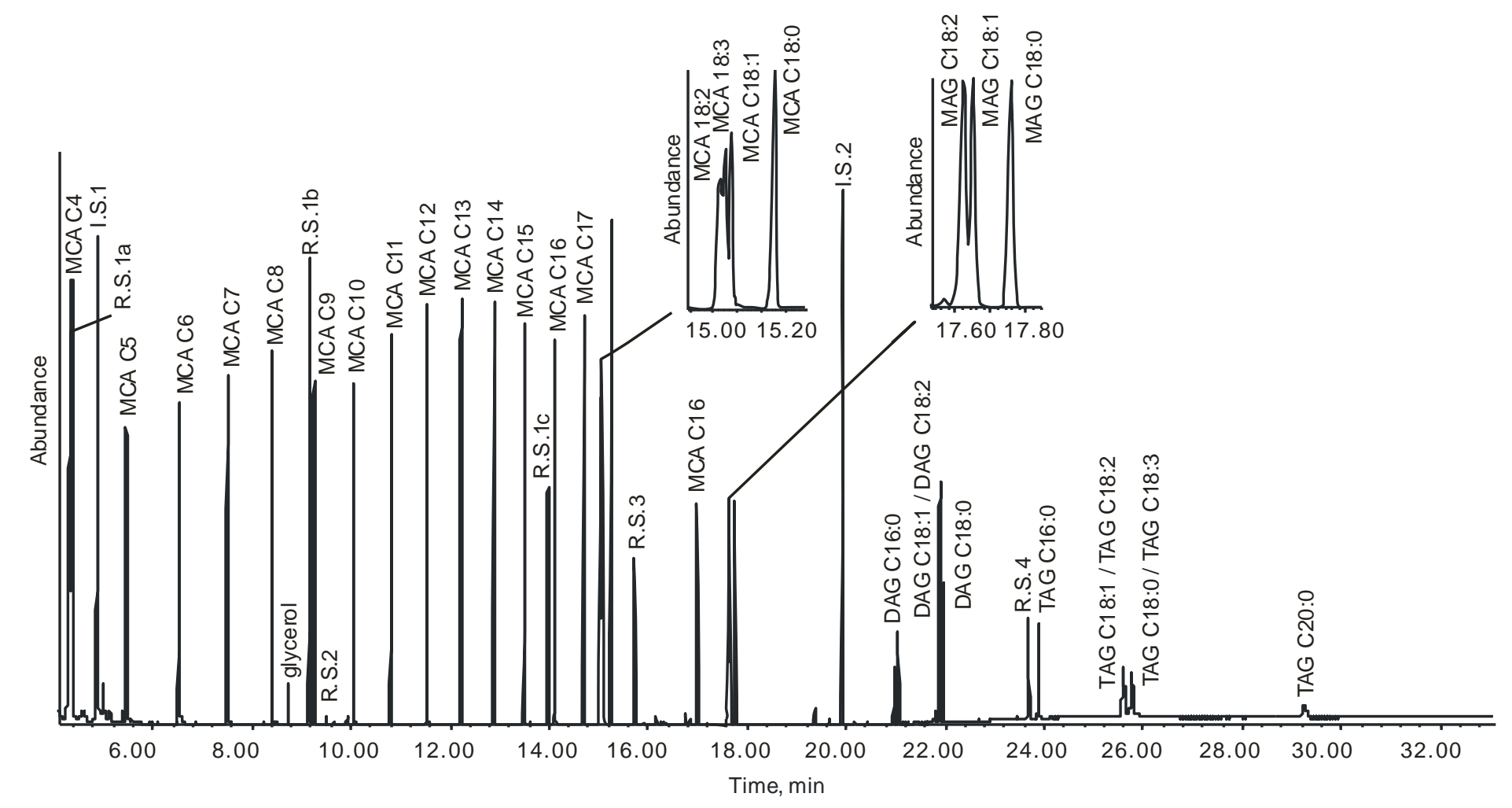


Figure 7

Figure 7

(A) FID

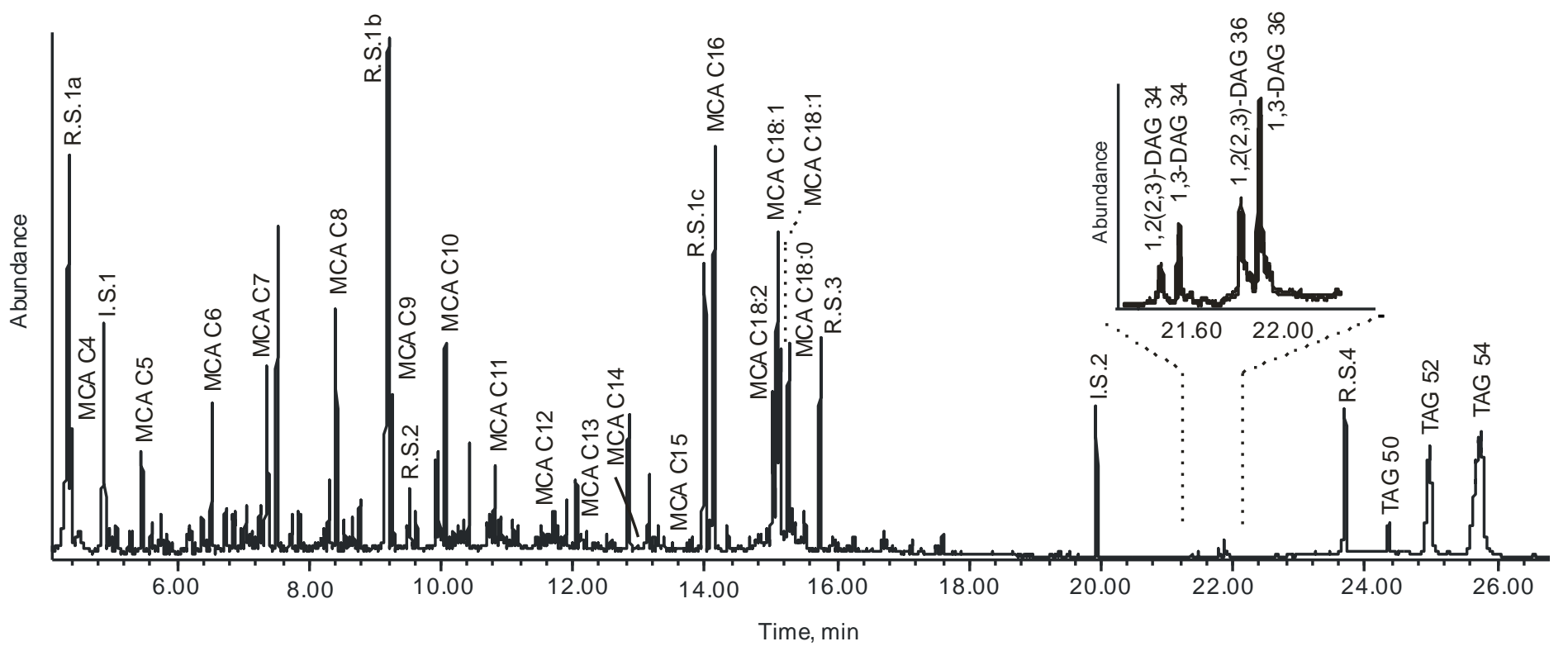

(B) MS/TIC

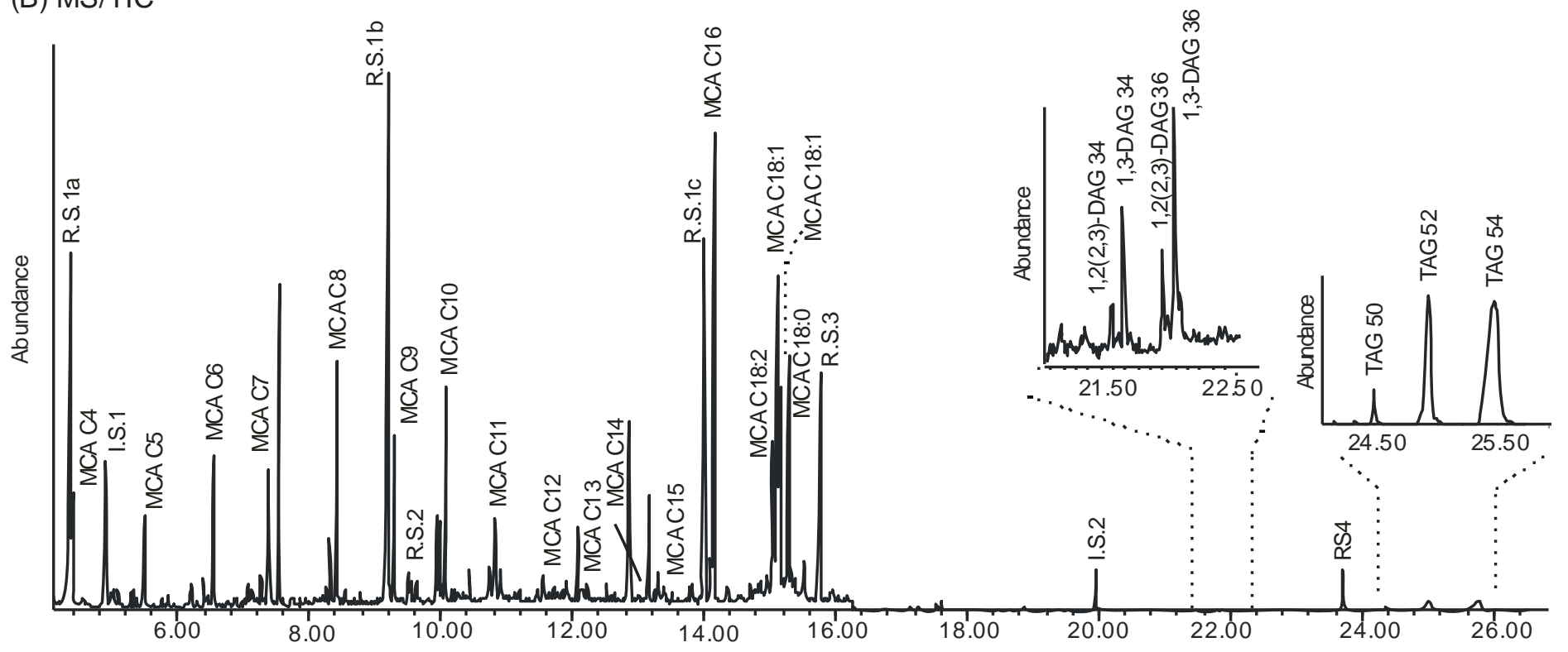


Table 1. Reagents used: (1) for method optimization (O) and (2) as calibration standards (C), including recovery and internal standards (R.S. and I.S., respectively). Molecular weights and target ions are provided for MSTFA derivatized compounds.

\begin{tabular}{|c|c|c|c|c|c|c|c|}
\hline $\begin{array}{l}\text { Pur- } \\
\text { pose }^{\text {a }}\end{array}$ & Name & Supplier $^{\text {b }}$ & $\begin{array}{l}\text { Abbrevia- } \\
\text { tion }\end{array}$ & Formula & $\begin{array}{c}\text { TMS- } \\
\text { derivatives } \\
\text { MW } \\
(\mathrm{g} / \mathrm{mol}) \\
\end{array}$ & $\begin{array}{l}\text { Quantita- } \\
\text { tion ion } \\
\text { (symbol) }\end{array}$ & $\begin{array}{l}\text { Confirmation } \\
\text { ion (symbol) } \\
\end{array}$ \\
\hline & $\begin{array}{l}\text { Monocarboxyl } \\
\text { ic acids }\end{array}$ & & MCAs & & & {$\left[\mathrm{M}-\mathrm{CH}_{3}\right]^{+}$} & $\underset{+}{[\mathrm{TMS}+\mathrm{COO}]}$ \\
\hline $\mathrm{C}$ & Butanoic acid & Sigma-Aldrich & $\mathrm{C}_{4} \mathrm{MCA}$ & $\mathrm{C}_{3} \mathrm{H}_{7} \mathrm{COOH}$ & 160 & 145 & 117 \\
\hline $\mathrm{O}, \mathrm{C}$ & Pentanoic acid & Sigma-Aldrich & $\mathrm{C}_{5} \mathrm{MCA}$ & $\mathrm{C}_{4} \mathrm{H}_{9} \mathrm{COOH}$ & 174 & 159 & 117 \\
\hline $\mathrm{O}, \mathrm{C}$ & Hexanoic acid & Acros & $\mathrm{C}_{6} \mathrm{MCA}$ & $\mathrm{C}_{5} \mathrm{H}_{11} \mathrm{COOH}$ & 188 & 173 & 117 \\
\hline $\mathrm{O}, \mathrm{C}$ & Heptanoic acid & Acros & $\mathrm{C}_{7} \mathrm{MCA}$ & $\mathrm{C}_{6} \mathrm{H}_{13} \mathrm{COOH}$ & 202 & 187 & 117 \\
\hline $\mathrm{O}, \mathrm{C}$ & Octanoic acid & Acros & $\mathrm{C}_{8} \mathrm{MCA}$ & $\mathrm{C}_{7} \mathrm{H}_{15} \mathrm{COOH}$ & 216 & 201 & 117 \\
\hline $\mathrm{O}, \mathrm{C}$ & Nonanoic acid & MP Biomedicals & $\mathrm{C}_{9} \mathrm{MCA}$ & $\mathrm{C}_{8} \mathrm{H}_{17} \mathrm{COOH}$ & 230 & 215 & 117 \\
\hline $\mathrm{O}, \mathrm{C}$ & Decanoic acid & Acros & $\mathrm{C}_{10} \mathrm{MCA}$ & $\mathrm{C}_{9} \mathrm{H}_{19} \mathrm{COOH}$ & 244 & 229 & 117 \\
\hline $\mathrm{O}, \mathrm{C}$ & Undecanoic & Acros & $\mathrm{C}_{11} \mathrm{MCA}$ & $\mathrm{C}_{10} \mathrm{H}_{21} \mathrm{COOH}$ & 258 & 243 & 117 \\
\hline $\mathrm{O}, \mathrm{C}$ & Dodecanoic & Sigma-Aldrich & $\mathrm{C}_{12} \mathrm{MCA}$ & $\mathrm{C}_{11} \mathrm{H}_{23} \mathrm{COOH}$ & 272 & 257 & 117 \\
\hline $\mathrm{O}, \mathrm{C}$ & Tridecanoic & MP Biomedicals & $\mathrm{C}_{13} \mathrm{MCA}$ & $\mathrm{C}_{12} \mathrm{H}_{25} \mathrm{COOH}$ & 286 & 271 & 117 \\
\hline $\mathrm{O}, \mathrm{C}$ & Tetradecanoic & Alfa Aesar & $\mathrm{C}_{14} \mathrm{MCA}$ & $\mathrm{C}_{13} \mathrm{H}_{27} \mathrm{COOH}$ & 300 & 285 & 117 \\
\hline $\mathrm{O}, \mathrm{C}$ & Pentadecanoic & Acros & $\mathrm{C}_{15} \mathrm{MCA}$ & $\mathrm{C}_{14} \mathrm{H}_{29} \mathrm{COOH}$ & 314 & 299 & 117 \\
\hline $\mathrm{O}, \mathrm{C}$ & Hexadecanoic & Acros & $\mathrm{C}_{16} \mathrm{MCA}$ & $\mathrm{C}_{15} \mathrm{H}_{31} \mathrm{COOH}$ & 328 & 313 & 117 \\
\hline $\mathrm{O}, \mathrm{C}$ & Heptadecanoic & Alfa Aesar & $\mathrm{C}_{17} \mathrm{MCA}$ & $\mathrm{C}_{16} \mathrm{H}_{33} \mathrm{COOH}$ & 342 & 327 & 117 \\
\hline $\mathrm{O}, \mathrm{C}$ & Octadecanoic & Acros & $\mathrm{C}_{18} \mathrm{MCA}$ & $\mathrm{C}_{17} \mathrm{H}_{35} \mathrm{COOH}$ & 356 & 341 & 117 \\
\hline $\mathrm{O}, \mathrm{C}$ & Oleic acid & Sigma-Aldrich & MCA C $_{18: 1}$ & $\mathrm{C}_{17} \mathrm{H}_{33} \mathrm{COOH}$ & 354 & 339 & 117 \\
\hline $\mathrm{C}$ & Linoleic acid & Sigma-Aldrich & $\mathrm{MCA} \mathrm{C}_{18: 2}$ & $\mathrm{C}_{17} \mathrm{H}_{31} \mathrm{COOH}$ & 352 & 337 & 117 \\
\hline $\mathrm{C}$ & $\alpha$-Linolenic & Sigma-Aldrich & $\operatorname{MCA~C~}_{18: 3}$ & $\mathrm{C}_{17} \mathrm{H}_{29} \mathrm{COOH}$ & 350 & 335 & 117 \\
\hline $\begin{array}{l}\text { R.S. } \\
\text { 1a }\end{array}$ & $\begin{array}{l}\text { Butanoic acid- } \\
d_{7}\end{array}$ & CDN Isotopes & $\begin{array}{l}\mathrm{C}_{4}-d_{7} \\
\mathrm{MCA}\end{array}$ & $\mathrm{C}_{3} \mathrm{D}_{7} \mathrm{COOH}$ & 168 & 152 & \\
\hline $\begin{array}{l}\text { R.S. } \\
1 b\end{array}$ & $\begin{array}{l}\text { Nonanoic acid- } \\
d_{17}\end{array}$ & CDN Isotopes & $\begin{array}{l}\mathrm{C}_{8}-d_{17} \\
\mathrm{MCA}\end{array}$ & $\mathrm{C}_{8} \mathrm{D}_{17} \mathrm{COOH}$ & 248 & 232 & 117 \\
\hline $\begin{array}{l}\text { R.S. } \\
1 \mathrm{c}\end{array}$ & $\begin{array}{l}\text { Hexadecanoic } \\
\text { acid- } d_{31}\end{array}$ & CDN Isotopes & $\begin{array}{l}\mathrm{C}_{16}-d_{31} \\
\mathrm{MCA}\end{array}$ & $\mathrm{C}_{15} \mathrm{D}_{31} \mathrm{COOH}$ & 360 & 344 & 120 \\
\hline I.S.1 & $\begin{array}{l}\text { 2- } \\
\text { Chlorotoluene }\end{array}$ & Sigma-Aldrich & $\begin{array}{l}\text { 2-chloro- } \\
\text { toluene }\end{array}$ & $\mathrm{C}_{7} \mathrm{H}_{7} \mathrm{Cl}$ & 127 & 91 & 126 \\
\hline & Alcohols & & AOLs & & & & \\
\hline $\begin{array}{l}\text { R.S. } \\
2\end{array}$ & Butanetriol & Sigma-Aldrich & butanetriol & $\mathrm{C}_{4} \mathrm{H}_{10} \mathrm{O}_{3}$ & 272 & 219 & \\
\hline C & Glycerol & Sigma-Aldrich & glycerol & $\mathrm{C}_{3} \mathrm{H}_{5}(\mathrm{OH})_{3}$ & 309 & 205 & 147 \\
\hline \multirow[t]{2}{*}{$\begin{array}{l}\text { R.S. } \\
3\end{array}$} & $\begin{array}{l}n \text {-Eicosanyl- } d_{41} \\
\text { alcohol }\end{array}$ & CDN Isotopes & $\begin{array}{l}\mathrm{C}_{20^{-}} d_{41} \\
\mathrm{AOL}\end{array}$ & $\mathrm{C}_{20} \mathrm{D}_{41} \mathrm{OH}$ & 412 & 396 & 105 \\
\hline & $\begin{array}{l}\text { Monoacyl- } \\
\text { glycerols }\end{array}$ & & MAGs & & & $\begin{array}{c}{[\mathrm{M}-} \\
\mathrm{CH}_{2} \mathrm{O}- \\
\mathrm{TMS}^{+}\end{array}$ & {$\left[\mathrm{M}-\mathrm{CH}_{3}\right]^{+}$} \\
\hline $\mathrm{O}, \mathrm{C}$ & Monopalmitin & Sigma-Aldrich & $\mathrm{C}_{16} \mathrm{MAG}$ & $\mathrm{C}_{19} \mathrm{H}_{40} \mathrm{O}_{4}$ & 474 & $371(\mathrm{P})$ & 459 \\
\hline $\mathrm{O}, \mathrm{C}$ & Monostearin & Sigma-Aldrich & $\mathrm{C}_{18: 0} \mathrm{MAG}$ & $\mathrm{C}_{21} \mathrm{H}_{52} \mathrm{O}_{4}$ & 502 & $399(\mathrm{~S})$ & 487 \\
\hline $\mathrm{O}, \mathrm{C}$ & Monoolein & Sigma-Aldrich & $\mathrm{C}_{18: 1} \mathrm{MAG}$ & $\mathrm{C}_{21} \mathrm{H}_{50} \mathrm{O}_{4}$ & 500 & $397(\mathrm{O})$ & 485 \\
\hline $\mathrm{O}, \mathrm{C}$ & Monolinolein & Sigma-Aldrich & $\mathrm{C}_{18: 2} \mathrm{MAG}$ & $\mathrm{C}_{21} \mathrm{H}_{48} \mathrm{O}_{4}$ & 498 & $395(\mathrm{~L})$ & 483 \\
\hline
\end{tabular}




\begin{tabular}{|c|c|c|c|c|c|c|c|}
\hline $\begin{array}{l}\text { Pur- } \\
\text { pose }^{a}\end{array}$ & Name & Supplier $^{\text {b }}$ & $\begin{array}{l}\text { Abbrevia- } \\
\text { tion }\end{array}$ & Formula & $\begin{array}{c}\text { TMS- } \\
\text { derivatives } \\
\text { MW } \\
(\mathrm{g} / \mathrm{mol})\end{array}$ & $\begin{array}{l}\text { Quantita- } \\
\text { tion ion } \\
\text { (symbol) }\end{array}$ & $\begin{array}{l}\text { Confirmation } \\
\text { ion (symbol) }\end{array}$ \\
\hline & $\begin{array}{l}\text { Diacyl- } \\
\text { glycerols }\end{array}$ & & DAGs & & & $\begin{array}{c}{[\mathrm{M}-} \\
\mathrm{RCOO}^{-} \\
\left.\mathrm{CH}_{2}\right]^{+}\end{array}$ & {$\left[\mathrm{M}-\mathrm{CH}_{3}\right]^{+}$} \\
\hline $\mathrm{O}, \mathrm{C}$ & Dipalmitate & Nu-Chek Prep. & $\mathrm{C}_{16} \mathrm{DAG}$ & $\mathrm{C}_{35} \mathrm{H}_{68} \mathrm{O}_{5}$ & 640 & $371(\mathrm{P})$ & 625 \\
\hline $\mathrm{C}$ & Distearin & Sigma-Aldrich & $\mathrm{C}_{18} \mathrm{DAG}$ & $\mathrm{C}_{39} \mathrm{H}_{76} \mathrm{O}_{5}$ & 696 & $399(\mathrm{~S})$ & 681 \\
\hline $\mathrm{C}$ & Diolein & Sigma-Aldrich & $\mathrm{C}_{18: 1} \mathrm{DAG}$ & $\mathrm{C}_{39} \mathrm{H}_{72} \mathrm{O}_{5}$ & 692 & $397(\mathrm{O})$ & 677 \\
\hline \multirow[t]{2}{*}{$\mathrm{O}, \mathrm{C}$} & Dilinolein & Sigma-Aldrich & $\mathrm{C}_{18: 2} \mathrm{DAG}$ & $\mathrm{C}_{39} \mathrm{H}_{68} \mathrm{O}_{5}$ & 688 & 395 (L) & 673 \\
\hline & $\begin{array}{l}\text { Triacyl- } \\
\text { glycerols }\end{array}$ & & TAGs & & & $\begin{array}{c}{[\mathrm{RCO}+12} \\
8]^{+}\end{array}$ & {$[\mathrm{M}-\mathrm{RCOO}]^{+}$} \\
\hline I.S.2 & Tridecanoin & Sigma-Aldrich & $\mathrm{C}_{10} \mathrm{TAG}$ & $\mathrm{C}_{33} \mathrm{H}_{62} \mathrm{O}_{6}$ & 555 & 283 & 383 \\
\hline $\mathrm{C}$ & Tripalmitin & $\begin{array}{l}\text { GLC-437, Nu- } \\
\text { Chek Prep. }\end{array}$ & $\mathrm{C}_{16} \mathrm{TAG}$ & $\mathrm{C}_{51} \mathrm{H}_{98} \mathrm{O}_{6}$ & 807 & $367(\mathrm{P})$ & $551(\mathrm{PP})$ \\
\hline $\mathrm{C}$ & Tristearin & $\begin{array}{l}\text { GLC-437, Nu- } \\
\text { Chek Prep. }\end{array}$ & $\mathrm{C}_{18} \mathrm{TAG}$ & $\mathrm{C}_{57} \mathrm{H}_{110} \mathrm{O}_{6}$ & 891 & $395(\mathrm{~S})$ & 607 (SS) \\
\hline $\mathrm{C}$ & Triolein & $\begin{array}{l}\text { GLC-437, Nu- } \\
\text { Chek Prep. }\end{array}$ & $\mathrm{C}_{18: 1} \mathrm{TAG}$ & $\mathrm{C}_{57} \mathrm{H}_{104} \mathrm{O}_{6}$ & 885 & $393(\mathrm{O})$ & $603(\mathrm{OO})$ \\
\hline $\mathrm{C}$ & Trilinolein & $\begin{array}{l}\text { GLC-437, Nu- } \\
\text { Chek Prep. }\end{array}$ & $\mathrm{C}_{18: 2} \mathrm{TAG}$ & $\mathrm{C}_{57} \mathrm{H}_{98} \mathrm{O}_{6}$ & 879 & 391 (L) & 599 (LL) \\
\hline $\mathrm{C}$ & Trilinolenin & $\begin{array}{l}\text { GLC- } 437, \mathrm{Nu}- \\
\text { Chek Prep. }\end{array}$ & $\mathrm{C}_{18: 3} \mathrm{TAG}$ & $\mathrm{C}_{57} \mathrm{H}_{92} \mathrm{O}_{6}$ & 873 & 389 (Ln) & $595(\mathrm{LnLn})$ \\
\hline $\mathrm{C}$ & Triarachidin & $\begin{array}{l}\text { GLC-437, Nu- } \\
\text { Chek Prep. }\end{array}$ & $\mathrm{C}_{20} \mathrm{TAG}$ & $\mathrm{C}_{63} \mathrm{H}_{122} \mathrm{O}_{6}$ & 975 & 423 & 663 \\
\hline $\mathrm{O}$ & Trioctanoin & $\begin{array}{l}\text { GLC-768, Nu- } \\
\text { Chek Prep. }\end{array}$ & $\mathrm{C}_{8} \mathrm{TAG}$ & $\mathrm{C}_{27} \mathrm{H}_{50} \mathrm{O}_{6}$ & 471 & 255 & 327 \\
\hline $\mathrm{O}$ & Trinonanoin & $\begin{array}{l}\text { GLC-768, Nu- } \\
\text { Chek Prep. }\end{array}$ & $\mathrm{C}_{9} \mathrm{TAG}$ & $\mathrm{C}_{30} \mathrm{H}_{56} \mathrm{O}_{6}$ & 513 & 269 & 355 \\
\hline $\mathrm{O}$ & Tridecanoin & $\begin{array}{l}\text { GLC-768, Nu- } \\
\text { Chek Prep. }\end{array}$ & $\mathrm{C}_{10} \mathrm{TAG}$ & $\mathrm{C}_{33} \mathrm{H}_{62} \mathrm{O}_{6}$ & 555 & 283 & 383 \\
\hline $\mathrm{O}$ & Triundecanoin & $\begin{array}{l}\text { GLC- } 768, \mathrm{Nu}- \\
\text { Chek Prep. }\end{array}$ & $\mathrm{C}_{11} \mathrm{TAG}$ & $\mathrm{C}_{36} \mathrm{H}_{68} \mathrm{O}_{6}$ & 597 & 297 & 411 \\
\hline $\mathrm{O}$ & Trilaurin & $\begin{array}{l}\text { GLC-768, Nu- } \\
\text { Chek Prep. }\end{array}$ & $\mathrm{C}_{12} \mathrm{TAG}$ & $\mathrm{C}_{39} \mathrm{H}_{74} \mathrm{O}_{6}$ & 639 & 311 & 439 \\
\hline $\mathrm{O}$ & Tritridecanoin & $\begin{array}{l}\text { GLC-768, Nu- } \\
\text { Chek Prep. }\end{array}$ & $\mathrm{C}_{13} \mathrm{TAG}$ & $\mathrm{C}_{42} \mathrm{H}_{80} \mathrm{O}_{6}$ & 681 & 325 & 467 \\
\hline $\mathrm{O}$ & Trimyristin & $\begin{array}{l}\text { GLC-768, Nu- } \\
\text { Chek Prep. }\end{array}$ & $\mathrm{C}_{14} \mathrm{TAG}$ & $\mathrm{C}_{45} \mathrm{H}_{86} \mathrm{O}_{6}$ & 723 & 339 & 495 \\
\hline $\mathrm{O}$ & $\begin{array}{l}\text { Tripentadecano } \\
\text { in }\end{array}$ & $\begin{array}{l}\text { GLC- } 768, \mathrm{Nu}- \\
\text { Chek Prep. }\end{array}$ & $\mathrm{C}_{15} \mathrm{TAG}$ & $\mathrm{C}_{48} \mathrm{H}_{92} \mathrm{O}_{6}$ & 765 & 353 & 523 \\
\hline $\mathrm{O}$ & Tripalmitin & $\begin{array}{l}\text { GLC-768, Nu- } \\
\text { Chek Prep. }\end{array}$ & $\mathrm{C}_{16} \mathrm{TAG}$ & $\mathrm{C}_{51} \mathrm{H}_{98} \mathrm{O}_{6}$ & 807 & 367 & 551 \\
\hline $\mathrm{O}$ & $\begin{array}{l}\text { Triheptadecano } \\
\text { in }\end{array}$ & $\begin{array}{l}\text { GLC-768, Nu- } \\
\text { Chek Prep. }\end{array}$ & $\mathrm{C}_{17} \mathrm{TAG}$ & $\mathrm{C}_{54} \mathrm{H}_{104} \mathrm{O}_{6}$ & 849 & 381 & 579 \\
\hline $\mathrm{O}$ & Tristearin & $\begin{array}{l}\text { GLC-768, Nu- } \\
\text { Chek Prep. }\end{array}$ & $\mathrm{C}_{18} \mathrm{TAG}$ & $\mathrm{C}_{57} \mathrm{H}_{110} \mathrm{O}_{6}$ & 891 & 395 & 607 \\
\hline $\mathrm{O}$ & Triolein & Sigma-Aldrich & $\mathrm{C}_{18: 1} \mathrm{TAG}$ & $\mathrm{C}_{57} \mathrm{H}_{104} \mathrm{O}_{6}$ & 885 & 393 & 603 \\
\hline $\mathrm{O}$ & $\begin{array}{l}\text { Trinonadecanoi } \\
\mathrm{n}\end{array}$ & $\begin{array}{l}\text { GLC-768, Nu- } \\
\text { Chek Prep. }\end{array}$ & $\mathrm{C}_{19} \mathrm{TAG}$ & $\mathrm{C}_{60} \mathrm{H}_{116} \mathrm{O}_{6}$ & 933 & 409 & 635 \\
\hline
\end{tabular}




\begin{tabular}{llllllll}
$\mathrm{O}$ & Triarachidin & $\begin{array}{l}\text { GLC-768, Nu- } \\
\text { Chek Prep. }\end{array}$ & $\mathrm{C}_{20}$ TAG & $\mathrm{C}_{63} \mathrm{H}_{122} \mathrm{O}_{6}$ & 975 & 423 & 663 \\
$\mathrm{O}$ & $\begin{array}{l}\text { Triheneicosanoi } \\
\text { GLC-768, Nu- }\end{array}$ & $\begin{array}{l}\mathrm{C}_{21} \text { TAG } \\
\text { Chek Prep. }\end{array}$ & $\mathrm{C}_{66} \mathrm{H}_{128} \mathrm{O}_{6}$ & 1017 & 437 & 691 \\
$\mathrm{O}$ & Tribehenin & $\begin{array}{l}\text { GLC-768, Nu- } \\
\text { Chek Prep. }\end{array}$ & $\mathrm{C}_{22}$ TAG & $\mathrm{C}_{69} \mathrm{H}_{134} \mathrm{O}_{6}$ & 1059 & 451 & 719 \\
$\begin{array}{l}\text { R.S. } \\
4\end{array}$ & Tripalmitin- $d_{98}$ & CDN Isotopes & $\begin{array}{l}\mathrm{C}_{16}-d_{98} \\
\mathrm{TAG}\end{array}$ & $\mathrm{C}_{51} \mathrm{D}_{98} \mathrm{O}_{6}$ & 897 & 406 & 619 \\
\hline
\end{tabular}

${ }^{a}$ Were used for method validation and quantification of samples. R.S.1a was used for MCAs $\mathrm{C}_{4}-\mathrm{C}_{6}$, R.S.1b - for $\mathrm{MCAs}_{7}-\mathrm{C}_{13}$, and R.S.1c - for $\mathrm{MCAs}_{14}-\mathrm{C}_{18}$ and unsaturated $\mathrm{MCAs}_{18}$. R.S.2 was used for glycerol, R.S.3 - for MAGs and DAGs, and R.S.4 - for TAGs. I.S.1 was applied to all MCAs and glycerol, and I.S.2 - to all acylglycerols.

${ }^{\mathrm{b}}$ Sigma-Aldrich (St. Louis, MO, USA), Acros (Fisher Scientific, Pittsburg, PA, USA), MP Biomedicals (Solon, OH, USA), Alfa Aesar (Ward Hill, MA, USA), CDN Isotopes (Pointe-Claire, Canada), Nu-Chek Prep. Inc. (Elysian, MN, USA). 
Table 2. $P$-values obtained in central composite design for specific analytes and final optimized PTV injection parameters for the

HTGC-FID/MS analysis of MCAs and acylglycerols in soybean oil OLPs.

\begin{tabular}{|c|c|c|c|c|c|c|c|c|c|c|c|c|c|c|}
\hline \multicolumn{15}{|c|}{$P$-values ${ }^{\mathrm{a}}$} \\
\hline \multirow[t]{3}{*}{ Source } & \multicolumn{14}{|c|}{ Target compounds } \\
\hline & \multicolumn{11}{|c|}{ MCAs } & \multicolumn{3}{|c|}{ TAGs } \\
\hline & $\mathrm{C}_{4}$ & $\mathrm{C}_{5}$ & $\mathrm{C}_{6}$ & $\mathrm{C}_{7}$ & $\mathrm{C}_{8}$ & $\mathrm{C}_{9}$ & $\mathrm{C}_{10}$ & $\mathrm{C}_{15}$ & $\mathrm{C}_{16}$ & $\mathrm{C}_{17}$ & $\mathrm{C}_{18}$ & $\mathrm{C}_{10}$ & $\mathrm{C}_{16}$ & $\mathrm{C}_{18}$ \\
\hline \multicolumn{15}{|l|}{ Main factors } \\
\hline \multirow{2}{*}{$\begin{array}{l}\text { PTV injection hold time at } \\
\text { initial } 40{ }^{\circ} \mathrm{C}\end{array}$} & 0.4 & 0.0 & 0.2 & 0.0 & 0.0 & 0.0 & 0.0 & 0.0 & 0.0 & 0.0 & 0.0 & 0.0 & 0.0 & 0.0 \\
\hline & 7 & $\mathbf{0}$ & 1 & 9 & 1 & $\mathbf{0}$ & $\mathbf{0}$ & $\mathbf{0}$ & $\mathbf{0}$ & $\mathbf{0}$ & $\mathbf{0}$ & 1 & 1 & 3 \\
\hline \multirow{2}{*}{ Splitless time } & 0.4 & 0.4 & 0.4 & 0.0 & 0.0 & 0.0 & 0.0 & 0.0 & 0.0 & 0.0 & 0.0 & 0.0 & 0.0 & 0.0 \\
\hline & 2 & 6 & 2 & $\mathbf{0}$ & $\mathbf{0}$ & $\mathbf{0}$ & $\mathbf{0}$ & $\mathbf{0}$ & $\mathbf{0}$ & $\mathbf{0}$ & 1 & $\mathbf{0}$ & $\mathbf{0}$ & $\mathbf{0}$ \\
\hline \multirow{2}{*}{ Oven hold time at initial $35^{\circ} \mathrm{C}$} & 0.1 & 0.3 & 0.0 & 0.5 & 0.6 & 0.7 & 0.3 & 0.2 & 0.3 & 0.3 & 0.4 & 0.4 & 0.4 & 0.7 \\
\hline & 6 & 9 & 1 & 5 & 5 & 3 & 4 & 4 & 4 & 9 & 0 & 1 & 9 & 7 \\
\hline \multicolumn{15}{|l|}{ Interactions } \\
\hline \multirow{2}{*}{ PTV $\times$ Splitless } & 0.2 & 0.6 & 0.9 & 0.1 & 0.0 & 0.0 & 0.0 & 0.0 & 0.0 & 0.0 & 0.0 & 0.0 & 0.0 & 0.0 \\
\hline & 6 & 7 & 4 & 7 & $\mathbf{0}$ & $\mathbf{0}$ & $\mathbf{0}$ & $\mathbf{0}$ & $\mathbf{0}$ & $\mathbf{0}$ & $\mathbf{0}$ & $\mathbf{0}$ & $\mathbf{0}$ & $\mathbf{0}$ \\
\hline \multirow{2}{*}{ PTV × Column } & 0.7 & 0.7 & 0.9 & 0.9 & 0.9 & 0.9 & 0.8 & 0.5 & 0.5 & 0.8 & 0.6 & 0.8 & 0.7 & 0.6 \\
\hline & 3 & 0 & 6 & 8 & 8 & 1 & 7 & 0 & 5 & 3 & 2 & 0 & 8 & 4 \\
\hline \multirow{2}{*}{ Splitless $\times$ Column } & 0.7 & 0.6 & 0.9 & 0.8 & 0.9 & 0.8 & 0.7 & 0.7 & 0.9 & 0.4 & 0.3 & 0.6 & 0.7 & 0.8 \\
\hline & 3 & 1 & 5 & 7 & 1 & 9 & 9 & 1 & 7 & 9 & 2 & 0 & 4 & 3 \\
\hline \multicolumn{15}{|c|}{ Optimized parameters } \\
\hline Injection conditions & \multicolumn{5}{|c|}{$\begin{array}{l}\text { PTV injection hold time } \\
\text { at an initial }\left(40{ }^{\circ} \mathrm{C}\right) \\
\text { temperature, min }\end{array}$} & \multicolumn{3}{|c|}{ Splitless time, $\min$} & \multicolumn{6}{|c|}{$\begin{array}{l}\text { Oven hold time at an initial ( } 35 \\
\left.{ }^{\circ} \mathrm{C}\right) \text { temperature, min }\end{array}$} \\
\hline Evaluated & \multicolumn{4}{|c|}{$0.26-2.44$} & \multicolumn{4}{|c|}{$1.09-4.11$} & \multicolumn{3}{|c|}{$1.09-4.11$} & & & \\
\hline Optimum & \multicolumn{4}{|c|}{$0.26-1.35$} & \multicolumn{4}{|c|}{$2.6-4.11$} & \multicolumn{3}{|c|}{$1.09-4.11$} & & & \\
\hline Selected & \multicolumn{4}{|l|}{0.7} & \multicolumn{3}{|c|}{2.6} & & \multicolumn{3}{|c|}{2.6} & & & \\
\hline
\end{tabular}

\footnotetext{
${ }^{a}$ Parameter or interaction highlighted in bold was considered to be influential as $P$-value $\leq 0.05$.
} 
Table 3. Instrumental LODs (ng) for target compounds obtained upon derivatization with MSTFA. Analysis was carried out via HTGC-FID/MS, operated in SITI mode with injection volume of 0.2 $\mu \mathrm{L}$. Given 2:1 FID to MS split ratio, the LODs were adjusted accordingly. The MS quantitation was performed using ions listed in Table 1.

\begin{tabular}{|c|c|c|c|}
\hline Target compounds & FID & TIC/EIC (SITI) & SIM/EIC (SITI) \\
\hline Pentanoic acid & 0.09 & 0.05 & 0.02 \\
\hline Hexanoic acid & 0.21 & 0.06 & 0.01 \\
\hline Heptanoic acid & 0.06 & 0.03 & 0.03 \\
\hline Octanoic acid & 0.11 & 0.05 & 0.02 \\
\hline Nonanoic acid & 0.17 & 0.07 & 0.01 \\
\hline Decanoic acid & 0.16 & 0.06 & 0.03 \\
\hline Undecanoic acid & 0.08 & 0.03 & 0.02 \\
\hline Dodecanoic acid & 0.11 & 0.06 & 0.05 \\
\hline Tridecanoic acid & 0.09 & 0.07 & 0.03 \\
\hline Tetradecanoic acid & 0.10 & 0.11 & 0.04 \\
\hline Pentadecanoic acid & 0.07 & 0.06 & 0.02 \\
\hline Hexadecanoic acid & 0.26 & 0.09 & 0.02 \\
\hline Heptadecanoic acid & 0.11 & 0.17 & 0.01 \\
\hline Oleic acid & 0.07 & 0.18 & 0.02 \\
\hline Octadecanoic acid & 0.07 & 0.05 & 0.03 \\
\hline 1-Monopalmitin & 0.27 & 0.07 & 0.07 \\
\hline 1-Monolinolein & 0.25 & 2.12 & 0.14 \\
\hline 1-Monoolein & 0.22 & 0.38 & 0.05 \\
\hline 1-Monostearin & 0.18 & 0.12 & 0.11 \\
\hline 1,2-Dipalmitin & 0.07 & 0.06 & 0.02 \\
\hline 1,2-Dilinolein & 0.11 & 1.75 & 0.07 \\
\hline & \multicolumn{3}{|c|}{ Quantified as $[\mathrm{RCO}+128]^{+}$} \\
\hline Trioctanoin & 0.10 & 0.03 & 0.05 \\
\hline Trinonanoin & 0.08 & 0.32 & 0.05 \\
\hline Tridecanoin & 0.09 & 0.01 & 0.05 \\
\hline Triundecanoin & 0.09 & 0.09 & 0.06 \\
\hline Trilaurin & 0.11 & 0.19 & 0.05 \\
\hline Tritridecanoin & 0.09 & 0.33 & 0.06 \\
\hline Trimyristin & 0.12 & 0.08 & 0.06 \\
\hline Tripentadecanoin & 0.10 & 0.15 & 0.06 \\
\hline Tripalmitin & 0.13 & 0.12 & 0.06 \\
\hline Triheptadecanoin & 0.09 & 0.16 & 0.07 \\
\hline Triolein & 0.10 & 1.06 & 0.07 \\
\hline Tristearin & 0.11 & 1.42 & 0.06 \\
\hline Trinonadecanoin & 0.11 & 1.21 & 0.03 \\
\hline Triarachidin & 0.15 & 1.76 & 0.08 \\
\hline
\end{tabular}




\begin{tabular}{llll} 
Triheneicosanoin & 0.19 & 1.80 & 0.12 \\
Tribehenin & 0.27 & 0.32 & 0.10 \\
\hline
\end{tabular}


Table 4. Sample preparation, intra- and inter-day repeatability of all target analytes in soybean oil organic liquid products (OLPs) quantified by GC/FID. The OLP samples were obtained after 5 min exposure to listed temperature and pressure. The results are presented as mean \pm one standard deviation.

\begin{tabular}{|c|c|c|c|c|c|c|}
\hline \multirow{3}{*}{ Component } & \multicolumn{3}{|c|}{ OLP $1\left(494{ }^{\circ} \mathrm{C}, 6205 \mathrm{kPa}\right)$} & \multicolumn{3}{|c|}{ OLP $2\left(578^{\circ} \mathrm{C}, 7584 \mathrm{kPa}\right)$} \\
\hline & \multicolumn{6}{|c|}{ Repeatability for } \\
\hline & $\begin{array}{l}\text { Sample } \\
\text { preparation } \\
\text { (derivatization) }\end{array}$ & $\begin{array}{l}\text { Intra-day } \\
\text { (injection) }\end{array}$ & $\begin{array}{l}\text { Inter-day } \\
\text { (over } 8 \\
\text { days) }\end{array}$ & $\begin{array}{l}\text { Sample } \\
\text { preparation } \\
\text { (derivatization) }\end{array}$ & $\begin{array}{l}\text { Intra-day } \\
\text { (injection) }\end{array}$ & $\begin{array}{l}\text { Inter-day } \\
\text { (over } 8 \\
\text { days) }\end{array}$ \\
\hline \multicolumn{7}{|c|}{ Monocarboxylic acids } \\
\hline $\mathrm{C}_{4} \mathrm{MCA}$ & $<\mathrm{LOQ}^{\mathrm{a}}$ & $<\mathrm{LOQ}$ & $<\mathrm{LOQ}$ & $<\mathrm{LOQ}$ & $<\mathrm{LOQ}$ & $<\mathrm{LOQ}$ \\
\hline $\mathrm{C}_{5} \mathrm{MCA}$ & $0.31 \pm 0.01$ & $0.29 \pm 0.01$ & $0.29 \pm 0.02$ & $0.32 \pm 0.01$ & $0.32 \pm 0.01$ & $0.33 \pm 0.01$ \\
\hline $\mathrm{C}_{6} \mathrm{MCA}$ & $0.44 \pm 0.02$ & $0.44 \pm 0.01$ & $0.45 \pm 0.03$ & $0.46 \pm 0.01$ & $0.47 \pm 0.02$ & $0.48 \pm 0.01$ \\
\hline $\mathrm{C}_{7} \mathrm{MCA}$ & $1.38 \pm 0.07$ & $1.50 \pm 0.01$ & $1.37 \pm 0.07$ & $1.22 \pm 0.02$ & $1.25 \pm 0.02$ & $1.26 \pm 0.02$ \\
\hline $\mathrm{C}_{8} \mathrm{MCA}$ & $0.50 \pm 0.04$ & $0.55 \pm 0.01$ & $0.53 \pm 0.02$ & $0.68 \pm 0.01$ & $0.69 \pm 0.01$ & $0.69 \pm 0.01$ \\
\hline $\mathrm{C}_{9} \mathrm{MCA}$ & $0.31 \pm 0.03$ & $0.37 \pm 0.01$ & $0.33 \pm 0.02$ & $0.45 \pm 0.01$ & $0.45 \pm 0.01$ & $0.46 \pm 0.01$ \\
\hline $\mathrm{C}_{10} \mathrm{MCA}$ & $0.70 \pm 0.04$ & $0.77 \pm 0.01$ & $0.69 \pm 0.03$ & $0.62 \pm 0.01$ & $0.63 \pm 0.01$ & $0.63 \pm 0.01$ \\
\hline $\mathrm{C}_{11} \mathrm{MCA}$ & $0.11 \pm 0.02$ & $0.14 \pm 0.01$ & $0.13 \pm 0.01$ & $0.14 \pm 0.01$ & $0.15 \pm 0.01$ & $0.15 \pm 0.01$ \\
\hline $\mathrm{C}_{12} \mathrm{MCA}$ & $<\mathrm{LOQ}$ & $<\mathrm{LOQ}$ & $<\mathrm{LOQ}$ & $0.03 \pm 0.01$ & $<\mathrm{LOQ}$ & $<\mathrm{LOQ}$ \\
\hline $\mathrm{C}_{13} \mathrm{MCA}$ & $<\mathrm{LOQ}$ & $<\mathrm{LOQ}$ & $<\mathrm{LOQ}$ & $<\mathrm{LOQ}$ & $<\mathrm{LOQ}$ & $<\mathrm{LOQ}$ \\
\hline $\mathrm{C}_{14} \mathrm{MCA}$ & $<\mathrm{LOQ}$ & $<\mathrm{LOQ}$ & $<\mathrm{LOQ}$ & $<\mathrm{LOQ}$ & $<\mathrm{LOQ}$ & $<\mathrm{LOQ}$ \\
\hline $\mathrm{C}_{15} \mathrm{MCA}$ & $<\mathrm{LOQ}$ & $<\mathrm{LOQ}$ & $<\mathrm{LOQ}$ & $<\mathrm{LOQ}$ & $<\mathrm{LOQ}$ & $<\mathrm{LOQ}$ \\
\hline $\mathrm{C}_{16} \mathrm{MCA}$ & $2.36 \pm 0.10$ & $2.46 \pm 0.01$ & $2.27 \pm 0.09$ & $1.44 \pm 0.02$ & $1.43 \pm 0.01$ & $1.44 \pm 0.03$ \\
\hline $\mathrm{C}_{17} \mathrm{MCA}$ & $<\mathrm{LOQ}$ & $<\mathrm{LOQ}$ & $<\mathrm{LOQ}$ & $<\mathrm{LOQ}$ & $<\mathrm{LOQ}$ & $<\mathrm{LOQ}$ \\
\hline $\mathrm{C}_{18: 2} \mathrm{MCA}$ & $1.34 \pm 0.06$ & $1.36 \pm 0.01$ & $1.29 \pm 0.07$ & $0.53 \pm 0.01$ & $0.55 \pm 0.01$ & $0.53 \pm 0.02$ \\
\hline $\mathrm{C}_{18: 3} \mathrm{MCA}$ & $\mathrm{ND}^{\mathrm{b}}$ & ND & ND & ND & ND & ND \\
\hline $\mathrm{C}_{18: 1} \mathrm{MCA}$ & $4.97 \pm 0.33$ & $5.33 \pm 0.07$ & $5.11 \pm 0.23$ & $2.37 \pm 0.04$ & $2.45 \pm 0.03$ & $2.52 \pm 0.06$ \\
\hline $\mathrm{C}_{18: 0} \mathrm{MCA}$ & $0.81 \pm 0.03$ & $0.87 \pm 0.02$ & $0.84 \pm 0.03$ & $0.49 \pm 0.01$ & $0.50 \pm 0.01$ & $0.50 \pm 0.01$ \\
\hline MCAs total & $12.88 \pm 0.67$ & $14.09 \pm 0.05$ & $13.30 \pm 0.48$ & $8.67 \pm 0.11$ & $9.20 \pm 0.06$ & $8.99 \pm 0.06$ \\
\hline Glycerol & ND & ND & ND & ND & ND & ND \\
\hline \multicolumn{7}{|c|}{ Monoacylglycerols } \\
\hline $\mathrm{C}_{16} \mathrm{MAG}$ & $<\mathrm{LOQ}$ & $<\mathrm{LOQ}$ & $<\mathrm{LOQ}$ & $<\mathrm{LOQ}$ & $<\mathrm{LOQ}$ & $<\mathrm{LOQ}$ \\
\hline $\mathrm{C}_{18: 2} \mathrm{MAG}$ & $0.28 \pm 0.01$ & $0.24 \pm 0.01$ & $0.23 \pm 0.01$ & $0.04 \pm 0.01$ & $0.04 \pm 0.01$ & $0.04 \pm 0.01$ \\
\hline $\mathrm{C}_{18: 1} \mathrm{MAG}$ & ND & ND & ND & ND & ND & ND \\
\hline $\mathrm{C}_{18: 0} \mathrm{MAG}$ & $<\mathrm{LOQ}$ & $<\mathrm{LOQ}$ & $<\mathrm{LOQ}$ & $<\mathrm{LOQ}$ & $<\mathrm{LOQ}$ & $<\mathrm{LOQ}$ \\
\hline MAGs total & $0.28 \pm 0.01$ & $0.24 \pm 0.01$ & $0.23 \pm 0.01$ & $0.04 \pm 0.01$ & $0.04 \pm 0.01$ & $0.04 \pm 0.01$ \\
\hline \multicolumn{7}{|l|}{ Diacylglycerols } \\
\hline DAG 34 total & $0.06 \pm 0.01$ & $0.07 \pm 0.01$ & $0.06 \pm 0.01$ & $0.01 \pm 0.01$ & $0.01 \pm 0.01$ & $0.01 \pm 0.01$ \\
\hline 1,2(2,3)-DAG 36 & $0.19 \pm 0.03$ & $0.21 \pm 0.01$ & $0.18 \pm 0.02$ & $0.03 \pm 0.01$ & $0.03 \pm 0.01$ & $0.03 \pm 0.01$ \\
\hline 1,3-DAG 36 & $0.33 \pm 0.07$ & $0.42 \pm 0.01$ & $0.32 \pm 0.03$ & $0.07 \pm 0.01$ & $0.06 \pm 0.01$ & $0.05 \pm 0.01$ \\
\hline DAGs total & $0.58 \pm 0.10$ & $0.71 \pm 0.01$ & $0.66 \pm 0.03$ & $0.11 \pm 0.01$ & $0.10 \pm 0.01$ & $0.09 \pm 0.01$ \\
\hline
\end{tabular}

Triacylglycerols 


\begin{tabular}{lllllll} 
TAG 50 & $0.44 \pm 0.03$ & $0.45 \pm 0.04$ & $0.38 \pm 0.06$ & $0.16 \pm 0.01$ & $0.16 \pm 0.01$ & $0.18 \pm 0.01$ \\
TAG 52 & $6.45 \pm 0.30$ & $6.13 \pm 0.10$ & $5.70 \pm 0.41$ & $2.67 \pm 0.06$ & $2.35 \pm 0.06$ & $2.27 \pm 0.07$ \\
TAG 54 & $14.47 \pm 1.18$ & $13.31 \pm 0.12$ & $11.71 \pm 1.12$ & $5.63 \pm 0.16$ & $4.92 \pm 0.10$ & $4.52 \pm 0.20$ \\
TAGs total & $\mathbf{2 1 . 3 6} \pm \mathbf{1 . 5 0}$ & $\mathbf{1 9 . 8 9} \pm \mathbf{0 . 2 3}$ & $\mathbf{1 7 . 7 9} \pm \mathbf{1 . 5 2}$ & $\mathbf{8 . 4 6} \pm \mathbf{0 . 2 5}$ & $\mathbf{7 . 4 3} \pm \mathbf{0 . 2 6}$ & $\mathbf{6 . 9 7} \pm \mathbf{0 . 2 6}$ \\
\hline
\end{tabular}

${ }^{\mathrm{a} B e l o w}$ the limit of quantification, ${ }^{\mathrm{b}}$ Not detected. 
Table 5. Sample preparation, intra- and inter-day repeatability of all target analytes in soybean oil organic liquid products (OLPs) TIC/EIC. The OLP samples were obtained after 5 min exposure to listed temperature and pressure. The results are presented as mean \pm one standard deviation. On MW and symbols of quantification ions see Table 1.

\begin{tabular}{|c|c|c|c|c|c|c|}
\hline \multirow{3}{*}{ Component } & \multicolumn{3}{|c|}{ OLP $1\left(494^{\circ} \mathrm{C}, 6205 \mathrm{kPa}\right)$} & \multicolumn{3}{|c|}{ OLP $2\left(578^{\circ} \mathrm{C}, 7584 \mathrm{kPa}\right)$} \\
\hline & \multicolumn{6}{|c|}{ Repeatability for } \\
\hline & $\begin{array}{c}\text { Sample } \\
\text { preparation } \\
\text { (derivatization) }\end{array}$ & $\begin{array}{c}\text { Intra-day } \\
\text { (injection) }\end{array}$ & $\begin{array}{c}\text { Inter-day } \\
\text { (over } 8 \\
\text { days) }\end{array}$ & $\begin{array}{c}\text { Sample } \\
\text { preparation } \\
\text { (derivatization) }\end{array}$ & $\begin{array}{l}\text { Intra-day } \\
\text { (injection) }\end{array}$ & $\begin{array}{c}\text { Inter-day } \\
\text { (over } 8 \\
\text { days) }\end{array}$ \\
\hline \multicolumn{7}{|l|}{ Monocarboxylic acids } \\
\hline $\mathrm{C}_{4} \mathrm{MCA}$ & $<\mathrm{LOQ}^{\mathrm{a}}$ & $0.09 \pm 0.01$ & $<$ LOQ & $0.23 \pm 0.01$ & $0.28 \pm 0.01$ & $0.23 \pm 0.01$ \\
\hline $\mathrm{C}_{5} \mathrm{MCA}$ & $<\mathrm{LOQ}$ & $0.23 \pm 0.01$ & $0.12 \pm 0.03$ & $0.27 \pm 0.01$ & $0.30 \pm 0.01$ & $0.26 \pm 0.01$ \\
\hline $\mathrm{C}_{6} \mathrm{MCA}$ & $0.34 \pm 0.02$ & $0.46 \pm 0.01$ & $0.33 \pm 0.04$ & $0.48 \pm 0.02$ & $0.50 \pm 0.01$ & $0.46 \pm 0.01$ \\
\hline $\mathrm{C}_{7} \mathrm{MCA}$ & $1.42 \pm 0.10$ & $1.59 \pm 0.01$ & $1.41 \pm 0.11$ & $1.30 \pm 0.04$ & $1.30 \pm 0.01$ & $1.31 \pm 0.03$ \\
\hline $\mathrm{C}_{8} \mathrm{MCA}$ & $0.45 \pm 0.04$ & $0.57 \pm 0.01$ & $0.42 \pm 0.05$ & $0.53 \pm 0.02$ & $0.55 \pm 0.01$ & $0.52 \pm 0.01$ \\
\hline $\mathrm{C}_{9} \mathrm{MCA}$ & $0.28 \pm 0.04$ & $0.41 \pm 0.01$ & $0.25 \pm 0.04$ & $0.42 \pm 0.01$ & $0.45 \pm 0.01$ & $0.41 \pm 0.01$ \\
\hline $\mathrm{C}_{10} \mathrm{MCA}$ & $0.65 \pm 0.05$ & $0.77 \pm 0.01$ & $0.63 \pm 0.07$ & $0.61 \pm 0.02$ & $0.64 \pm 0.01$ & $0.60 \pm 0.02$ \\
\hline $\mathrm{C}_{11} \mathrm{MCA}$ & $<\mathrm{LOQ}$ & $0.05 \pm 0.01$ & $<\mathrm{LOQ}$ & $<\mathrm{LOQ}$ & $0.08 \pm 0.01$ & $0.03 \pm 0.01$ \\
\hline $\mathrm{C}_{12} \mathrm{MCA}$ & $<\mathrm{LOQ}$ & $<\mathrm{LOQ}$ & $<\mathrm{LOQ}$ & $<\mathrm{LOQ}$ & $0.03 \pm 0.01$ & $<\mathrm{LOQ}$ \\
\hline $\mathrm{C}_{13} \mathrm{MCA}$ & $<\mathrm{LOQ}$ & $<\mathrm{LOQ}$ & $<\mathrm{LOQ}$ & $<$ LOQ & $0.03 \pm 0.01$ & $<\mathrm{LOQ}$ \\
\hline $\mathrm{C}_{14} \mathrm{MCA}$ & $<\mathrm{LOQ}$ & $<\mathrm{LOQ}$ & $<\mathrm{LOQ}$ & $<\mathrm{LOQ}$ & $0.02 \pm 0.01$ & $<\mathrm{LOQ}$ \\
\hline $\mathrm{C}_{15} \mathrm{MCA}$ & $<\mathrm{LOQ}$ & $<\mathrm{LOQ}$ & $<\mathrm{LOQ}$ & $<\mathrm{LOQ}$ & $0.02 \pm 0.01$ & $<\mathrm{LOQ}$ \\
\hline $\mathrm{C}_{16} \mathrm{MCA}$ & $2.33 \pm 0.09$ & $2.54 \pm 0.01$ & $2.33 \pm 0.08$ & $1.47 \pm 0.04$ & $1.43 \pm 0.01$ & $1.45 \pm 0.02$ \\
\hline $\mathrm{C}_{17} \mathrm{MCA}$ & $<\mathrm{LOQ}$ & $<\mathrm{LOQ}$ & $<\mathrm{LOQ}$ & $<\mathrm{LOQ}$ & $0.02 \pm 0.01$ & $<\mathrm{LOQ}$ \\
\hline $\mathrm{C}_{18: 2} \mathrm{MCA}$ & $2.93 \pm 0.20$ & $3.21 \pm 0.01$ & $3.01 \pm 0.19$ & $1.30 \pm 0.02$ & $1.27 \pm 0.01$ & $1.27 \pm 0.03$ \\
\hline $\mathrm{C}_{18: 3} \mathrm{MCA}$ & $\mathrm{ND}^{\mathrm{b}}$ & ND & ND & ND & ND & ND \\
\hline $\mathrm{C}_{18: 1} \mathrm{MCA}$ & $2.6 \pm 0.2$ & $2.77 \pm 0.02$ & $2.5 \pm 0.2$ & $1.36 \pm 0.04$ & $1.36 \pm 0.05$ & $1.34 \pm 0.04$ \\
\hline $\mathrm{C}_{18: 0} \mathrm{MCA}$ & $0.81 \pm 0.03$ & $0.93 \pm 0.01$ & $0.80 \pm 0.04$ & $0.49 \pm 0.01$ & $0.52 \pm 0.01$ & $0.49 \pm 0.01$ \\
\hline MCAs total & $11.8 \pm 0.9$ & $13.62 \pm 0.03$ & $11.8 \pm 0.9$ & $8.5 \pm 0.3$ & $8.80 \pm 0.06$ & $8.4 \pm 0.2$ \\
\hline Glycerol & $<$ LOQ & $<\mathrm{LOQ}$ & $<$ LOQ & $<$ LOQ & $<$ LOQ & $<$ LOQ \\
\hline \multicolumn{7}{|l|}{ Monoacylglycerols } \\
\hline $\mathrm{C}_{16} \mathrm{MAG}$ & $<\mathrm{LOQ}$ & $<\mathrm{LOQ}$ & $<\mathrm{LOQ}$ & $<\mathrm{LOQ}$ & $<\mathrm{LOQ}$ & $<\mathrm{LOQ}$ \\
\hline $\mathrm{C}_{18: 2} \mathrm{MAG}$ & $<\mathrm{LOQ}$ & $<\mathrm{LOQ}$ & ND & $<\mathrm{LOQ}$ & ND & ND \\
\hline $\mathrm{C}_{18: 1} \mathrm{MAG}$ & $<\mathrm{LOQ}$ & $<$ LOQ & ND & ND & ND & ND \\
\hline $\mathrm{C}_{18: 0} \mathrm{MAG}$ & $<\mathrm{LOQ}$ & $<\mathrm{LOQ}$ & ND & $<\mathrm{LOQ}$ & ND & ND \\
\hline MAGs total & $<$ LOQ & $<\mathrm{LOQ}$ & $<$ LOQ & $<\mathrm{LOQ}$ & $<$ LOQ & $<$ LOQ \\
\hline \multicolumn{7}{|l|}{ Diacylglycerols } \\
\hline DAG 34 total & $<\mathrm{LOQ}$ & $<\mathrm{LOQ}$ & $<\mathrm{LOQ}$ & $<\mathrm{LOQ}$ & $<\mathrm{LOQ}$ & $<\mathrm{LOQ}$ \\
\hline 1,2(2,3)-DAG $36(\mathrm{~S})$ & $<\mathrm{LOQ}$ & $<\mathrm{LOQ}$ & $<\mathrm{LOQ}$ & $<\mathrm{LOQ}$ & $<\mathrm{LOQ}$ & $<\mathrm{LOQ}$ \\
\hline 1,2(2,3)-DAG $36(\mathrm{O})$ & $<\mathrm{LOQ}$ & $<\mathrm{LOQ}$ & $<\mathrm{LOQ}$ & $<\mathrm{LOQ}$ & $<\mathrm{LOQ}$ & $<\mathrm{LOQ}$ \\
\hline 1,2(2,3)-DAG 36 (L) & $<\mathrm{LOQ}$ & $<\mathrm{LOQ}$ & $<\mathrm{LOQ}$ & $<\mathrm{LOQ}$ & $<\mathrm{LOQ}$ & $<\mathrm{LOQ}$ \\
\hline 1,2(2,3)-DAG $36(\mathrm{Ln})$ & ND & ND & ND & ND & ND & ND \\
\hline 1,3-DAG $36(\mathrm{~S})$ & $<$ LOQ & $<\mathrm{LOQ}$ & $<\mathrm{LOQ}$ & $<$ LOQ & $<$ LOQ & $<\mathrm{LOQ}$ \\
\hline
\end{tabular}




\begin{tabular}{|c|c|c|c|c|c|c|}
\hline 1,3-DAG $36(\mathrm{O})$ & $<\mathrm{LOQ}$ & $<\mathrm{LOQ}$ & $<\mathrm{LOQ}$ & $<\mathrm{LOQ}$ & $<\mathrm{LOQ}$ & $<\mathrm{LOQ}$ \\
\hline 1,3-DAG 36 (L) & $0.46 \pm 0.02$ & $0.44 \pm 0.01$ & $0.43 \pm 0.08$ & $0.10 \pm 0.01$ & $0.09 \pm 0.01$ & $0.08 \pm 0.01$ \\
\hline 1,3-DAG 36 (Ln) & $<\mathrm{LOQ}$ & $<\mathrm{LOQ}$ & $<\mathrm{LOQ}$ & $<\mathrm{LOQ}$ & $<\mathrm{LOQ}$ & $<\mathrm{LOQ}$ \\
\hline DAGs total & $0.46 \pm 0.02$ & $0.44 \pm 0.01$ & $0.43 \pm 0.08$ & $0.10 \pm 0.01$ & $0.09 \pm 0.01$ & $0.08 \pm 0.01$ \\
\hline \multicolumn{7}{|c|}{ Triacylglycerols quantified as $[\mathrm{RCO}+128]^{+}$} \\
\hline TAG $50(\mathrm{P})$ & $<\mathrm{LOQ}$ & $<\mathrm{LOQ}$ & $<\mathrm{LOQ}$ & $0.09 \pm 0.01$ & $0.08 \pm 0.01$ & $<\mathrm{LOQ}$ \\
\hline TAG $50(\mathrm{~S})$ & ND & ND & ND & ND & ND & ND \\
\hline TAG $50(\mathrm{O})$ & $<$ LOQ & $<\mathrm{LOQ}$ & ND & ND & ND & ND \\
\hline TAG 50 (L) & $<\mathrm{LOQ}$ & $<\mathrm{LOQ}$ & ND & ND & ND & ND \\
\hline TAG 50 (Ln) & ND & ND & ND & ND & ND & ND \\
\hline TAG 50 total & $<\mathrm{LOQ}$ & $<\mathrm{LOQ}$ & $<\mathrm{LOQ}$ & $0.09 \pm 0.01$ & $0.08 \pm 0.01$ & $<\mathrm{LOQ}$ \\
\hline TAG $52(\mathrm{P})$ & $0.69 \pm 0.05$ & $0.70 \pm 0.01$ & $0.55 \pm 0.03$ & $0.26 \pm 0.01$ & $0.21 \pm 0.01$ & $0.23 \pm 0.01$ \\
\hline TAG 52 (S) & $<\mathrm{LOQ}$ & $<\mathrm{LOQ}$ & $<\mathrm{LOQ}$ & $<\mathrm{LOQ}$ & $<\mathrm{LOQ}$ & $<\mathrm{LOQ}$ \\
\hline TAG $52(\mathrm{O})$ & $1.38 \pm 0.07$ & $1.31 \pm 0.02$ & $1.24 \pm 0.06$ & $0.45 \pm 0.01$ & $0.41 \pm 0.04$ & $0.47 \pm 0.08$ \\
\hline TAG 52 (L) & $3.9 \pm 0.8$ & $4.3 \pm 0.3$ & $3.55 \pm 0.08$ & $1.5 \pm 0.3$ & $1.5 \pm 0.3$ & $1.2 \pm 0.2$ \\
\hline TAG 52 (Ln) & $<\mathrm{LOQ}$ & $<\mathrm{LOQ}$ & $<\mathrm{LOQ}$ & $0.42 \pm 0.01$ & $0.36 \pm 0.01$ & $<\mathrm{LOQ}$ \\
\hline TAG 52 total & $6.0 \pm 0.8$ & $6 \pm 1$ & $5.3 \pm 0.2$ & $2.5 \pm 0.4$ & $2.4 \pm 0.6$ & $1.95 \pm 0.05$ \\
\hline TAG $54(\mathrm{O})$ & $2.45 \pm 0.08$ & $2.39 \pm 0.09$ & $2.1 \pm 0.1$ & $0.95 \pm 0.06$ & $0.79 \pm 0.06$ & $0.81 \pm 0.06$ \\
\hline TAG 54 (L) & $8.4 \pm 0.5$ & $8.6 \pm 0.2$ & $6.0 \pm 0.3$ & $3.3 \pm 0.3$ & $3.0 \pm 0.5$ & $2.2 \pm 0.2$ \\
\hline TAG 54 (Ln) & $<\mathrm{LOQ}$ & $<\mathrm{LOQ}$ & $<\mathrm{LOQ}$ & $0.67 \pm 0.04$ & $0.56 \pm 0.07$ & $<\mathrm{LOQ}$ \\
\hline TAG 54 (S) & $<\mathrm{LOQ}$ & $<\mathrm{LOQ}$ & $<\mathrm{LOQ}$ & $0.20 \pm 0.01$ & $0.17 \pm 0.01$ & $<\mathrm{LOQ}$ \\
\hline TAG 54 total & $10.8 \pm 0.5$ & $11 \pm 2$ & $8 \pm 2$ & $5.1 \pm 0.4$ & $4.5 \pm 0.6$ & $3.0 \pm 0.2$ \\
\hline TAGs total & $17 \pm 2$ & $17 \pm 2$ & $9 \pm 2$ & $7.7 \pm 0.7$ & $6.9 \pm 0.7$ & $4.4 \pm 0.2$ \\
\hline
\end{tabular}

${ }^{\mathrm{a}}$ Below the limit of quantification, ${ }^{\mathrm{b}}$ Not detected. 
Suppl. Table 1. Chromatographic methods developed for the simultaneous analysis of MCAs and acylglycerols.

\begin{tabular}{|c|c|c|c|c|c|c|c|}
\hline Matrix & $\begin{array}{l}\text { Sample } \\
\text { preparation }\end{array}$ & $\begin{array}{l}\text { Chromatographic } \\
\text { separation }\end{array}$ & Detection & Injector & Species analyzed & Limitations & Ref. \\
\hline $\begin{array}{l}\text { soybean, palm } \\
\text { and coconut oils }\end{array}$ & $\begin{array}{l}\text { HMDS / TFA } \\
\text { silylation }\end{array}$ & $\begin{array}{l}\mathrm{GC}, \\
\mathrm{DB}-5 \text { column, } \\
\text { final } \mathrm{T}=370^{\circ} \mathrm{C}\end{array}$ & $\begin{array}{l}\text { FID, } \\
360^{\circ} \mathrm{C}\end{array}$ & $\begin{array}{l}\text { split } 1: 50 \text {, } \\
360^{\circ} \mathrm{C}\end{array}$ & $\begin{array}{l}\text { MCAs } \mathrm{C}_{6}-\mathrm{C}_{24} \text {, DAGs, TAGs } \\
\text { and sterols }\end{array}$ & $\begin{array}{l}\text { emphasis on MCAs only: DAGs and } \\
\text { TAGs were not individually identified }\end{array}$ & [13] \\
\hline vegetable oils & $\begin{array}{l}\text { BSTFA }^{c} \\
\text { silylation }\end{array}$ & $\begin{array}{l}\mathrm{GC}, \\
\mathrm{BPX} 5 \text { column, } \\
\text { final } \mathrm{T}=360^{\circ} \mathrm{C}\end{array}$ & $\begin{array}{l}\text { FID, } \\
370^{\circ} \mathrm{C}\end{array}$ & $\begin{array}{l}\text { on-column, } \\
45^{\circ} \mathrm{C}\end{array}$ & $\begin{array}{l}\text { MCAs } \mathrm{C}_{14}-\mathrm{C}_{18}, \text { MAGs, } \\
\text { DAGs, TAGs, sterols }\end{array}$ & $\begin{array}{l}\text { identification and quantification of } \\
\text { species present in standard mixture only, } \\
\text { low MW MCAs were not considered }\end{array}$ & [14] \\
\hline biodiesel & $\begin{array}{l}\text { BSTFA } \\
\text { silylation }\end{array}$ & $\begin{array}{l}\mathrm{GC}, \\
\text { SAC } 5 \text { column, } \\
\text { final } \mathrm{T}=275^{\circ} \mathrm{C}\end{array}$ & $\begin{array}{l}\text { MS, } \\
230^{\circ} \mathrm{C} \text { ion } \\
\text { source, } 150{ }^{\circ} \mathrm{C} \\
\text { quadrupole }\end{array}$ & $\begin{array}{l}\text { splitless, } \\
280^{\circ} \mathrm{C}\end{array}$ & $\begin{array}{l}\text { even number MCAs } \mathrm{C}_{6}-\mathrm{C}_{24} \text {, } \\
\text { glycerol, sterols, MAG } \mathrm{C}_{18: 1}\end{array}$ & DAGs or TAGs were not considered & [38] \\
\hline biodiesel & & HPLC & DAD-MS & & $\begin{array}{l}\text { MCA C }_{18} \text {, glycerol, MAGs, } \\
\text { DAGs and TAGs }\end{array}$ & $\begin{array}{l}\text { unable to measure glycerol, low MW } \\
\text { MCAs were not considered }\end{array}$ & [37] \\
\hline $\begin{array}{l}\text { biodiesel } \\
\text { mixtures }\end{array}$ & & $\begin{array}{l}\text { non-aqueous } \\
\text { RP-LC }\end{array}$ & UV-Vis & & $\begin{array}{l}\text { MCAs } C_{18: 1}, C_{18: 2}, C_{18: 3} \\
\text { MAGs, DAGs, TAGs and } \\
\text { FAME }\end{array}$ & $\begin{array}{l}\text { low MW MCAs were not considered, } \\
\text { quantification was not reported }\end{array}$ & [40] \\
\hline biodiesel & & UPLC & DAD-ELSD & & $\begin{array}{l}\text { even number MCAs } \mathrm{C}_{16}-\mathrm{C}_{20} \text {, } \\
\text { glycerol, MAGs, DAGs, } \\
\text { TAGs and FAMEs }\end{array}$ & $\begin{array}{l}\text { low MW MCAs were not considered, } \\
\text { quantification was not reported }\end{array}$ & [42] \\
\hline $\begin{array}{l}\text { vegetable oils } \\
\text { or animal fats }\end{array}$ & & SFC & UV-ELSD & & $\begin{array}{l}\text { MCAs, FAME, MAGs, } \\
\text { DAGs and TAGs }\end{array}$ & $\begin{array}{l}\text { no detailed characterization: separation } \\
\text { and quantification as classes of } \\
\text { compounds }\end{array}$ & [41] \\
\hline biodiesel & & SFC & MS-UV-ELSD & & $\begin{array}{l}\text { glycerol, MCAs } \mathrm{C}_{16}-\mathrm{C}_{18} \text { and } \\
\text { FAME }\end{array}$ & $\begin{array}{l}\text { quantification was not reported, DAGs } \\
\text { or TAGs were not considered }\end{array}$ & [39] \\
\hline
\end{tabular}


Suppl. Table 2. Design matrix for central composite design showing PTV injection experimental parameters.

\begin{tabular}{|c|c|c|c|c|c|c|}
\hline \multirow[b]{2}{*}{$\begin{array}{l}\text { Run } \\
\text { order }\end{array}$} & \multicolumn{3}{|l|}{ Coded levels ${ }^{\mathrm{a}}$} & \multicolumn{3}{|l|}{ Uncoded levels } \\
\hline & $\begin{array}{l}\text { PTV hold time at } \\
\text { initial } 40^{\circ} \mathrm{C} \text {, min }\end{array}$ & $\begin{array}{l}\text { Splitless } \\
\text { time, min }\end{array}$ & $\begin{array}{l}\text { Oven hold time at } \\
\text { initial } 35^{\circ} \mathrm{C} \text {, min }\end{array}$ & $\begin{array}{l}\text { PTV hold time at } \\
\text { initial } 40^{\circ} \mathrm{C} \text {, min }\end{array}$ & $\begin{array}{l}\text { Splitless } \\
\text { time, min }\end{array}$ & $\begin{array}{l}\text { Oven hold time at } \\
\text { initial } 35^{\circ} \mathrm{C} \text {, min }\end{array}$ \\
\hline 1 & 1 & 1 & 1 & 2 & 3.5 & 3.5 \\
\hline 2 & -1 & -1 & 1 & 0.7 & 1.7 & 3.5 \\
\hline 3 & 0 & 0 & 0 & 1.35 & 2.6 & 2.6 \\
\hline 4 & -1 & -1 & -1 & 0.7 & 1.7 & 1.7 \\
\hline 5 & 1 & -1 & -1 & 2 & 1.7 & 1.7 \\
\hline 6 & 0 & 0 & -1.68 & 1.35 & 2.6 & 1.09 \\
\hline 7 & -1 & 1 & -1 & 0.7 & 3.5 & 1.7 \\
\hline 8 & -1.68 & 0 & 0 & 0.26 & 2.6 & 2.6 \\
\hline 9 & 0 & 0 & 0 & 1.35 & 2.6 & 2.6 \\
\hline 10 & 0 & -1.68 & 0 & 1.35 & 1.09 & 2.6 \\
\hline 11 & 0 & 0 & 0 & 1.35 & 2.6 & 2.6 \\
\hline 12 & 0 & 0 & 0 & 1.35 & 2.6 & 2.6 \\
\hline 13 & 1 & 1 & -1 & 2 & 3.5 & 1.7 \\
\hline 14 & 0 & 1.68 & 0 & 1.35 & 4.11 & 2.6 \\
\hline 15 & 0 & 0 & 0 & 1.35 & 2.6 & 2.6 \\
\hline 16 & 1.68 & 0 & 0 & 2.44 & 2.6 & 2.6 \\
\hline 17 & 1 & -1 & 1 & 2 & 1.7 & 3.5 \\
\hline 18 & -1 & 1 & 1 & 0.7 & 3.5 & 3.5 \\
\hline 19 & 0 & 0 & 0 & 1.35 & 2.6 & 2.6 \\
\hline 20 & 0 & 0 & 1.68 & 1.35 & 2.6 & 4.11 \\
\hline
\end{tabular}

${ }^{\mathrm{a} C}$ Codified values: " \pm 1 " corresponds to factorial points, "0" corresponds to center points, " \pm 1.68 " corresponds to axial points. 
Suppl. Table 3. Possible soybean oil acylglycerols formed by various combinations of $\mathrm{C}_{16: 0}, \mathrm{C}_{18: 0}, \mathrm{C}_{18: 1}, \mathrm{C}_{18: 2}$ and $\mathrm{C}_{18: 3}$ acyl chains: abbreviations, acyl carbon numbers (ACN), number of double bonds (DB) and MW of expected characteristic ions.

\begin{tabular}{|c|c|c|c|c|c|c|c|c|}
\hline \multicolumn{9}{|c|}{ Acyl chains } \\
\hline \multicolumn{2}{|c|}{ Abbreviation } & ACN:DB & \multicolumn{3}{|c|}{ Systematic name } & \multicolumn{2}{|c|}{ Trivial name } & {$[\mathrm{RCO}]^{+}$} \\
\hline \multicolumn{2}{|l|}{$\mathrm{P}$} & $16: 0$ & \multicolumn{3}{|c|}{ Hexadecanoic } & \multicolumn{2}{|c|}{ Palmitic } & {$\left[\mathrm{C}_{15} \mathrm{H}_{31} \mathrm{CO}\right]^{+}$} \\
\hline \multicolumn{2}{|l|}{ S } & 18:0 & \multicolumn{3}{|l|}{ Octadecanoic } & \multicolumn{2}{|l|}{ Stearic } & {$\left[\mathrm{C}_{17} \mathrm{H}_{35} \mathrm{CO}\right]^{+}$} \\
\hline \multicolumn{2}{|l|}{$\mathrm{O}$} & $18: 1$ & \multicolumn{3}{|c|}{ cis-9-Octadecenoic } & \multicolumn{2}{|l|}{ Oleic } & {$\left[\mathrm{C}_{17} \mathrm{H}_{33} \mathrm{CO}\right]^{+}$} \\
\hline \multicolumn{2}{|l|}{$\mathrm{L}$} & $18: 2$ & \multicolumn{3}{|c|}{ cis-9,12-Octadecadienoic } & \multicolumn{2}{|c|}{ Linoleic } & {$\left[\mathrm{C}_{17} \mathrm{H}_{31} \mathrm{CO}\right]^{+}$} \\
\hline \multicolumn{2}{|l|}{ Ln } & $18: 3$ & \multicolumn{3}{|c|}{ cis-9,12,15-Octadecatrienoic } & Linolen & & {$\left[\mathrm{C}_{17} \mathrm{H}_{29} \mathrm{CO}\right]^{+}$} \\
\hline Monoa & lycerols & & & & & & & \\
\hline & ACN:DB & {$[\mathrm{RCO}]^{+}$} & {$[\mathrm{RCO}+74]^{+}$} & {$[\mathrm{RCO}+128]^{+}$} & & {$[\mathrm{M}-\mathrm{CH}$} & & \\
\hline $\mathrm{P}$ & $16: 0$ & 239 & 313 & 367 & & 459 & & \\
\hline$S$ & 18:0 & 267 & 341 & 395 & & 487 & & \\
\hline $\mathrm{O}$ & $18: 1$ & 265 & 339 & 393 & & 485 & & \\
\hline $\mathrm{L}$ & $18: 2$ & 263 & 337 & 391 & & 483 & & \\
\hline Ln & $18: 3$ & 261 & 335 & 389 & & 481 & & \\
\hline Diacyl & arols & & & & & & & \\
\hline & ACN:DB & {$\left[\mathrm{M}-\mathrm{R}_{1} \mathrm{COO}\right]^{+}$} & {$\left[\mathrm{M}-\mathrm{R}_{2} \mathrm{COO}\right]^{+}$} & {$\left[\mathrm{M}-\mathrm{R}_{1} \mathrm{COO}-\mathrm{C}\right.$} & $\left.\mathrm{H}_{2}\right]^{+}$ & {$\left[\mathrm{M}-\mathrm{R}_{2} \mathrm{C}\right.$} & $\left.\mathrm{O}-\mathrm{CH}_{2}\right]^{+}$ & {$\left[\mathrm{M}-\mathrm{CH}_{3}\right]^{+}$} \\
\hline PP & $32: 0$ & 385 & 385 & 371 & & 371 & & 625 \\
\hline PS & $34: 0$ & 385 & 413 & 371 & & 399 & & 653 \\
\hline PO & $34: 1$ & 385 & 411 & 371 & & 397 & & 651 \\
\hline PL & $34: 2$ & 385 & 409 & 371 & & 395 & & 649 \\
\hline PLn & $34: 3$ & 385 & 407 & 371 & & 393 & & 647 \\
\hline SS & $36: 0$ & 413 & 413 & 399 & & 399 & & 681 \\
\hline SO & $36: 1$ & 413 & 411 & 399 & & 397 & & 679 \\
\hline SL & $36: 2$ & 413 & 409 & 399 & & 395 & & 677 \\
\hline $\mathrm{OO}$ & $36: 2$ & 411 & 411 & 397 & & 397 & & 677 \\
\hline SLn & $36: 3$ & 413 & 407 & 399 & & 393 & & 675 \\
\hline OL & $36: 3$ & 411 & 409 & 397 & & 395 & & 675 \\
\hline OLn & $36: 4$ & 411 & 407 & 397 & & 393 & & 673 \\
\hline LL & $36: 4$ & 409 & 409 & 395 & & 395 & & 673 \\
\hline LLn & $36: 5$ & 409 & 407 & 395 & & 393 & & 671 \\
\hline LnLn & $36: 6$ & 407 & 407 & 393 & & 393 & & 669 \\
\hline Triacyl & erols & & & & & & & \\
\hline & $\mathrm{ACN}: \mathrm{DB}^{1}$ & {$\left[\mathrm{R}_{1} \mathrm{CO}+128\right]^{+}$} & {$\left[\mathrm{R}_{2} \mathrm{CO}+128\right]^{+}$} & {$\left[\mathrm{R}_{3} \mathrm{CO}+128\right]^{+}$} & {$[\mathrm{M}-1$} & $\mathrm{COO}^{+}$ & {$\left[\mathrm{M}-\mathrm{R}_{2} \mathrm{COO}\right]^{+}$} & {$\left[\mathrm{M}-\mathrm{R}_{3} \mathrm{COO}\right]^{+}$} \\
\hline PPP & $48: 0$ & 367 & 367 & 367 & 551 & & 551 & 551 \\
\hline PPS & $50: 0$ & 367 & 367 & 395 & 579 & & 579 & 551 \\
\hline POP & $50: 1$ & 367 & 393 & 367 & 577 & & 551 & 577 \\
\hline PLP & $50: 2$ & 367 & 262 & 367 & 575 & & 551 & 575 \\
\hline PLnP & $50: 3$ & 367 & 389 & 367 & 573 & & 551 & 573 \\
\hline PSS & 52:0 & 367 & 395 & 395 & 607 & & 579 & 579 \\
\hline SOP & $52: 1$ & 395 & 393 & 367 & 577 & & 579 & 605 \\
\hline OOP & $52: 2$ & 393 & 393 & 367 & 577 & & 575 & 603 \\
\hline SLP & $52: 2$ & 395 & 391 & 367 & 575 & & 579 & 603 \\
\hline LOP & $52: 3$ & 391 & 393 & 367 & 577 & & 575 & 601 \\
\hline
\end{tabular}




\begin{tabular}{llllllll} 
SLnP & $52: 3$ & 395 & 389 & 367 & 573 & 579 & 601 \\
LLP & $52: 4$ & 391 & 391 & 367 & 575 & 575 & 599 \\
OLnP & $52: 4$ & 393 & 389 & 367 & 573 & 577 & 599 \\
LnLP & $52: 5$ & 389 & 391 & 367 & 575 & 573 & 597 \\
LnLnP & $52: 6$ & 389 & 389 & 367 & 573 & 573 & 595 \\
SSS & $54: 0$ & 395 & 395 & 395 & 607 & 607 & 607 \\
SOS & $54: 1$ & 395 & 393 & 395 & 605 & 607 & 605 \\
SLS & $54: 2$ & 395 & 391 & 395 & 603 & 607 & 603 \\
SOO & $54: 2$ & 395 & 393 & 393 & 603 & 605 & 605 \\
OOO & $54: 3$ & 393 & 393 & 393 & 603 & 603 & 603 \\
SLO & $54: 3$ & 395 & 391 & 393 & 601 & 605 & 603 \\
SSLn & $54: 3$ & 395 & 395 & 389 & 601 & 601 & 607 \\
OLO & $54: 4$ & 393 & 391 & 393 & 601 & 603 & 601 \\
SLL & $54: 4$ & 395 & 391 & 391 & 599 & 603 & 603 \\
SOLn & $54: 4$ & 395 & 393 & 389 & 599 & 601 & 605 \\
OLL & $54: 5$ & 393 & 391 & 391 & 599 & 601 & 601 \\
OLnO & $54: 5$ & 393 & 389 & 393 & 599 & 603 & 599 \\
SLLn & $54: 5$ & 395 & 391 & 389 & 597 & 601 & 603 \\
LLL & $54: 6$ & 391 & 391 & 391 & 599 & 599 & 599 \\
SLnLn & $54: 6$ & 395 & 389 & 389 & 595 & 601 & 601 \\
OLLn & $54: 6$ & 393 & 391 & 389 & 597 & 599 & 601 \\
LLLn & $54: 7$ & 391 & 391 & 389 & 597 & 597 & 599 \\
OLnLn & $54: 7$ & 393 & 389 & 389 & 595 & 599 & 599 \\
LLnLn & $54: 8$ & 391 & 389 & 389 & 595 & 597 & 597 \\
LnLnLn & $54: 9$ & 389 & 389 & 389 & 595 & 595 & 595 \\
\hline & & & & & & \\
\hline
\end{tabular}


Suppl. Table 4. Calibration parameters for MCAs upon derivatization with MSTFA determined by HTGC-FID/MS in SITI. The MS quantitation was performed using ions listed in Table 1.

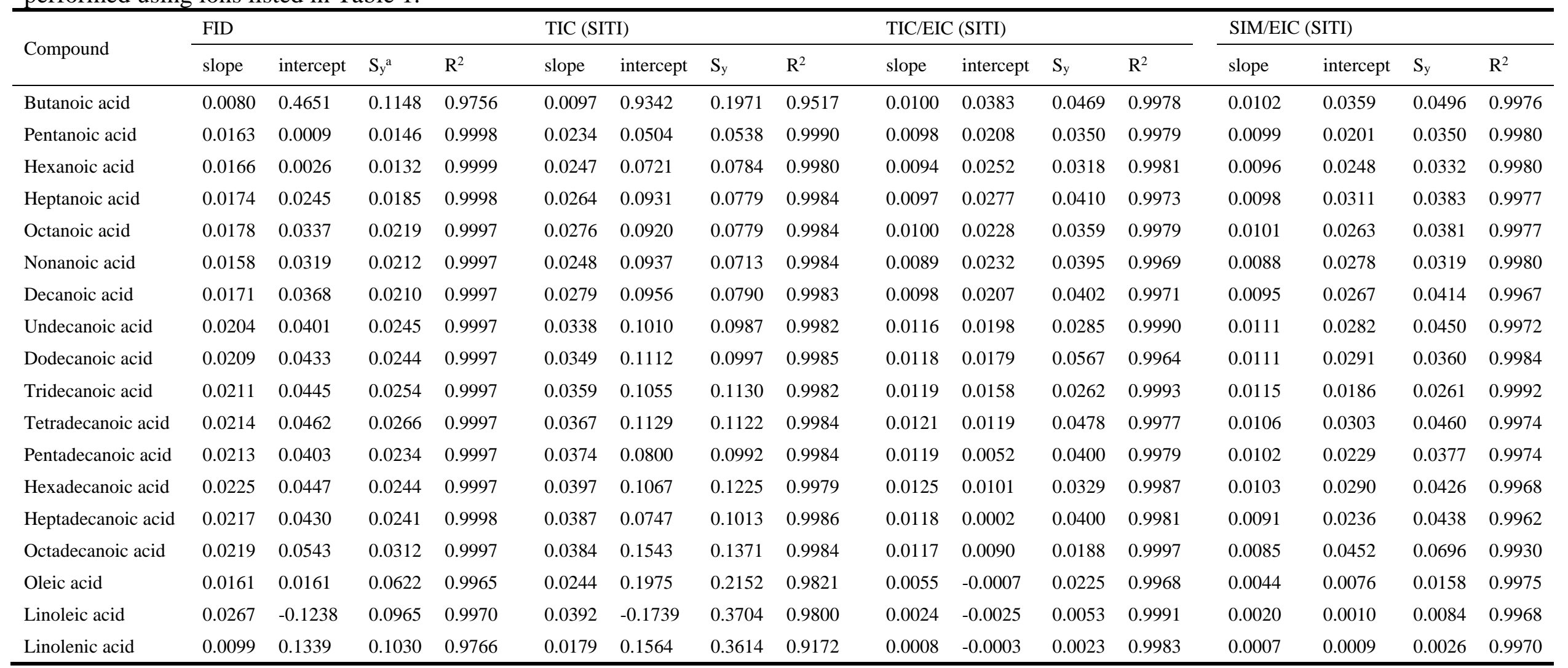

\footnotetext{
${ }^{a}$ The standard error for the $y$ estimate.
} 
Suppl. Table 5. Calibration parameters for acylglycerols upon derivatization with MSTFA determined by HTGC-FID/MS. The MS quantitation was performed using ions listed in Table 1.

\begin{tabular}{|c|c|c|c|c|c|c|c|c|c|c|c|c|c|c|c|c|}
\hline \multirow[t]{2}{*}{ Compound } & \multicolumn{4}{|l|}{ FID } & \multicolumn{4}{|c|}{ TIC (SITI) } & \multicolumn{4}{|c|}{ TIC/EIC (SITI) } & \multicolumn{4}{|c|}{ SIM/EIC (SITI) } \\
\hline & slope & intercept & $\mathrm{S}_{\mathrm{y}}^{\mathrm{a}}$ & $\mathrm{R}^{2}$ & slope & intercept & $\mathrm{S}_{\mathrm{y}}$ & $\mathrm{R}^{2}$ & slope & intercept & $\mathrm{S}_{\mathrm{y}}$ & $\mathrm{R}^{2}$ & slope & intercept & $\mathrm{S}_{\mathrm{y}}$ & $\mathrm{R}^{2}$ \\
\hline Glycerol & 0.0143 & 0.0002 & 0.0025 & 0.9997 & 0.0410 & 0.0045 & 0.0139 & 0.9989 & 0.0108 & 0.0011 & 0.0043 & 0.9987 & 0.0114 & 0.0007 & 0.0040 & 0.9990 \\
\hline Monopalmitin & 0.0208 & 0.0122 & 0.0110 & 0.9999 & 0.0298 & -0.0552 & 0.0341 & 0.9995 & 0.1178 & -0.3534 & 0.2005 & 0.9991 & 0.0800 & -0.0220 & 0.1630 & 0.9987 \\
\hline Monostearin & 0.0204 & 0.0118 & 0.0103 & 0.9999 & 0.0309 & -0.0406 & 0.0577 & 0.9987 & 0.1099 & -0.2426 & 0.3192 & 0.9974 & 0.0632 & 0.1220 & 0.2452 & 0.9954 \\
\hline Monoolein & 0.0205 & 0.0547 & 0.1563 & 0.9785 & 0.0141 & -0.0211 & 0.0623 & 0.9560 & 0.0417 & -0.1030 & 0.0935 & 0.9984 & 0.0273 & 0.0071 & 0.0845 & 0.9970 \\
\hline Monolinolein & 0.0221 & 0.0757 & 0.0221 & 0.9984 & 0.0100 & 0.0967 & 0.0744 & 0.9837 & 0.0130 & -0.0437 & 0.0300 & 0.9984 & 0.0090 & -0.0077 & 0.0235 & 0.9980 \\
\hline Dipalmitin & 0.0199 & 0.0167 & 0.0030 & 0.9999 & 0.0321 & -0.1084 & 0.0463 & 0.9980 & 0.0610 & -0.2006 & 0.1049 & 0.9977 & 0.0443 & -0.0983 & 0.0641 & 0.9984 \\
\hline Distearin & 0.0184 & 0.0123 & 0.0049 & 0.9999 & 0.0353 & -0.0858 & 0.0575 & 0.9976 & 0.0802 & -0.1963 & 0.0832 & 0.9992 & 0.0509 & -0.0443 & 0.1037 & 0.9969 \\
\hline Diolein & 0.0195 & 0.0271 & 0.0179 & 0.9998 & 0.0180 & -0.1345 & 0.0555 & 0.9978 & 0.0203 & -0.0765 & 0.0416 & 0.9971 & 0.0122 & -0.0192 & 0.0154 & 0.9989 \\
\hline \multirow[t]{2}{*}{ Dilinolein } & 0.0200 & 0.0245 & 0.0180 & 0.9998 & 0.0050 & -0.0721 & 0.0625 & 0.9967 & 0.0071 & -0.0325 & 0.0216 & 0.9925 & 0.0089 & -0.0370 & 0.0205 & 0.9956 \\
\hline & & & & & & & & & \multicolumn{4}{|c|}{ Quantified as [RCO+128] } & & & & \\
\hline Tripalmitin & 0.0161 & 0.0129 & 0.0062 & 0.9998 & 0.0157 & -0.0481 & 0.0283 & 0.9972 & 0.0133 & -0.0278 & 0.0370 & 0.9983 & 0.0107 & -0.0178 & 0.0246 & 0.9960 \\
\hline Tristearin & 0.0125 & 0.0085 & 0.0069 & 0.9995 & 0.0101 & -0.0309 & 0.0214 & 0.9912 & 0.0116 & -0.0373 & 0.0464 & 0.9965 & 0.0077 & -0.0147 & 0.0167 & 0.9961 \\
\hline Triolein & 0.0119 & 0.0072 & 0.0060 & 0.9997 & 0.0044 & -0.0048 & 0.0150 & 0.9849 & 0.0049 & -0.0516 & 0.0240 & 0.9970 & 0.0037 & -0.0290 & 0.0181 & 0.9871 \\
\hline Trilinolein & 0.0081 & 0.0078 & 0.0149 & 0.9995 & 0.0012 & -0.0109 & 0.0192 & 0.9663 & 0.0008 & -0.0111 & 0.0106 & 0.9842 & 0.0005 & -0.0037 & 0.0018 & 0.9895 \\
\hline Trilinolenin & 0.0059 & 0.1507 & 0.3684 & 0.9920 & 0.0008 & -0.0856 & 0.0425 & 0.9951 & 0.0008 & -0.0095 & 0.0351 & 0.9351 & 0.0004 & -0.0042 & 0.0014 & 0.9922 \\
\hline \multirow[t]{2}{*}{ Triarachidin } & 0.0080 & -0.0004 & 0.0095 & 0.9989 & 0.0053 & -0.0113 & 0.0152 & 0.9722 & 0.0044 & -0.0534 & 0.0332 & 0.9861 & 0.0025 & -0.0212 & 0.0155 & 0.9786 \\
\hline & & & & & & & & & \multicolumn{4}{|c|}{ Quantified as [M-RCOO] ${ }^{+}$} & & & & \\
\hline Tripalmitin & $\mathrm{NA}^{\mathrm{b}}$ & NA & NA & NA & NA & NA & NA & NA & 0.0254 & -0.1200 & 0.0524 & 0.9933 & 0.0213 & -0.0213 & 0.0510 & 0.9948 \\
\hline Tristearin & NA & NA & NA & NA & NA & NA & NA & NA & 0.0168 & -0.0862 & 0.0193 & 0.9883 & 0.0142 & -0.0663 & 0.0416 & 0.9913 \\
\hline Triolein & NA & NA & NA & NA & NA & NA & NA & NA & 0.0136 & -0.0955 & 0.0159 & 0.9824 & 0.0116 & -0.0780 & 0.0590 & 0.9827 \\
\hline Trilinolein & NA & NA & NA & NA & NA & NA & NA & NA & 0.0033 & -0.0290 & 0.0104 & 0.9884 & 0.0027 & -0.0155 & 0.0118 & 0.9818 \\
\hline Trilinolenin & NA & NA & NA & NA & NA & NA & NA & NA & 0.0015 & -0.0446 & 0.0100 & 0.9967 & 0.0009 & -0.0078 & 0.0052 & 0.9853 \\
\hline Triarachidin & NA & NA & NA & NA & NA & NA & NA & NA & 0.0015 & -0.0016 & 0.0019 & 0.8682 & 0.0037 & -0.0183 & 0.0222 & 0.9749 \\
\hline
\end{tabular}

\footnotetext{
${ }^{\mathrm{a}}$ The standard error for the $y$ estimate, ${ }^{\mathrm{b}}$ Not applicable as those values provided above in the table.
} 
Suppl. Table 6. Composition of OLPs quantified by TIC/EIC and FID. The OLP samples were obtained after 5 min exposure to listed temperature and pressure. The results are presented as mean of weight $\% \pm$ one standard deviation of three sample preparations (derivatizations). On MW and abbreviation of quantification ions see Table 1. Composition of OLP 1 and 2 is reported in Tables 4 and 5.

\begin{tabular}{|c|c|c|c|c|c|c|c|c|}
\hline \multirow{4}{*}{ Component } & \multicolumn{8}{|c|}{ Composition weight $\%$ of OLP } \\
\hline & \multicolumn{4}{|c|}{ Quantified by TIC/EIC } & \multicolumn{4}{|c|}{ Quantified by FID } \\
\hline & OLP 3 & OLP 4 & OLP 5 & OLP 6 & OLP 3 & OLP 4 & OLP 5 & OLP 6 \\
\hline & $\begin{array}{l}470^{\circ} \mathrm{C} \\
2930 \mathrm{kPa}\end{array}$ & $\begin{array}{l}486^{\circ} \mathrm{C} \\
5516 \mathrm{kPa}\end{array}$ & $\begin{array}{l}590^{\circ} \mathrm{C} \\
9997 \mathrm{kPa}\end{array}$ & $\begin{array}{l}620^{\circ} \mathrm{C} \\
4826 \mathrm{kPa}\end{array}$ & $\begin{array}{l}470^{\circ} \mathrm{C} \\
2930 \mathrm{kPa}\end{array}$ & $\begin{array}{l}486^{\circ} \mathrm{C} \\
5516 \mathrm{kPa}\end{array}$ & $\begin{array}{l}590^{\circ} \mathrm{C} \\
9997 \mathrm{kPa}\end{array}$ & $\begin{array}{l}620^{\circ} \mathrm{C} \\
4826 \mathrm{kPa}\end{array}$ \\
\hline \multicolumn{9}{|l|}{ Monocarboxylic acids } \\
\hline Butanoic acid & $<\mathrm{LOQ}^{\mathrm{a}}$ & $0.17 \pm 0.01$ & $0.12 \pm 0.01$ & $<\mathrm{LOQ}$ & $<\mathrm{LOQ}$ & $<\mathrm{LOQ}$ & $<\mathrm{LOQ}$ & $<\mathrm{LOQ}$ \\
\hline Pentanoic acid & $0.09 \pm 0.01$ & $0.23 \pm 0.01$ & $0.15 \pm 0.01$ & $<\mathrm{LOQ}$ & $0.16 \pm 0.01$ & $0.29 \pm 0.01$ & $0.17 \pm 0.01$ & $0.21 \pm 0.02$ \\
\hline Hexanoic acid & $0.20 \pm 0.01$ & $0.41 \pm 0.01$ & $0.28 \pm 0.01$ & $<\mathrm{LOQ}$ & $0.20 \pm 0.01$ & $0.39 \pm 0.01$ & $0.28 \pm 0.04$ & $<\mathrm{LOQ}$ \\
\hline Heptanoic acid & $0.72 \pm 0.01$ & $1.00 \pm 0.03$ & $0.97 \pm 0.04$ & $0.47 \pm 0.02$ & $0.69 \pm 0.01$ & $0.96 \pm 0.02$ & $0.93 \pm 0.04$ & $0.51 \pm 0.01$ \\
\hline Octanoic acid & $0.25 \pm 0.01$ & $0.45 \pm 0.01$ & $0.35 \pm 0.02$ & $<$ LOQ & $0.27 \pm 0.01$ & $0.49 \pm 0.01$ & $0.37 \pm 0.02$ & $0.26 \pm 0.01$ \\
\hline Nonanoic acid & $0.20 \pm 0.01$ & $0.37 \pm 0.01$ & $0.25 \pm 0.01$ & $<\mathrm{LOQ}$ & $0.20 \pm 0.01$ & $0.39 \pm 0.01$ & $0.24 \pm 0.01$ & $0.21 \pm 0.01$ \\
\hline Decanoic acid & $0.33 \pm 0.01$ & $0.48 \pm 0.01$ & $0.46 \pm 0.02$ & $<\mathrm{LOQ}$ & $0.34 \pm 0.01$ & $0.50 \pm 0.01$ & $0.48 \pm 0.02$ & $0.25 \pm 0.01$ \\
\hline Undecanoic acid & $<\mathrm{LOQ}$ & $0.05 \pm 0.01$ & $<\mathrm{LOQ}$ & $<\mathrm{LOQ}$ & $0.07 \pm 0.01$ & $0.14 \pm 0.01$ & $0.09 \pm 0.01$ & $<\mathrm{LOQ}$ \\
\hline Dodecanoic acid & $<\mathrm{LOQ}$ & $<\mathrm{LOQ}$ & $<\mathrm{LOQ}$ & $<\mathrm{LOQ}$ & $<\mathrm{LOQ}$ & $0.03 \pm 0.01$ & $<\mathrm{LOQ}$ & $<\mathrm{LOQ}$ \\
\hline Tridecanoic acid & $<\mathrm{LOQ}$ & $<\mathrm{LOQ}$ & $<\mathrm{LOQ}$ & $<$ LOQ & $<\mathrm{LOQ}$ & $<\mathrm{LOQ}$ & $<$ LOQ & $<\mathrm{LOQ}$ \\
\hline Tetradecanoic acid & $<\mathrm{LOQ}$ & $<\mathrm{LOQ}$ & $<\mathrm{LOQ}$ & $<\mathrm{LOQ}$ & $<\mathrm{LOQ}$ & $<\mathrm{LOQ}$ & $<\mathrm{LOQ}$ & $<\mathrm{LOQ}$ \\
\hline Pentadecanoic acid & $<\mathrm{LOQ}$ & $<\mathrm{LOQ}$ & $<\mathrm{LOQ}$ & $<\mathrm{LOQ}$ & $<\mathrm{LOQ}$ & $<\mathrm{LOQ}$ & $<\mathrm{LOQ}$ & $<\mathrm{LOQ}$ \\
\hline Hexadecanoic acid & $0.95 \pm 0.02$ & $1.36 \pm 0.07$ & $1.17 \pm 0.06$ & $1.51 \pm 0.03$ & $0.95 \pm 0.02$ & $1.32 \pm 0.08$ & $1.18 \pm 0.05$ & $1.53 \pm 0.01$ \\
\hline Heptadecanoic acid & $<\mathrm{LOQ}$ & $<\mathrm{LOQ}$ & $<\mathrm{LOQ}$ & $<\mathrm{LOQ}$ & $<\mathrm{LOQ}$ & $<\mathrm{LOQ}$ & $<\mathrm{LOQ}$ & $<\mathrm{LOQ}$ \\
\hline Linoleic acid & $1.13 \pm 0.01$ & $1.49 \pm 0.04$ & $1.26 \pm 0.06$ & $1.43 \pm 0.02$ & $0.56 \pm 0.02$ & $0.55 \pm 0.01$ & $0.55 \pm 0.02$ & $0.84 \pm 0.02$ \\
\hline Linolenic acid & $\mathrm{ND}^{\mathrm{b}}$ & ND & ND & ND & ND & ND & ND & ND \\
\hline Oleic acid & $0.97 \pm 0.03$ & $1.41 \pm 0.03$ & $1.23 \pm 0.03$ & $1.73 \pm 0.01$ & $1.63 \pm 0.05$ & $2.56 \pm 0.07$ & $2.09 \pm 0.10$ & $2.56 \pm 0.04$ \\
\hline Octadecanoic acid & $0.30 \pm 0.01$ & $0.46 \pm 0.03$ & $0.39 \pm 0.02$ & $0.51 \pm 0.02$ & $0.29 \pm 0.01$ & $0.47 \pm 0.04$ & $0.40 \pm 0.02$ & $0.50 \pm 0.03$ \\
\hline MCAs total & $5.15 \pm 0.07$ & $7.8 \pm 0.3$ & $6.6 \pm 0.3$ & $5.6 \pm 0.4$ & $5.4 \pm 0.2$ & $8.19 \pm 0.3$ & $6.87 \pm 0.3$ & $6.86 \pm 0.05$ \\
\hline Glycerol & $<$ LOQ & $<$ LOQ & $<$ LOQ & ND & ND & ND & ND & ND \\
\hline \multicolumn{9}{|l|}{ Monoacylglycerols } \\
\hline Monopalmitin & $<\mathrm{LOQ}$ & $<\mathrm{LOQ}$ & $<\mathrm{LOQ}$ & ND & $<\mathrm{LOQ}$ & $<\mathrm{LOQ}$ & $<\mathrm{LOQ}$ & $<\mathrm{LOQ}$ \\
\hline Monolinolein & ND & $<\mathrm{LOQ}$ & $<\mathrm{LOQ}$ & ND & $<\mathrm{LOQ}$ & $0.05 \pm 0.01$ & $0.09 \pm 0.01$ & $0.23 \pm 0.04$ \\
\hline Monoolein & ND & ND & ND & ND & $<\mathrm{LOQ}$ & $<\mathrm{LOQ}$ & $<\mathrm{LOQ}$ & $<\mathrm{LOQ}$ \\
\hline Monostearin & $<\mathrm{LOQ}$ & $<\mathrm{LOQ}$ & $<\mathrm{LOQ}$ & ND & $<\mathrm{LOQ}$ & $<\mathrm{LOQ}$ & $<\mathrm{LOQ}$ & $<\mathrm{LOQ}$ \\
\hline MAGs total & $<$ LOQ & $<$ LOQ & $<$ LOQ & ND & $<$ LOQ & $0.05 \pm 0.01$ & $0.09 \pm 0.01$ & $0.23 \pm 0.04$ \\
\hline \multicolumn{9}{|l|}{ Diacylglycerols } \\
\hline $\begin{array}{l}\text { DAG, ACN } 34 \text { total } \\
\text { 1,2(2,3)-DAG, ACN } 36\end{array}$ & \multicolumn{7}{|c|}{ 1,2(2,3)-DAG, ACN 36} & $<$ LOQ \\
\hline $\mathrm{C}_{18: 0}$ acyl chain & $<\mathrm{LOQ}$ & $<\mathrm{LOQ}$ & $<\mathrm{LOQ}$ & ND & $\mathrm{NA}^{\mathrm{d}}$ & NA & NA & NA \\
\hline $\mathrm{C}_{18: 1}$ acyl chain & $<\mathrm{LOQ}$ & $0.04 \pm 0.01$ & $<$ LOQ & ND & NA & NA & NA & NA \\
\hline $\mathrm{C}_{18: 2}$ acyl chain & $0.12 \pm 0.01$ & $0.09 \pm 0.01$ & $0.08 \pm 0.01$ & ND & NA & NA & NA & NA \\
\hline $\mathrm{C}_{18: 3}$ acyl chain & $<\mathrm{LOQ}$ & $0.04 \pm 0.01$ & $<\mathrm{LOQ}$ & ND & NA & NA & NA & NA \\
\hline 1,2(2,3)-DAG, ACN 36 total & $0.12 \pm 0.01$ & $0.17 \pm 0.01$ & $0.08 \pm 0.01$ & ND & $0.25 \pm 0.01$ & $0.15 \pm 0.01$ & $0.12 \pm 0.01$ & $<$ LOQ \\
\hline \multicolumn{9}{|l|}{ 1,3-DAG, ACN 36} \\
\hline $\mathrm{C}_{18: 0}$ acyl chain & $<\mathrm{LOQ}$ & $<\mathrm{LOQ}$ & $<\mathrm{LOQ}$ & ND & NA & NA & NA & NA \\
\hline $\mathrm{C}_{18: 1}$ acyl chain & $0.06 \pm 0.01$ & $0.05 \pm 0.01$ & $<\mathrm{LOQ}$ & ND & NA & NA & NA & NA \\
\hline
\end{tabular}




\begin{tabular}{|c|c|c|c|c|c|c|c|c|}
\hline $\mathrm{C}_{18: 2}$ acyl chain & $0.13 \pm 0.01$ & $0.11 \pm 0.01$ & $0.11 \pm 0.01$ & ND & NA & NA & NA & NA \\
\hline $\mathrm{C}_{18: 3}$ acyl chain & $0.08 \pm 0.01$ & $0.06 \pm 0.01$ & $0.07 \pm 0.01$ & ND & NA & NA & NA & NA \\
\hline 1,3-DAG, ACN 36 total & $0.27 \pm 0.02$ & $0.22 \pm 0.02$ & $0.18 \pm 0.01$ & ND & $0.22 \pm 0.01$ & $0.26 \pm 0.01$ & $0.18 \pm 0.01$ & $<$ LOQ \\
\hline DAGs total & $0.39 \pm 0.01$ & $0.58 \pm 0.02$ & $0.26 \pm 0.02$ & ND & $0.52 \pm 0.01$ & $0.47 \pm 0.01$ & $0.34 \pm 0.01$ & $<$ LOQ \\
\hline
\end{tabular}

\section{Triacylglycerols}

Quantified as [RCO+128]

TAG, ACN 50

$\mathrm{C}_{16: 0}$ acyl chain

$\mathrm{C}_{18: 0}$ acyl chain

$\mathrm{C}_{18: 1}$ acyl chain

$\mathrm{C}_{18: 2}$ acyl chain

$\mathrm{C}_{18: 3}$ acyl chain

TAG, ACN 50 total

$0.28 \pm 0.04$
$\mathrm{ND}$
$<\mathrm{LOQ}$
$0.89 \pm 0.3$
$\mathrm{ND}$
$\mathbf{1 . 1} \pm \mathbf{0 . 3}$

$0.18 \pm 0.01 \quad$ ND

ND ND ND

$<$ LOQ

$<$ LOQ

ND

$0.43 \pm 0.02$

$0.69 \pm 0.05$

ND

ND

ND

ND

TAG, ACN 52

$\mathrm{C}_{16: 0}$ acyl chain

$\mathrm{C}_{18: 0}$ acyl chain

$0.92 \pm 0.06$

$0.57 \pm 0.02$

$0.9 \pm 0.4$

ND

$0.50 \pm 0.02 \quad 0.52 \pm 0.05 \quad$ ND

$<$ LOQ

$\mathrm{C}_{18: 1}$ acyl chain

$1.6 \pm 0.2$

$\mathrm{C}_{18: 2}$ acyl chain

$5 \pm 0.64$

$<$ LOQ

$$
<\mathrm{LOQ}
$$

ND

$0.90 \pm 0.07$

$0.93 \pm 0.05$

ND

$2.9 \pm 0.38$

$2.74 \pm 0.10$

ND

$1.2 \pm 0.2$

$0.76 \pm 0.04$

$0.70 \pm 0.01$

ND

TAG, ACN 52 total

$8.7 \pm 0.79$

$5.1 \pm 0.3$

$4.9 \pm 0.52$

ND

$0.59 \pm 0.07$

$0.33 \pm 0.03$

$0.38 \pm 0.02$

ND

$3.2 \pm 0.3$

$1.78 \pm 0.07$

$1.81 \pm 0.08 \quad$ ND

$11 \pm 2$

$6.4 \pm 0.56$

$5.9 \pm 0.4$

ND

$2.3 \pm 0.2$

$1.39 \pm 0.09$

$1.24 \pm 0.08 \quad$ ND

TAG, ACN 54 total

$17 \pm 2$

$10 \pm 0.6$

$9.3 \pm 0.38 \quad$ ND

$\begin{array}{rrr}15.49 \pm 0.83 & 15.0 \pm 0.5 \quad \text { ND }\end{array}$

$27 \pm 3$

NA
NA
NA
NA
NA
$\mathbf{0 . 7 3} \pm \mathbf{0 . 0 8}$

$\begin{array}{lll}\text { NA } & \text { NA } & \text { NA } \\ \text { NA } & \text { NA } & \text { NA } \\ \text { NA } & \text { NA } & \text { NA } \\ \text { NA } & \text { NA } & \text { NA }\end{array}$

NA

NA

NA

TAGs total

${ }^{\mathrm{a} B e l o w}$ the limit of quan

quantification,

${ }^{b}$ Not detected,

NA
NA
NA
NA
NA

$11.6 \pm 0.3$

NA

NA

NA

NA

$23.4 \pm 0.5$

$35.7 \pm 0.8$
NA

NA

NA

NA

NA

$6.07 \pm 0.08$

NA

NA

NA

NA

$12.2 \pm 0.6$

$18.6 \pm 0.7$
$0.41 \pm 0.02$

$<$ LOQ

NA

NA

NA

NA

NA

NA

$5.9 \pm 0.3$

$0.52 \pm 0.02$

NA

NA

NA

NA NA

$11.9 \pm 0.2 \quad 1.06 \pm 0.04$

$18.2 \pm 0.5 \quad 1.58 \pm 0.05$ 
Suppl. Table 7. Triacylglycerol composition in OLPs quantified by TIC/EIC using [M-RCOO] ${ }^{+}$. The OLP samples were obtained after 5 min exposure to listed temperature and pressure. The results are presented as mean weight $\% \pm$ one standard deviation of three sample preparations (derivatizations).

\begin{tabular}{|c|c|c|c|c|c|c|c|c|}
\hline \multirow{5}{*}{ Component } & \multirow{5}{*}{$\begin{array}{l}\text { Quantifica } \\
\text { tion ion }\end{array}$} & \multirow{5}{*}{$\begin{array}{l}\text { Calibration } \\
\text { ion }\end{array}$} & \multicolumn{6}{|c|}{ Composition wt. \% of OLP } \\
\hline & & & \multicolumn{6}{|c|}{ Quantified by TIC/EIC using [M-RCOO] $^{+}$} \\
\hline & & & OLP 1 & OLP 2 & OLP 3 & OLP 4 & OLP 5 & OLP 6 \\
\hline & & & $494^{\circ} \mathrm{C}$ & $578^{\circ} \mathrm{C}$ & $470^{\circ} \mathrm{C}$ & $486^{\circ} \mathrm{C}$ & $590^{\circ} \mathrm{C}$ & $620^{\circ} \mathrm{C}$ \\
\hline & & & $6205 \mathrm{kPa}$ & $7584 \mathrm{kPa}$ & $2930 \mathrm{kPa}$ & $5516 \mathrm{kPa}$ & $9997 \mathrm{kPa}$ & $4826 \mathrm{kPa}$ \\
\hline \multicolumn{9}{|l|}{ Triacylglycerols, $\mathbf{A C N}^{\mathrm{a}}$} \\
\hline \multicolumn{9}{|l|}{ TAG, ACN 50} \\
\hline $\begin{array}{l}\text { combination of two } \mathrm{C}_{16: 0} \\
\text { acyl chains }\end{array}$ & 551 & 551 & $<\mathrm{LOQ}^{\mathrm{b}}$ & $0.11 \pm 0.01$ & $0.36 \pm 0.03$ & $0.20 \pm 0.01$ & $0.23 \pm 0.01$ & $\mathrm{ND}^{\mathrm{c}}$ \\
\hline $\begin{array}{c}\text { combination of } \mathrm{C}_{16: 0} \text { and } \\
\mathrm{C}_{18: 0} \text { acyl chains }\end{array}$ & 579 & 551 & ND & ND & ND & ND & ND & ND \\
\hline $\begin{array}{c}\text { combination of } \mathrm{C}_{16: 0} \text { and } \\
\mathrm{C}_{18: 1} \text { acyl chains }\end{array}$ & 577 & 551 & $<\mathrm{LOQ}$ & $<\mathrm{LOQ}$ & $<\mathrm{LOQ}$ & $<\mathrm{LOQ}$ & $<\mathrm{LOQ}$ & ND \\
\hline $\begin{array}{c}\text { combination of } \mathrm{C}_{16: 0} \text { and } \\
\mathrm{C}_{18: 2} \text { acyl chains }\end{array}$ & 575 & 551 & $<\mathrm{LOQ}$ & $<\mathrm{LOQ}$ & $0.20 \pm 0.03$ & $0.11 \pm 0.01$ & $<\mathrm{LOQ}$ & ND \\
\hline $\begin{array}{c}\text { combination of } \mathrm{C}_{16: 0} \text { and } \\
\mathrm{C}_{18: 3} \text { acyl chains }\end{array}$ & 573 & 551 & $<\mathrm{LOQ}$ & $<\mathrm{LOQ}$ & $<\mathrm{LOQ}$ & $<\mathrm{LOQ}$ & $<\mathrm{LOQ}$ & ND \\
\hline TAG, ACN 50 total & & & $<\mathbf{L O Q}$ & $0.11 \pm 0.01$ & $0.56 \pm 0.05$ & $0.31 \pm 0.01$ & $0.23 \pm 0.01$ & ND \\
\hline \multicolumn{9}{|l|}{ TAG, ACN 52} \\
\hline $\begin{array}{c}\text { combination of } \mathrm{C}_{16: 0} \text { and } \\
\mathrm{C}_{18: 0} \text { acyl chains }\end{array}$ & 579 & 551 & $<\mathrm{LOQ}$ & $0.15 \pm 0.01$ & $0.49 \pm 0.03$ & $0.27 \pm 0.01$ & $0.31 \pm 0.02$ & ND \\
\hline $\begin{array}{c}\text { combination of } \mathrm{C}_{16: 0} \text { and } \\
\mathrm{C}_{18: 1} \text { acyl chains }\end{array}$ & 577 & 551 & $0.87 \pm 0.06$ & $0.47 \pm 0.06$ & $1.8 \pm 0.2$ & $0.96 \pm 0.09$ & $0.99 \pm 0.05$ & $<\mathrm{LOQ}$ \\
\hline $\begin{array}{c}\text { combination of } \mathrm{C}_{16: 0} \text { and } \\
\mathrm{C}_{18: 2} \text { acyl chains }\end{array}$ & 575 & 551 & $0.71 \pm 0.03$ & $0.37 \pm 0.09$ & $1.4 \pm 0.1$ & $0.76 \pm 0.01$ & $0.73 \pm 0.04$ & $<\mathrm{LOQ}$ \\
\hline $\begin{array}{c}\text { combination of } \mathrm{C}_{16: 0} \text { and } \\
\mathrm{C}_{18: 3} \text { acyl chains }\end{array}$ & 573 & 551 & $<\mathrm{LOQ}$ & $0.11 \pm 0.06$ & $0.35 \pm 0.03$ & $0.20 \pm 0.01$ & $0.21 \pm 0.01$ & ND \\
\hline $\begin{array}{l}\text { combination of two } \mathrm{C}_{18: 1} \\
\text { or } \mathrm{C}_{18: 0} \text { and } \mathrm{C}_{18: 2} \text { acyl } \\
\text { chains }\end{array}$ & 603 & 603 & $<\mathrm{LOQ}$ & $0.13 \pm 0.01$ & $0.35 \pm 0.03$ & $0.21 \pm 0.01$ & $0.26 \pm 0.01$ & ND \\
\hline $\begin{array}{l}\text { combination of two } \mathrm{C}_{18: 2} \\
\text { or } \mathrm{C}_{18: 1} \text { and } \mathrm{C}_{18: 3} \text { acyl } \\
\text { chains }\end{array}$ & 599 & 599 & $1.04 \pm 0.02$ & $0.48 \pm 0.04$ & $1.8 \pm 0.2$ & $0.94 \pm 0.03$ & $0.95 \pm 0.05$ & ND \\
\hline $\begin{array}{l}\text { combination of two } \mathrm{C}_{18: 3} \\
\text { acyl chains }\end{array}$ & 595 & 595 & ND & ND & $<\mathrm{LOQ}$ & $<\mathrm{LOQ}$ & $<\mathrm{LOQ}$ & ND \\
\hline combination of $\mathrm{C}_{18: 1}$ and & & & & & & & & \\
\hline $\begin{array}{c}\mathrm{C}_{18: 2} \text { or } \mathrm{C}_{18: 0} \text { and } \mathrm{C}_{18: 3} \\
\text { acyl chains }\end{array}$ & 601 & 603 & $<\mathrm{LOQ}$ & $0.16 \pm 0.01$ & $0.50 \pm 0.03$ & $0.27 \pm 0.01$ & $0.33 \pm 0.01$ & ND \\
\hline $\begin{array}{c}\text { combination of } \mathrm{C}_{18: 1} \text { and } \\
\mathrm{C}_{18: 2} \text { acyl chains }\end{array}$ & 597 & 599 & $<\mathrm{LOQ}$ & $0.19 \pm 0.01$ & $0.64 \pm 0.05$ & $0.37 \pm 0.02$ & $0.39 \pm 0.01$ & ND \\
\hline $\begin{array}{c}\text { combination of } \mathrm{C}_{18: 0} \text { and } \\
\mathrm{C}_{18: 1} \text { acyl chains }\end{array}$ & 605 & 607 & $<\mathrm{LOQ}$ & $<\mathrm{LOQ}$ & $<\mathrm{LOQ}$ & $<\mathrm{LOQ}$ & $<\mathrm{LOQ}$ & ND \\
\hline $\begin{array}{l}\text { combination of two } \mathrm{C}_{18: 0} \\
\text { acyl chains }\end{array}$ & 607 & 607 & ND & ND & $<\mathrm{LOQ}$ & ND & $<\mathrm{LOQ}$ & ND \\
\hline TAG, ACN 52 total & & & $2.6 \pm 0.7$ & $2.1 \pm 0.3$ & $7.3 \pm 0.6$ & $3.98 \pm 0.07$ & $4.2 \pm 0.2$ & ND \\
\hline \multicolumn{9}{|l|}{ TAG, ACN 54} \\
\hline $\begin{array}{l}\text { combination of two } \mathrm{C}_{18: 1} \\
\text { or } \mathrm{C}_{18: 0} \text { and } \mathrm{C}_{18: 2} \text { acyl } \\
\text { chains }\end{array}$ & 603 & 603 & $1.9 \pm 0.2$ & $1.03 \pm 0.04$ & $3.9 \pm 0.4$ & $2.22 \pm 0.02$ & $2.2 \pm 0.2$ & $<\mathrm{LOQ}$ \\
\hline $\begin{array}{c}\text { combination of two } \mathrm{C}_{18: 2} \\
\text { or } \mathrm{C}_{18: 1} \text { and } \mathrm{C}_{18: 3} \text { acyl } \\
\text { chains }\end{array}$ & 599 & 599 & $5.3 \pm 0.7$ & $3.0 \pm 0.2$ & $11.9 \pm 0.8$ & $6.7 \pm 0.3$ & $5.7 \pm 0.4$ & $<\mathrm{LOQ}$ \\
\hline $\begin{array}{l}\text { combination of two } \mathrm{C}_{18: 3} \\
\text { acyl chains }\end{array}$ & 595 & 595 & $<\mathrm{LOQ}$ & $<\mathrm{LOQ}$ & $2.05 \pm 0.13$ & $1.20 \pm 0.03$ & $<\mathrm{LOQ}$ & ND \\
\hline combination of $\mathrm{C}_{18: 1}$ and & & & & & & & & \\
\hline $\begin{array}{c}\mathrm{C}_{18: 2} \text { or } \mathrm{C}_{18: 0} \text { and } \mathrm{C}_{18: 3} \\
\text { acyl chains }\end{array}$ & 601 & 603 & $1.9 \pm 0.2$ & $1.00 \pm 0.03$ & $3.9 \pm 0.3$ & $2.17 \pm 0.02$ & $2.0 \pm 0.2$ & $<\mathrm{LOQ}$ \\
\hline $\begin{array}{c}\text { combination of } \mathrm{C}_{18: 1} \text { and } \\
\mathrm{C}_{18: 2} \text { acyl chains }\end{array}$ & 597 & 599 & $1.9 \pm 0.34$ & $1.02 \pm 0.03$ & $3.98 \pm 0.4$ & $2.16 \pm 0.01$ & $1.82 \pm 0.08$ & ND \\
\hline $\begin{array}{c}\text { combination of } \mathrm{C}_{18: 0} \text { and } \\
\mathrm{C}_{18: 1} \text { acyl chains }\end{array}$ & 605 & 607 & $0.8 \pm 0.2$ & $0.38 \pm 0.01$ & $1.43 \pm 0.08$ & $0.78 \pm 0.03$ & $0.82 \pm 0.08$ & $<\mathrm{LOQ}$ \\
\hline $\begin{array}{l}\text { combination of two } \mathrm{C}_{18: 0} \\
\text { acyl chains }\end{array}$ & 607 & 607 & $<\mathrm{LOQ}$ & $0.11 \pm 0.01$ & $0.32 \pm 0.05$ & $0.20 \pm 0.01$ & $0.21 \pm 0.01$ & ND \\
\hline TAG, ACN 54 total & & & $12 \pm 2$ & $6.5 \pm 0.2$ & $27 \pm 2$ & $15.4 \pm 0.3$ & $12.7 \pm 0.8$ & $<\mathbf{L O Q}$ \\
\hline TAGs total & & & $15 \pm 2$ & $8.7 \pm 0.3$ & $35 \pm 3$ & $19.7 \pm 0.5$ & $17 \pm 1$ & $<\mathbf{L O Q}$ \\
\hline
\end{tabular}

